WHOI - 76-94

\title{
ACCURACY OF TEMPERATURE MEASUREMENTS \\ WITH THE VACM
}

\author{
Richard E. Payne, Alvin L. Bradshaw, \\ Jerome P. Dean, Karl E. Schleicher \\ WOODS HOLE OCEANOGRAPHIC INSTITUTION \\ Woods Hole, Massachusetts 02543
}

October 1976

TECHNICAL REPORT

Prepared for the Office of Naval Research under Contract N00014-76-C-0197; NR 083-400.

Reproduction in whole or in part is permitted for any purpose of the United States Government. In citing this manuscript in a bibliography, the reference should be followed by the phrase: UNPUBLISHED MANUSCRIPT.

Approved for public release; distribution unZimited.

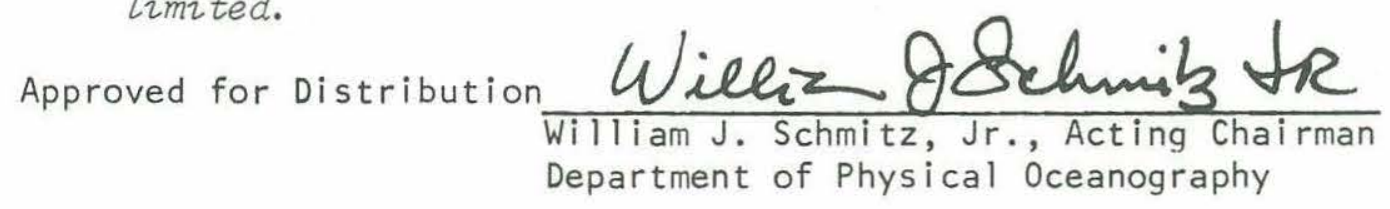




\section{Table of Contents}

1. Introduction 2

2. $\mathrm{V} / \mathrm{F}$ Converter Operation 4

3. V/F Converter Calibration 8

4. Thermistor Calibrations: Methods and Facilities 10

5. Thermistor Calibrations: Results 19

6. Temperature Accuracy and Precision

A. NBS Intercomparison 23

B. IWEX Intercomparison 26

C. Mooring 551 Intercomparison 33

D. Error Analysis 36

Appendices

I. Some Useful Numbers 42

II. CALIBB Program 44

III. CALCOLIN Program 71 


\section{Preface}

For the past five years the Buoy Group at Woods Hole Oceanographic Institution has included temperature as one of the variables recorded in its current meters. These measurements began with the first successful deployments of Vector Averaging Current Meters (VACMs) in 1971. Circuitry designed for making highly accurate temperature measurements has been included in all the Buoy Project's VACMs. During the past year we have begun to add similar circuitry to the EG\&G 850 current meters. This report is intended to describewhat we have learned about making water temperature measurements with VACMs.

Among the authors, K. Schleicher and A. Bradshaw are responsible for thermistor calibrations, J. Dean for quality control of VACM maintenance and calibration work, and R. Payne for data analysis.

\section{$\underline{\text { Acknowledgments }}$}

We would like to mention the efforts of R. Koehler and J. McCullough who had the principal responsibility of designing the VACM. Ms. Sharrill D. Wood of the National Bureau of Standards very kindly calibrated a set of thermistors for us to provide an independent check of our calibration facilities. 
1. Introduction

The Vector Averaging Current Meter (VACM) was designed several years ago by engineers at the Woods Hole Oceanographic Institution in response to the needs of scientists associated with the Buoy Project at that Institution. After the first few prototypes were built and tested the design was turned over to the AMF Electrical Products Division of Alexandria, Virginia which builds and sells the instrument. Included in the original design and in the standard instrument sold by AMF is circuitry capable of making accurate temperature measurements. This report describes calibration techniques we have found effective for both sensor and electronics as well as evaluations of the performance of the two components independently and as a system.

System description

A thermistor is mounted in the lower plate of a chassis assembly which, in turn, is mounted on the end plate of the pressure housing of the VACM. An electrical current through the thermistor is sensed by an electronic circuit which provides a series of pulses whose rate is proportional to the current. These pulses are summed, typically, over a 15 minute interval and the total recorded as part of the VACM data record on a magnetic tape cassette. This arrangement allows true time averaging of the thermistor resistance over the entire recording interval. For most oceanographic applications this is equivalent to a time average of temperature. This technique has been used since about 1971 and has proved to be quite reliable and accurate.

The standard VACM uses a Yellow Springs Instrument Corp. (YSI) thermistor, part \#44032, with $0.1^{\circ} \mathrm{C}$ interchangeability. In addition to these we have recently been using in our routine operations some Thermometrics Corp. thermistors with quite similar characteristics developed for the Internal Wave Experiment (IWEX). This report will describe results on the YSI thermistors only since we have accumulated the most experience with them. The epoxy encapsulated thermistors are potted in an aluminum screw for attachment to the VACM chassis. The nominal resistance of the thermistor is $30,000 \mathrm{ohms}$ at $25^{\circ} \mathrm{C}$ with a temperature coefficient of $-4.5 \% /^{\circ} \mathrm{C}$. 
The thermal time constant (time required for the thermistor to sense 638 of a step change in temperature) for the device when installed in a VACM end cap is a function of water current speed and has been measured to be approximately 100 seconds for an average current of $14 \mathrm{~cm} / \mathrm{sec}$.

We believe that the absolute accuracy of our temperature measurements in VACMs is better than $.01^{\circ} \mathrm{C}$. This has been substantiated by the intercomparisons described in this report and by analysis of the errors inherent in the the instrument (Section 6). Thermistor stability and the practical difficulties of making extremely precise temperature calibrations appear to be the limiting factors. Making a series of calibrations over several years and culling unstable thermistors are necessary for highest accuracy.

We might point out that making meaningful absolute temperature measurements with accuracies of $.01^{\circ} \mathrm{C}$ requires stability and accuracy of depth which strains present day mooring techniques. In the main thermocline in the Atlantic Ocean the temperature gradient is of the order of $20 \mathrm{~m}^{\circ} \mathrm{C} / \mathrm{m}$. A temperature accuracy of $10 \mathrm{~m}^{\circ} \mathrm{C}$ there is equivalent to a depth accuracy of $50 \mathrm{~cm}$.

There are other reasons for making precise calibration of sensors and associated circuitry. Currently many of our moorings are out for periods approaching 1 year. Much of the use made of temperatures, such as computing low frequency heat fluxes, depends more on the stability of temperature measurements than on their absolute accuracy. A drift of $20 \mathrm{~m}^{\circ} \mathrm{C} /$ year in a thermistor can make temperature measurements well below the main thermocline virtually meaningless unless it can be corrected for. Accuracy of drift rate estimates depends on the uncertainty in individual calibrations and the length of time over which the calibrations have been made. Doubling the uncertainty in accuracy of individual thermistor calibrations doubles the length of time over which calibrations must be made to achieve the same accuracy in drift rate estimates. We find that a minimum of 3 calibrations over 2 years are required to determine drift rates to our specifications. Although highly accurate calibrations are expensive, an increase in calibration period would leave us with virtually no certifiably stable thermistors. 
2. $\mathrm{V} / \mathrm{F}$ Converter Operation

In the VACM the thermistor is used to vary the electrical current into a converter (called the voltage to frequency ( $\mathrm{V} / \mathrm{F}$ ) converter). Since the period of the pulse train output of the converter is proportional to the input current, the average resistance (and therefore temperature) of the sensor over a precisely measured time interval can be obtained by counting the pulses in that interval. The pulses are summed, typically for 15 minutes. A technical discussion of the circuitry can be found in the VACM technical manual, AMF Publication \#SLS 106-11419, Section 2.2.1. The technique described has been used since about 1971 and has proved to be quite precise and reliable.

Referring to Figure 1, operational amplifier (op amp), A, and feedback capacitor, $C_{1}$, form a current integrator. Ideally, an op amp has infinite gain, the input summing points (+ and -) have zero potential between them, and no current can flow into the input terminals. A stable, precise reference voltage, $V$, is applied to $R_{T}$, the series combination of thermistor $R_{t}$ and a fixed precision resistor $R_{s}$, resulting in a current $i_{r}=V / R_{T^{*}}$ Since no current can flow into the op amp, current $i_{r}$ must flow in $C_{1}$ and equal $i_{f}$.

Figure 1

$\mathrm{V} / \mathrm{F}$ Converter

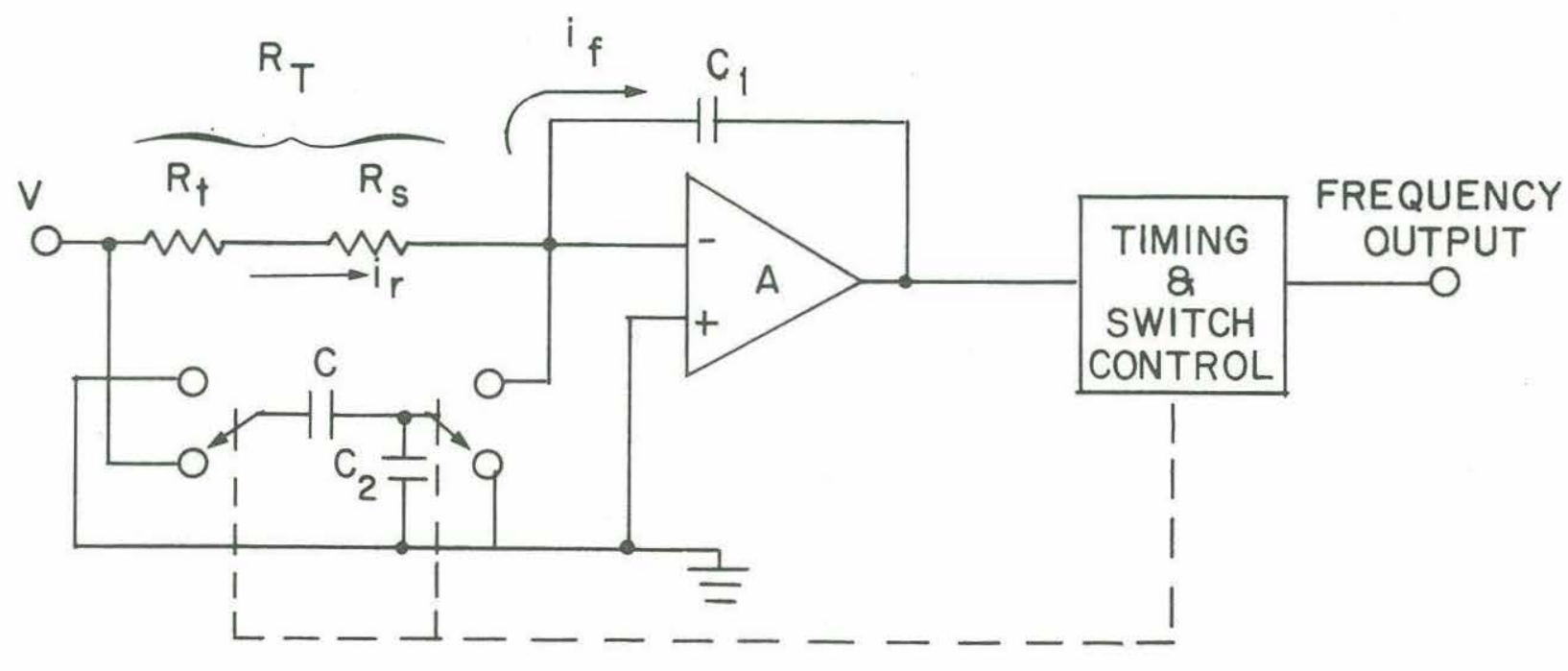


Periodically, a precise electrical charge, $Q$, is applied to the op amp input summing point and is transferred to capacitor $C_{1}$. This charge $Q$ is dispensed by $i_{f^{\prime}}$ and the time period, $P$, required to remove the charge is a function of the current $i_{f}$.

The charge $\&$ accumulated on the precision capacitor $C$ by reference voltage $\mathrm{V}$ is

$$
Q=\mathrm{CV} \text {. }
$$

The input current flowing in the thermistor is

$$
i_{r}=V / R_{T} \cdot
$$

The discharge of $Q$ by current $i_{f}$ in time $P$ is

$$
i_{f}=Q / P=C V / P \text {. }
$$

Since

$$
i_{f}=i_{r}
$$

then

$$
\begin{aligned}
V / R_{T} & =C V / P \text {, or } \\
P & =R_{T} C=\left(R_{t}+R_{S}\right) C .
\end{aligned}
$$

The period $P$ is proportional to the total resistance $R_{T}$, hence related to the thermistor resistance $R_{t} \cdot R_{t}$ is converted to temperature by substitution into the calibration equation (see section 5 ).

Solid state FET switches transfer the charge from $C$ to $C_{1}$ via op amp A. After an appropriate interval (nominally 400 microseconds) the switches reconnect $C$ to $V$ to recharge $C . C_{1}$ continues to discharge and after time interval $P, C_{1}$ is discharged, the switches again transfer the charge on $C$ to the integrator, and the cycle begins again. C and $\mathrm{C}_{2}$ form a voltage divider to reduce the voltage at the input of $\mathrm{A}$ to prevent driving the op amp input into saturation where it would draw current. 
Additional circuitry controls the switching and provides closed loop operation whereby the cycle is reinitialized as soon as the charge is dispensed. The circuit also provides a slight delay in the switching (about 10 micro-seconds) to allow break-before-make action of the switches to prevent loss of charge.

Since the frequency output is a function of the total resistance $R_{T}$ and the capacitance of capacitor $C\left(P=R_{T}\right)$, the circuit is relatively insensitive to variations in components in the circuit except for $R_{S}$ and $C$. The series resistor $R_{S}$ is chosen to produce a nearly linear relationship between the current in the thermistor and its temperature. With this resistor value equal to $37,300 \mathrm{ohms}$, the current in the thermistor-resistor network is linear with temperature within $1.7 \%$ over the range of $0^{\circ} \mathrm{C}$ to $30^{\circ} \mathrm{C}$. Although the network is somewhat non-linear temperature excursions in the ocean do not often cause biases in a 15 minute average. The output frequency of the converter is proportional to current input within $.01 \%$.

There is a slight error in the period (not exactly equal to $R_{T} C$ ) and is probably due to a finite reaction time of the op amp to the charge applied at its input. An empirical constant, $\mathrm{K}$, can be determined from tests, resulting in a more nearly exact equation

$$
P=R_{T} C+K \text {. }
$$

$\mathrm{K}$ has been found to be about 0.5 microseconds for a typical instrument.

The expression for computing thermistor resistance from the period of the $\mathrm{V} / \mathrm{F}$ converter output signal is straightforward to derive, if rather involved. One begins with the valid assumptions that the voltage across $R_{t}$ and $R_{S}$ in Fig. $I$ is constant and that the frequency of the $V / F$ converter is directly proportional to the current through $R_{t}$ and $R_{S}$. The resulting expression is:

$$
R_{t}=\frac{\left(\frac{1}{P}+K_{2}\right) R_{S}}{K_{1}-K_{2}-\frac{1}{P}}
$$




$$
\text { where } \begin{aligned}
\mathrm{P} & =\mathrm{T}_{\mathrm{S}} / \mathrm{N}=\text { period of } \mathrm{V} / \mathrm{F} \text { output } \\
\mathrm{K}_{1} & =\left(\frac{1}{\mathrm{P}_{2}}-\frac{1}{\mathrm{P}_{1}}\right) / \mathrm{D} \\
\mathrm{K}_{2} & =\left[\frac{\mathrm{R}_{1}}{\mathrm{P}_{2}\left(\mathrm{R}_{\mathrm{S}}+\mathrm{R}_{1}\right)}-\frac{\mathrm{R}_{2}}{\mathrm{P}_{1}\left(\mathrm{R}_{\mathrm{S}}+\mathrm{R}_{2}\right)}\right] / \mathrm{D} \\
\mathrm{D} & =\frac{\mathrm{R}_{2}}{\mathrm{R}_{\mathrm{S}}+\mathrm{R}_{2}}-\frac{\mathrm{R}_{1}}{\mathrm{R}_{S}+\mathrm{R}_{1}}
\end{aligned}
$$

and $R_{1}, R_{2}, P_{1}, P_{2}$ are the input resistances and output periods of two $\mathrm{V} / \mathrm{F}$ calibration points. 
3. $\mathrm{V} / \mathrm{F}$ Converter calibration

Since the $V / F$ converter transforms the resistance changes of the thermistor into electrical signals it is essential that it be calibrated as carefully as the thermistor. Our calibration procedure is designed to monitor the long term behavior as well as provide a calibration for a specific setting of an instrument.

Before and after each deployment the $\mathrm{V} / \mathrm{F}$ converter is calibrated at seven precise $(.001 \%)$ input resistances corresponding to nominal thermistor resistance values at seven temperatures. The values are shown in Table 1. The period at the $5^{\circ} \mathrm{C}$ point is adjusted to read $1820.4 \mu \mathrm{s}$ at $74434 \Omega$ and the seven periods are recorded again, both at room temperature and in a cold room at $25^{\circ} \mathrm{C}$. A record is made at the periods before and after adjustment which allows us to monitor the temporal stability of each converter. The cold room values are used in decoding most data since they correspond closely to the in situ conditions of the instruments in typical moorings.

Table 1

$\underline{V} / \mathrm{F}$ Converter Calibration Results

\begin{tabular}{|c|c|c|}
\hline Temperature & Input Resistance & Period $\left(x 10^{-6}\right.$ seconds \\
\hline $0^{\circ} \mathrm{C}$ & $94972 \Omega$ & $2154.871 \pm .075$ \\
\hline 5 & 74434 & $1820.412 \pm .004$ \\
\hline 10 & 58747 & $1564.911 \pm .056$ \\
\hline 15 & 46675 & 1368.2 \\
\hline 20 & 37299 & $1215.640 \pm .093$ \\
\hline 25 & 29998 & $1096.765 \pm .109$ \\
\hline 30 & 24269 & $1003.464 \pm .127$ \\
\hline
\end{tabular}

The period values in Table 1 are the means and standard deviations of the data points at each temperature for the 175 calibrations investigated. Only a nominal value has been included for the $15^{\circ} \mathrm{C}$ point because we discovered some of the calibrations were made with an incorrectly labeled precision resistor. 
The period-resistance relationship is linear. In decoding the data from a current meter we use the $5^{\circ} \mathrm{C}$ and $25^{\circ} \mathrm{C}$ points to determine the relation. We checked the linearity for 175 calibrations of 45 instruments by comparing the actual calibration points and the values computed from the straight line determined by the $5^{\circ} \mathrm{C}$ and $25^{\circ} \mathrm{C}$ points. The result was that, in all but five calibrations, the error introduced by using the straight line was equivalent to $1 \mathrm{~m}^{\circ} \mathrm{C}$ and in those five it was equivalent to about $2 \mathrm{~m}^{\circ} \mathrm{C}$ inaccuracy in the decoded temperatures.

Using the $5^{\circ} \mathrm{C}$ and $25^{\circ} \mathrm{C}$ points from Table 1 the period-resistance relation is

$$
\operatorname{PER}(\mu s)=608.243+0.01628515 * \mathrm{R} .
$$

A least squares fit of all but the $15^{\circ} \mathrm{C}$ point yields

$$
\operatorname{PER}(\mu s)=608.231+0.01628516 * R \text {. }
$$

The two equations fit the data equally well. The standard deviation of the first is $0.013 \mu \mathrm{sec}$, and of the second, $0.018 \mu \mathrm{sec}$. The accuracy in period required for $\pm 1 \mathrm{~m}^{\circ} \mathrm{C}$ accuracy in temperature is $\pm 0.08 \mu \mathrm{sec}$ at $0^{\circ} \mathrm{C}$, $\pm 0.05 \mu \mathrm{sec}$ at $10^{\circ} \mathrm{C}$, and $\pm 0.03 \mu \mathrm{sec}$ at $20^{\circ} \mathrm{C}$. We have also fit an equation like the first of the preceding paragraph to the data of the 175 individual V/F calibrations. After solving each equation for $R$ and subtracting the input resistances we computed an r.m.s. residual for each calibration. The mean of this residual over all the calibrations is 0.9 ohms. All but three of the residuals were less than 3 ohms. One ohm represents $0.22 \mathrm{~m}^{\circ} \mathrm{C}$ at $0^{\circ} \mathrm{C}$ and $0.99 \mathrm{~m}^{\circ} \mathrm{C}$ at $30^{\circ} \mathrm{C}$ for our standard thermistors.

The calibrations also show that the stability of the V/F converters is such that they will maintain $1 \mathrm{~m}^{\circ} \mathrm{C}$ accuracy over the period of one year, a stability of 3 parts in $10^{5}$. 
4. Thermistor Calibrations: Methods and Facilities

All of our thermistor calibrations have been made with the same variety of equipment: a constant temperature bath, a platinum resistance thermometer (PRT) and bridges to measure the resistance of both the PRT and the thermistor. Calibrations began in January 1973. In August 1973 (just prior to batch 11) there was a bath modification resulting in an improvement in accuracy. In December 1974 (just prior to Batch 45) most of the system was replaced for some improvement in accuracy and a large improvement in convenience and speed.

We will describe both calibration systems and the errors connected with them.

A. System 1. January 1973 - December 1974. Batches 1-10

Figure 2 shows a diagram of the first bath. It was one used previously (Bradshaw and Schleicher, 1970) but its precision of control was improved for this application. It consisted of an outer and an inner bath, both filled with a stirred water-ethylene glycol solution. The outer bath had heating and cooling coils. The inner bath was heated to maintain it $1-2^{\circ} \mathrm{C}$ above the temperature of the outer bath. Within the inner bath was a kerosene-filled aluminum vessel containing the thermistor mounting block (see Fig. 3). The kerosene was stirred.

The thermistor mounting block was made from a 10" length of aluminum hexagonal bar stock 1 1/4" across the flats. The thermistors were screwed into radial tapped holes in the flat sides, 4 to a side. The platinum resistance thermometer was mounted in a $3 / 8^{\prime \prime}$ diameter hole drilled to within 1/2" of the bottom. Mercury was used in the bottom of the well for good thermal contact.

A guarded Wheatstone bridge, Leeds and Northrup type 4737-A20, was used to measure thermistor resistance.

A Leeds and Northrup type 8163-C platinum resistance thermometer was used to measure the temperature of the thermistor mounting block. The resistance of the thermometer was measured with a Leeds and Northrup type 8068-B Mueller bridge using a nanovoltmeter as a null meter. The calibration of the PRT was checked periodically at the triple point temperature of water with a Trans-Sonic Equiphase type 130 triple point cell. 
Up to 23 thermistors were mounted in the aluminum block. The thermistor leads were connected to cables going to the Wheatstone bridge via terminal strips. The 24 th terminal pair of these strips was usually connected to a pair of bare wires immersed in the kerosene. The resistance of this open line was monitored with a megohmmeter as a check on any condition (contaminated oil, condensation, etc.) which could cause a significant shunting error in the thermistor resistance measurements.

Resistance of the thermistors was measured in sequence at a set of temperatures starting at approximately $0^{\circ} \mathrm{C}$ and increasing in $5^{\circ} \mathrm{C}$ steps to $30^{\circ} \mathrm{C}$. Voltage across the thermistor was set to correspond to that appearing in the current meter to avoid differences in power dissipated in the thermistor. The whole sequence of measurements took 2 or 3 days. Estimated Random and Systematic Errors of Measurements

During this period (January 1973 - January 1975) a change was made in the apparatus which affected the estimated precision of measurement. This occurred in August 1973 when a temperature gradient was discovered in the oil-filled vessel. From tests made at this time (by interchanging the thermistors in the highest and lowest position in a similar mounting block) the largest temperature difference from the top of the mounting block to the bottom appeared to be $.004^{\circ} \mathrm{C}$ at a bath temperature of $0^{\circ} \mathrm{C}$. After changing the oil level and introducing baffles inside the aluminum vessel, retesting showed that the difference, if any, was less than $.001^{\circ} \mathrm{C}$. The estimated random error prior to Batch 11 (September 7, 1973) includes a factor based on the larger gradient.

The temperature variation in the water bath due to the control cycle ( $1 \mathrm{cycle} / \mathrm{min}$ ) was usually less than $1 \mathrm{~m}^{\circ} \mathrm{C}$. The oil-filled vessel further reduced the cycling variation to the order of several tenths of a millidegree as measured by the platinum thermometer. The longer term temperature variation inside the mounting block could be followed by the thermistors and by the platinum thermometer and under typical conditions did not vary by more than $1 \mathrm{~m}^{\circ} \mathrm{C}$ over the time required to make all measurements at one temperature point ( 1 to $11 / 2$ hour for 23 thermistors). 
The values of the " $\alpha$ " and " $\delta$ " constants of the platinum thermometer are traceable to a NBS calibration (see NBS Monograph 126, 1973, for symbol nomenclature) and its resistance was checked regularly at the triple point of water. This resistance changed by the equivalent of about $2.5 \mathrm{~m}^{\circ} \mathrm{C}$ over the two year period. The Mueller bridge calibration corrections are traceable to a NBS calibration. This thermometer-bridge combination was checked in February 1975 against that of a newer Leeds and Northrup platinum thermometer and Guildline Current Comparator Resistance Bridge (see section B in this chapter). The temperatures indicated by the two systems differed by not more than $0.7 \mathrm{~m}^{\circ} \mathrm{C}$ at $30^{\circ} \mathrm{C}$. The warranted (uncorrected) accuracy of the type 4737 guarded Wheatstone bridge used to measure the thermistor resistances is $\pm 100 \mathrm{ppm}$ at $25^{\circ} \mathrm{C}$ (equivalent to $\pm 2 \mathrm{~m}^{\circ} \mathrm{C}$ ). The accuracy is derated by $10 \mathrm{ppm}$ per ${ }^{\circ} \mathrm{C}$ difference from $25^{\circ} \mathrm{C}$. Corrections to the bridge dial readings were found at $25^{\circ} \mathrm{C}$ using resistance ladders, one element of which had been measured to an accuracy of $5 \mathrm{ppm}$. The accuracy of the corrected guarded Wheatstone bridge readings at $25^{\circ} \mathrm{C}$ was then taken as about $5 \mathrm{ppm}$, equivalent to $0.1 \mathrm{~m}^{\circ} \mathrm{C}$ when applied to the measurement of thermistor resistance.

The corrections described above were used throughout the January 1973 to December 1974 period. In November 1974, they were checked by measuring the resistances of the Guarded Wheatstone Bridge using a Guildline Comparator Bridge and Guildline standard resistors. Differences of up to $20 \mathrm{ppm}\left(0.4 \mathrm{~m}^{\circ} \mathrm{C}\right)$ were found. These could be accounted for by the temperature of the Guarded Bridge $\left(23-24^{\circ} \mathrm{C}\right.$ instead of $\left.25^{\circ} \mathrm{C}\right)$ and by a drift in the Guildline standard resistors; however, this figure, $0.4 \mathrm{~m}^{\circ} \mathrm{C}$, instead of $0.1 \mathrm{~m}^{\circ} \mathrm{C}$ as found earlier, is taken as the systematic error associated with the type 4737 bridge.

The first two columns of Table 2 sum up our estimates of the errors inherent in the VACM thermistor calibration for the calibration system in use until January 1975.

B. System II. January 1975 (Batch 45) to present

In January 1975 we began using a new set of thermistor calibration apparatus which has moderately improved the calibration accuracy and substantially increased the speed and convenience of making calibrations. 
The new bath system consists of a Tronac Model 400 constant temperature bath with a Tronac Model 40 temperature controller. This is a single bath system making it easier to change the bath temperature rapidly.

The new thermistor mounting block (Fig. 4) was machined from an aluminum cylinder, 4 inch diameter by 4 inch long. Six lengthwise, 1 inch deep cuts around the cylinder allow recessed mounting of 4 thermistors per cut. The platinum thermometer is mounted in a $3 / 8$ inch diameter hole drilled through the axis of the cylinder. The mounting block is enclosed in an aluminum housing which is purged with dry nitrogen and hermetically sealed before being placed in the bath.

The new platinum resistance thermometer is a Leeds and Northrup Model 8167-25B. Its resistance is measured with a Guildine Instruments Model 9975 thermometer bridge. As used in thermometry, the bridge determines the ratio of the platinum probe resistance and a high precision, stable resistor mounted in a temperature controlled air bath. As with the Mueller bridge, a four terminal measurement of the probe resistance is made and the effect of the thermal emf's is eliminated by current reversals. Readings can be made in far less time and with greater precision than with the Mueller bridge used previously.

The rest of the equipment, the Wheatstone bridge and null meter for measuring thermistor resistance, and the triple point cell, remains the same as before.

The calibration procedure is the same as before except that the amount of time required to calibrate a normal batch of 24 thermistors is now 12 hours or less. Estimated Random and Systematic Errors of Measurements

During this period (January 1975 to the present) the random and systematic errors of measurements were estimated to be somewhat less than in the previous period. They are summarized in column 3 of Table 2 . The mounting block gradient, one of the main sources of error in precision during the previous period, was improved through the use of the newer apparatus. A test done in March 1976 which included a careful measurement of the vertical profile of the temperature along the axis of the platinum thermometer well as well as the exchange of 
thermistor position indicated a maximum variation of less than $0.6 \mathrm{~m}^{\circ} \mathrm{C}$. As a result of the improved temperature control of the new bath the error due to the short term temperature cycling of the mounting block was estimated to be not more than $0.1 \mathrm{~m}^{\circ} \mathrm{C}$. Actually, much of the time, the temperature read by the platinum probe did not change during the scanning of 24 thermistors at one temperature ( $1 / 2$ to $3 / 4$ hours) by more than 0.1 or $0.2 \mathrm{~m}^{\circ} \mathrm{C}$. When the drift was larger than this the tracking of the recorded thermistor temperature and platinum thermometer temperature was close enough so that the errors were still kept within the $0.1 \mathrm{~m}^{\circ} \mathrm{C}$ figure.

The largest source of error in precision with this new equipment was due to the drift of the platinum thermometer between triple point readings. Of course, most of this error can be corrected by interpolating linearly between check points but since this would have delayed the processing and reporting of the data it was not done. In the future it is planned to take more frequent triple point checks to reduce this source of error.

The random errors due to temperature effects on the bridge used to measure the thermistor resistances remain the same as in the previous period. There are no significant temperature effects $\left(<0.1 \mathrm{~m}^{\circ} \mathrm{C}\right)$ on the Guildline bridge.

The systematic error of the platinum resistance thermometer is estimated to be $0.5 \mathrm{~m}^{\circ} \mathrm{C}$ from information obtained from the manufacturer Leeds and Northrup (L\&N).

The Guildline bridge error in ratio measurement is certified by the manufacturer not to exceed $\pm\left(2\right.$ parts in $10^{7}$ of reading +1 step of last dial). This would cause an insignificant sytematic error in the temperature $\left(<.1 \mathrm{~m}^{\circ} \mathrm{C}\right)$.

The systematic errors associated with the type 4737 bridge and the triple point cell remain the same as before. 


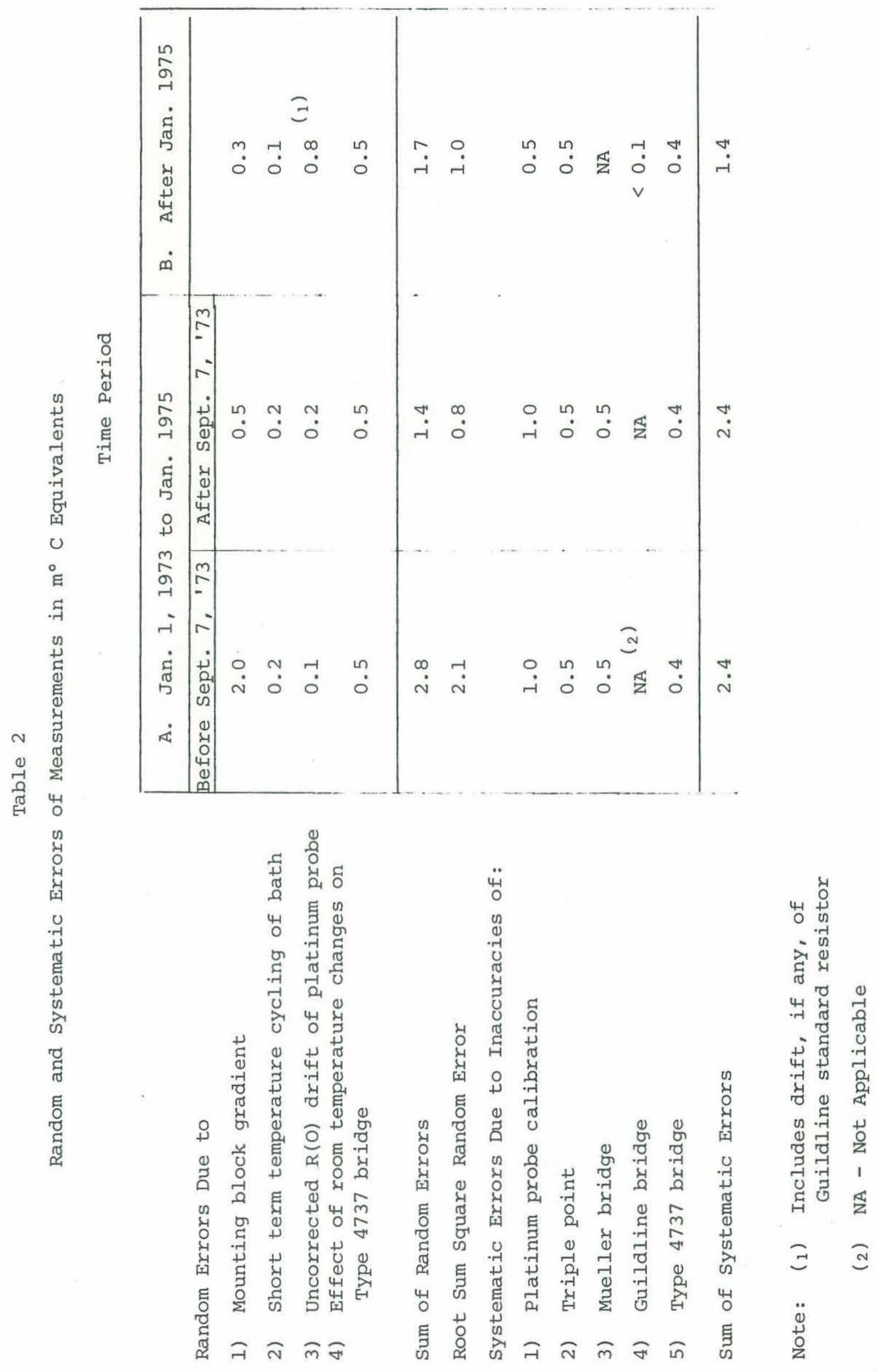




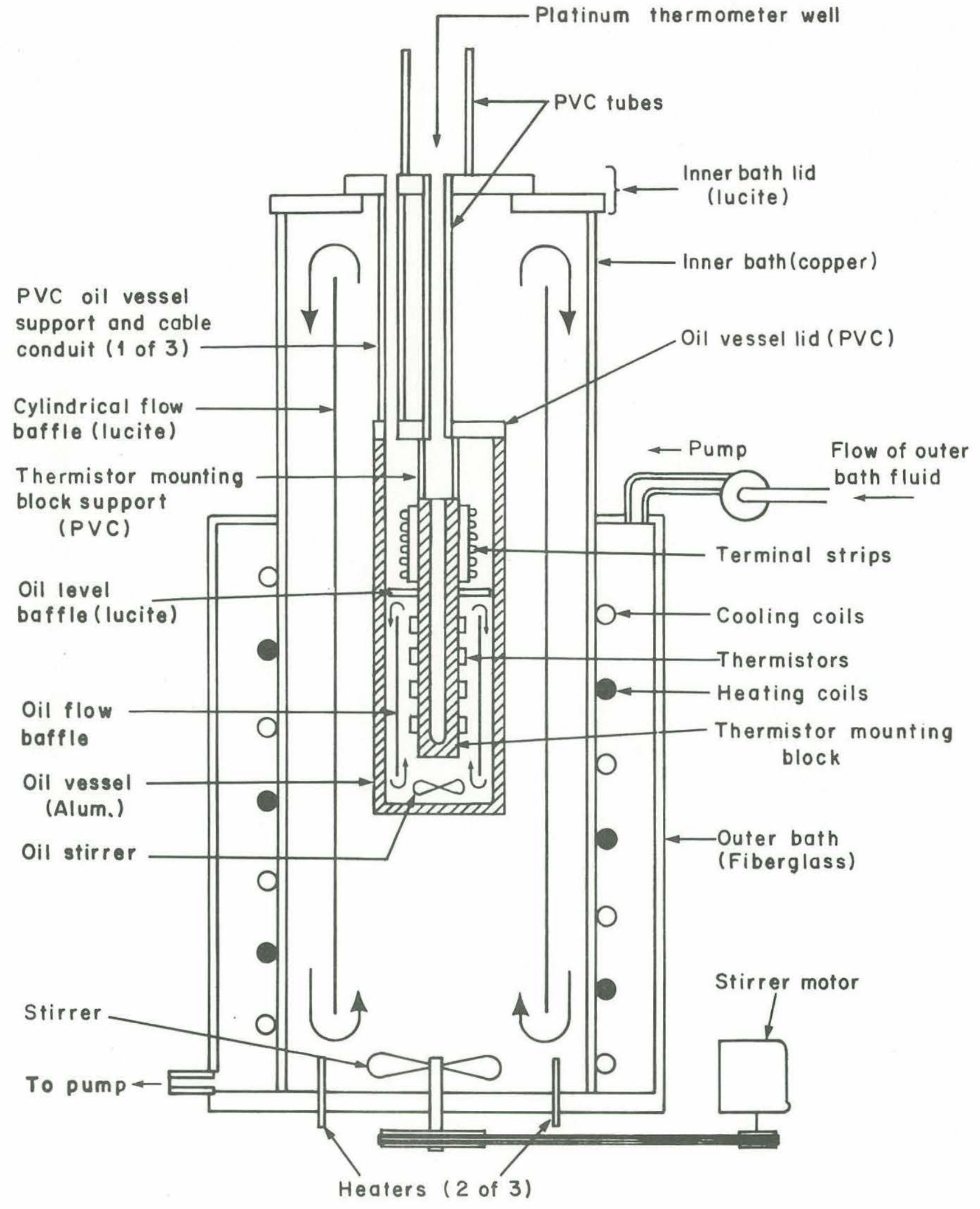

Figure 2

CONSTANT TEMPERATURE BATH WITH THERMISTOR MOUNTING BLOCK 


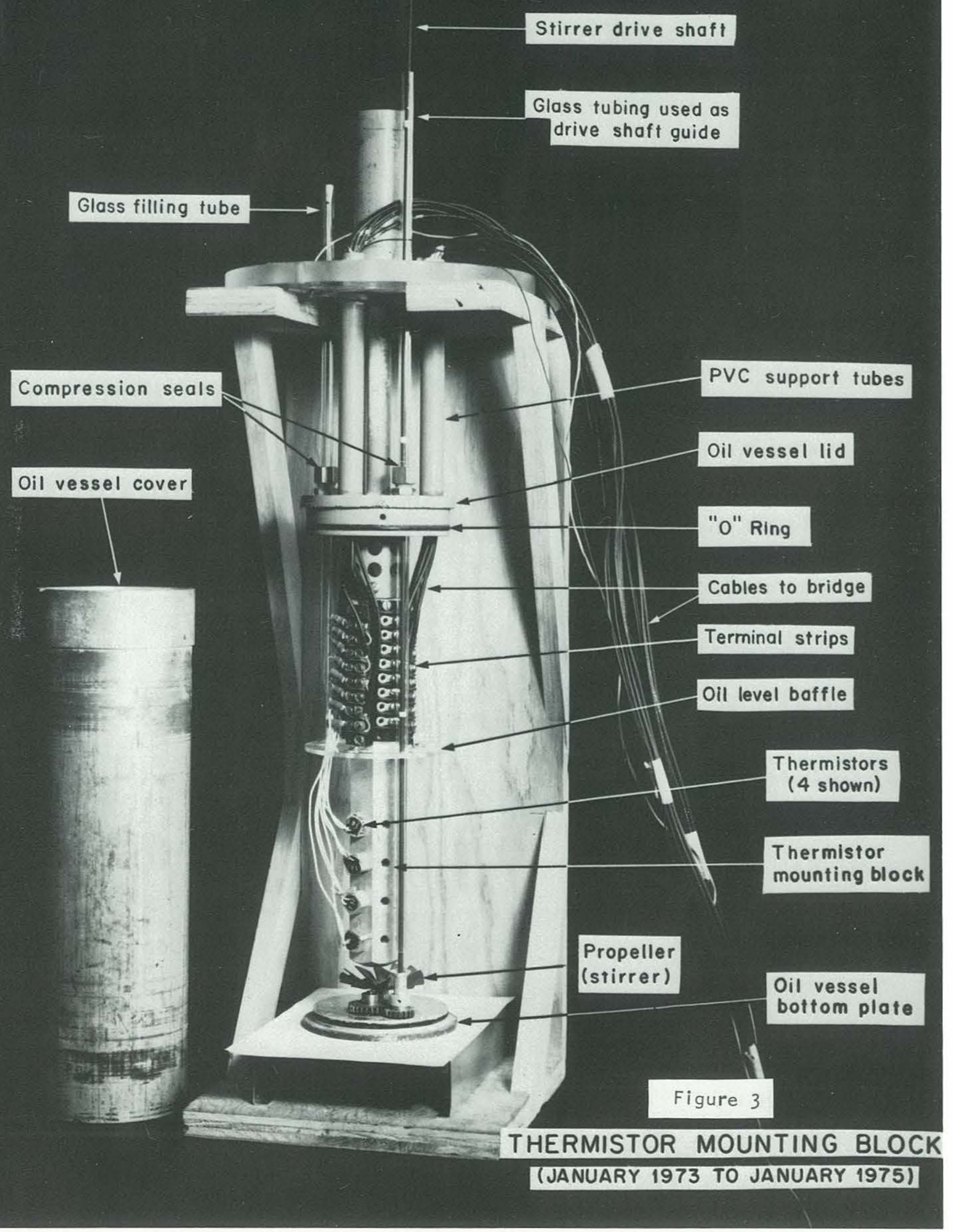




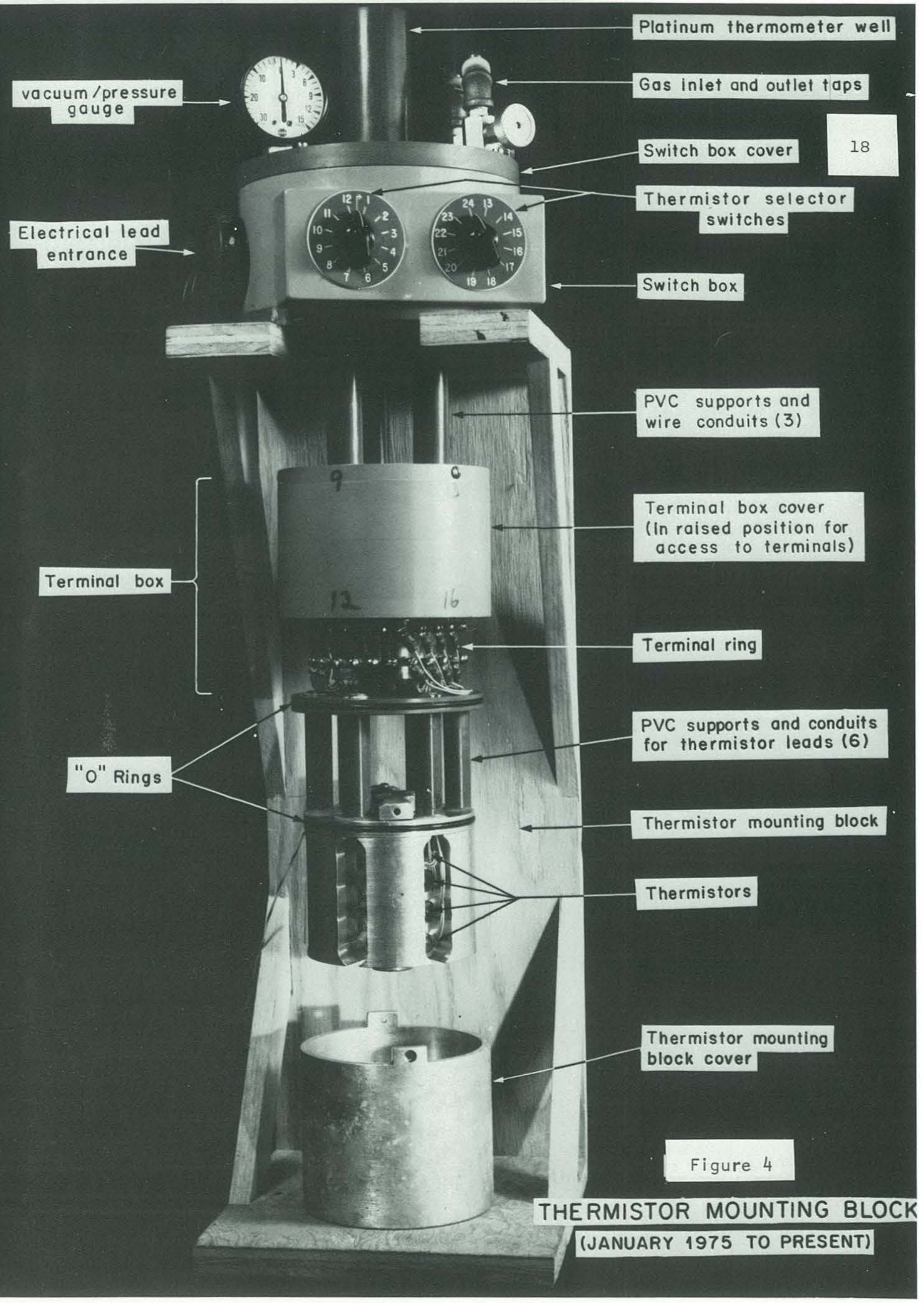


5. Thermistor Calibration Results

In this section we will describe what we have learned from calibrations to date of our YSI type 44032 thermistors.

We now own 163 YSI type 44032 thermistors which have each had at least one calibration. Of these, 69 meet the criteria for being included in this study, i.e., at least three calibrations over at least two years. We intend to continue regular calibrations of all our thermistors.

Our analysis of thermistor performance is based on the outputs of the computer programs CALIBB and CALCOLIN, described in Appendices II and III. CALIBB fits the resistance, temperature calibration data to the expression (Bennett, 1972, Steinhart and Hart, 1968)

$$
T^{-1}=A+B \ln R+C(\ln R)^{3}
$$

by a least squares technique. A residual is computed for each data point as the difference between the observed temperature and a temperature computed from the observed thermistor resistance and the A, B, C constants from that calibration. The r.m.s. value of this residual for the seven data points in a calibration is printed out in CALIBB and falls in the range $0-1 \mathrm{~m}^{\circ} \mathrm{C}$ for nearly all of our calibrations. The mean value for all our past calibrations is $.2 \mathrm{~m}^{\circ} \mathrm{C}$, which shows how well the above equation fits the data.

Using CALCOLIN we can estimate the rate at which the temperature indicated by a thermistor is changing relative to the true temperature of its environment. We should remember, however, that what is actually changing is the resistance of the thermistor at a given temperature.

Table 3 and Figure 5 sum up the calibration histories of the 69 thermistors with sufficient calibration history. Table 3 lists for each thermistor, in order of increasing drift rate magnitude, the total number of calibrations, the elapsed time in years between the first and latest calibration, the mean drift rate, and the standard deviation about the mean drift. The drift rate and standard deviation are means over the least squares fit at each of the seven calibration temperatures and are computed in CALCOLIN. In this table drift rate has the opposite sign 
from the number in the CALCOLIN output since it is the rate at which temperature would appear to change if the thermistor were kept immersed in a bath whose temperature was held constant. Positive drift rate indicates that thermistor resistance at constant temperature is decreasing with time.

The standard deviations listed in Table 3 show that our calibrations are consistent with each other to better than $1 \mathrm{~m}^{\circ} \mathrm{C}$. Standard deviations are less than this, for the most part, except for the higher drift rates. There is other evidence for the repeatibility of our calibrations. Calibration batches 52 and 53 were done within 1 week of each other and 19 thermistors were common to both batches. The mean difference between the two calibrations for each of the 19 thermistors was $.3 \mathrm{~m}^{\circ} \mathrm{C}$. The r.m.s. difference was $.97 \mathrm{~m}^{\circ} \mathrm{C}$.

Figure 5 is a histogram of the mean drift rate magnitudes for the 69 thermistors in Table 3. The dividing line we have chosen between stable and unstable thermistors is arbitrary but can be rationalized. The absolute accuracy of our temperature measurements is no worse than $\pm 10 \mathrm{~m}^{\circ} \mathrm{C}$ and may be as good as $\pm 5 \mathrm{~m}^{\circ} \mathrm{C}$. For a typical deployment of 9-12 months we would prefer that the thermistor drift be less than $5 \mathrm{~m}^{\circ} \mathrm{C}$ so that correction for drift is not necessary. The dip in the distribution around $3 \mathrm{~m}^{\circ} \mathrm{C} /$ year provides a natural place to draw the line. Since the thermistors we use are standard off-the-shelf units with no preselection applied we would expect the distribution shown in Figure 5 to be typical. Thus, in any batch of thermistors we would expect $65-75 \%$ of them to have drift rates less than $5 \mathrm{~m}^{\circ} \mathrm{C} /$ year and about $10 \%$ of them to have drift rates greater than $10 \mathrm{~m}^{\circ} \mathrm{C} /$ year. A few of these would have drift rates high enough to make them unuseable for any scientific purpose. We should point out that high drift rates seem to decrease with time but we will need several more years of calibrations before we can elaborate on that topic. 


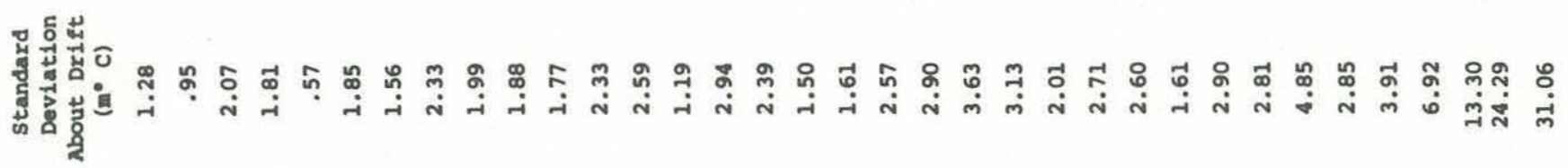

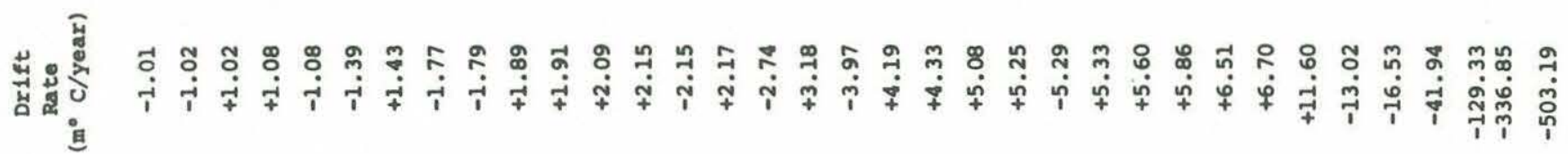
In

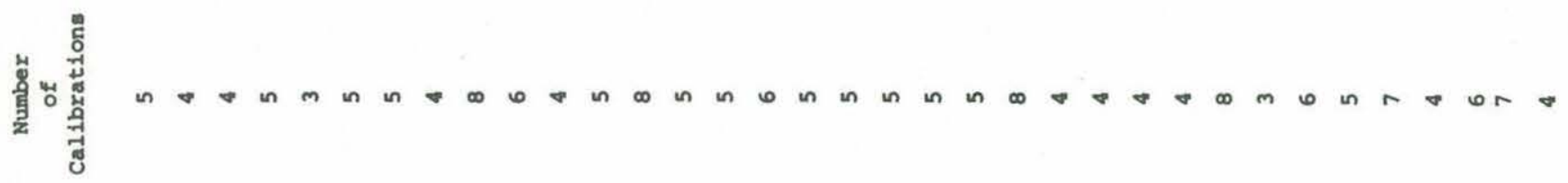

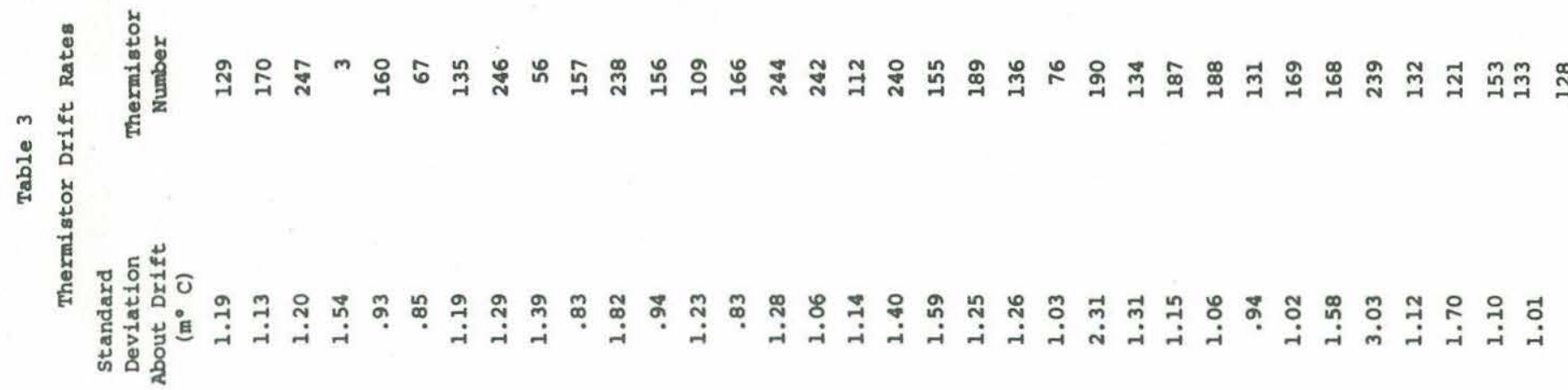

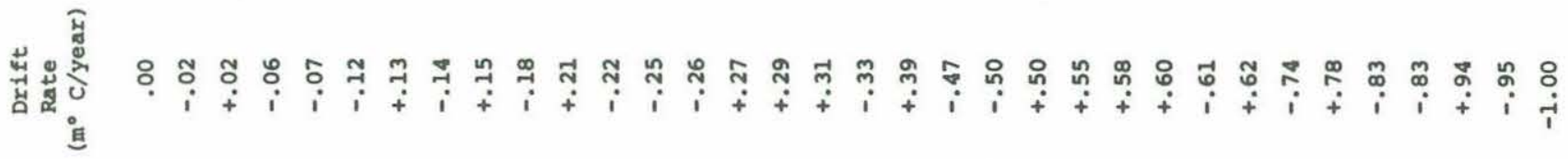
If

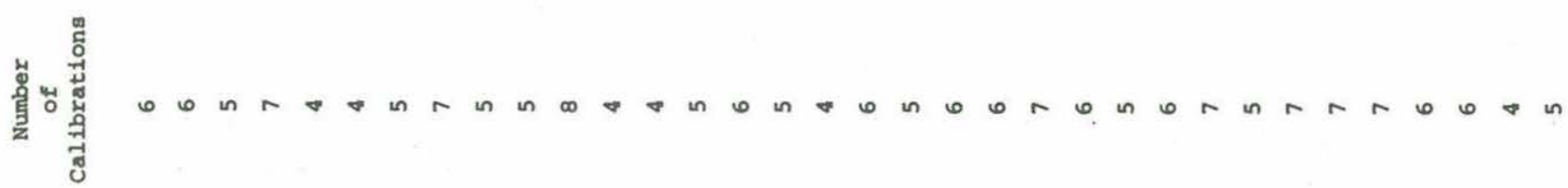
|l 

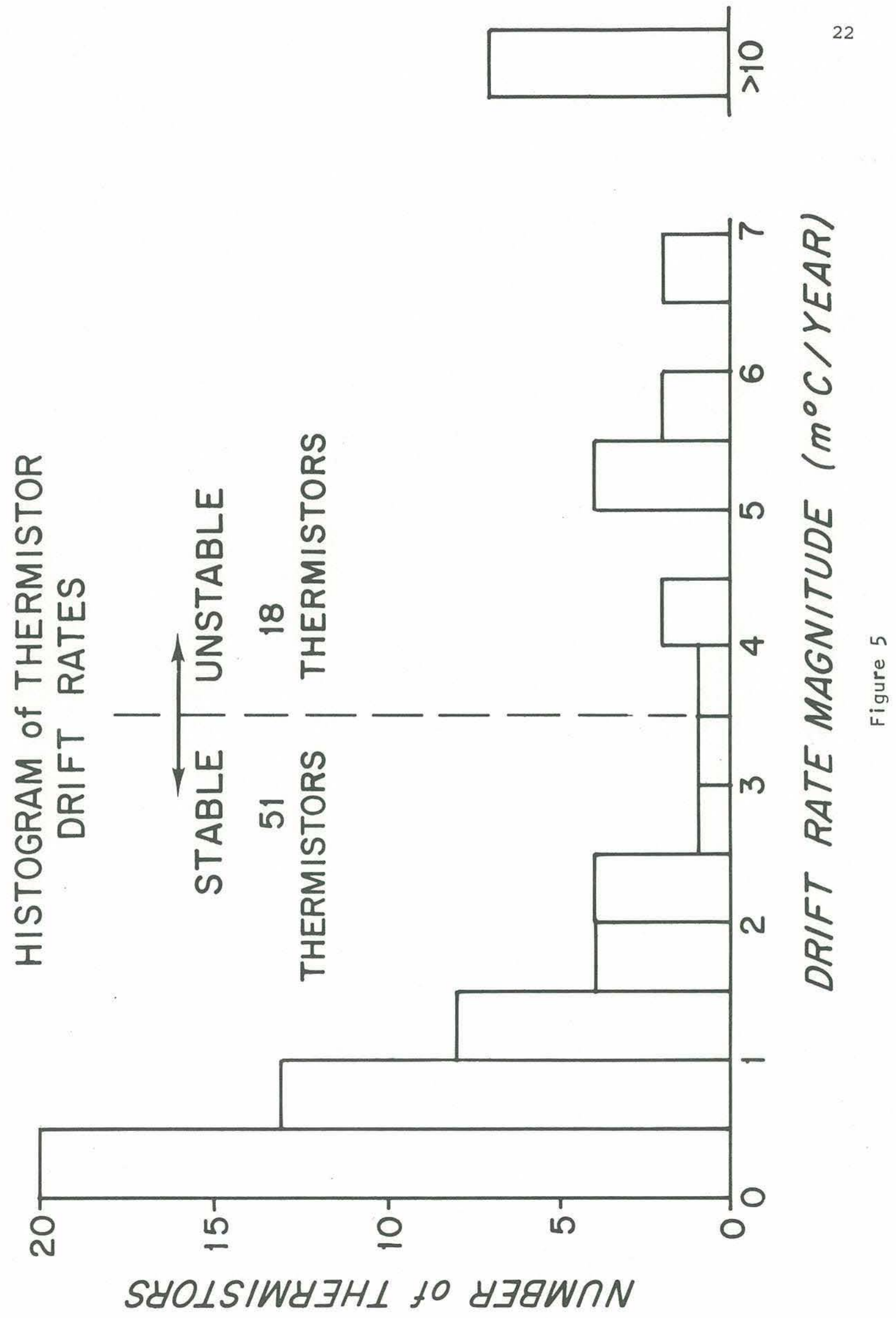
6. Temperature Accuracy and Precision

6. A. NBS Intercomparison

In December 1973 we sent 17 thermistors to the National Bureau of Standards (NBS) where they were calibrated by Ms. Sharrill D. Wood. Upon their return to W.H.O.I. in April 1974 they were calibrated by Karl Schleicher. The results give us a comparison of the results of our calibration techniques vs. those at NBS.

The thermistors chosen for this intercomparison were of two types, both preselected by the manufacturer for stability and both purchased for a special application of the VACM. One type ("5000 series") has $4000 \Omega$ resistance at $25^{\circ} \mathrm{C}$ and is used in a differential circuit to measure the difference in water temperature between the top and bottom of the VACM, thus giving local temperature gradient (See Section 6. B., IWEX). The other type ("6000 series") is different from our standard YSI thermistor in that it is pretested for stability and has a slightly different mechanical configuration. Their temperature-resistance specifications are the same as the standard VACM thermistors, having $30,000 \Omega$ resistance at $25^{\circ} \mathrm{C}$.

Normal W.H.O.I. calibrations are run with the same current passed through the thermistor as in the VACM at that temperature so that the self-heating will be quite similar. For this intercomparison, however, all resistance measurements at NBS and W.H.O.I. were made with $10 \mu a$ current through the thermistors, substantially lower than normal operating currents, to give a minimum amount of self-heating.

Table 4 shows the difference in resistance at several temperatures between the NBS and W.H.O.I. calibrations and the equivalent temperature difference. The resistances were calculated from the A, B, C constants (See Appendix II) at the indicated temperatures. The temperature difference was calculated by multiplying the resistance difference by $d T / d R$ as calculated from the A, B, C constants with the expression

$$
\frac{d T}{d R}=-\frac{T_{a b s}^{2}}{R}\left[B+3 C(\ln R)^{2}\right]
$$

The individual temperature and resistance differences in Table 4 
appear fairly random. For the most part the r.m.s. differences for each thermistor are within $5 \mathrm{~m}^{\circ} \mathrm{C}$. The mean difference is $-1.6 \pm 3.1 \mathrm{~m}^{\circ} \mathrm{C}$. This is probably what one should realistically expect for comparisons between two laboratories and may be indicative of the absolute accuracy of calibrations at any one laboratory. The standard deviation is consistent with the scatter we find between several calibrations of a stable thermistor.

Calibration results of two of the "6000 series" thermistors were omitted since later calibrations showed them to be drifting at a rate which would make comparison of the NBS and W.H.O.I. results meaningless. Four of the thermistors listed were destroyed for testing purposes after only two calibrations. These were $6003,6017,6046,6118$. These show some of the highest differences for the 6000 series thermistors in Table 4. Because of the limited number of calibrations we cannot be sure that the differences were not caused by drift. 


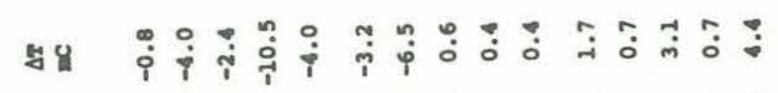

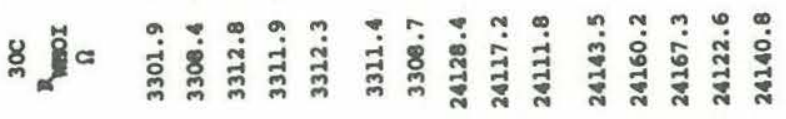

ka

번

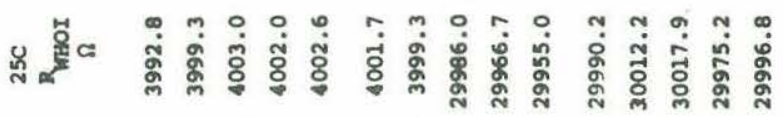

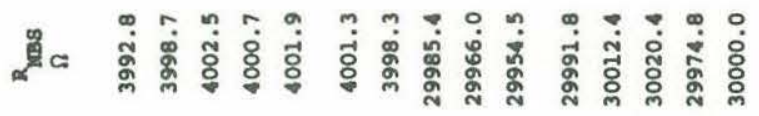

出杲

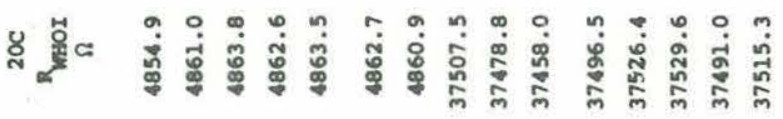

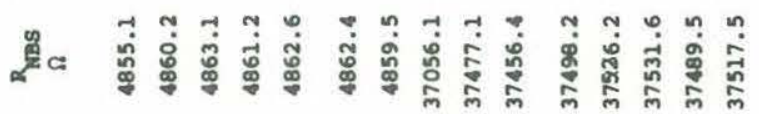

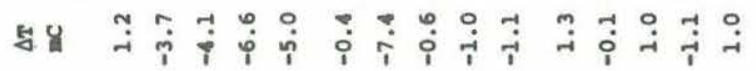

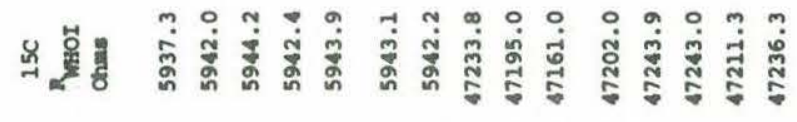

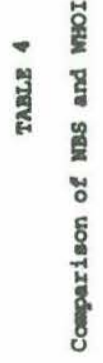

○

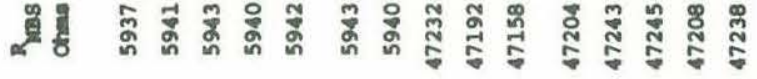

与4

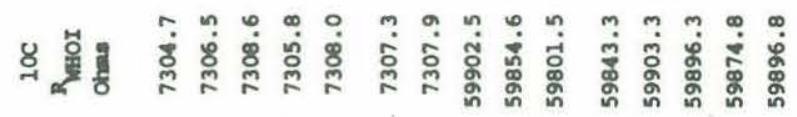

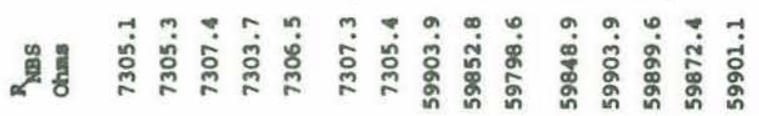

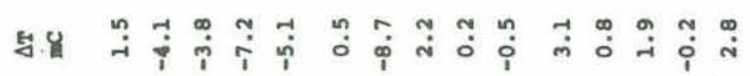

य 范

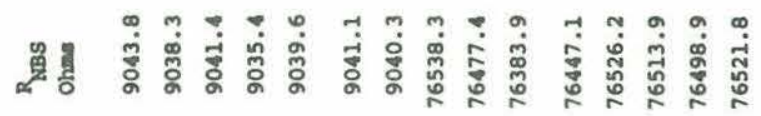

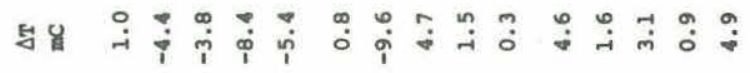

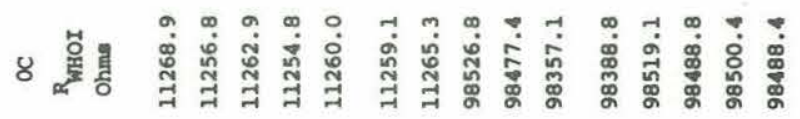

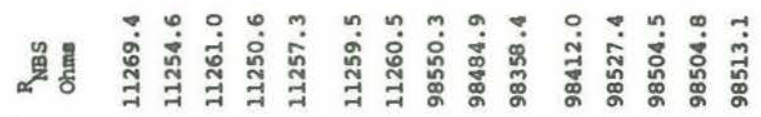

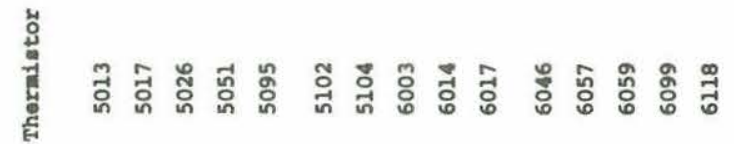


6. B. IWEX

During November 1973 a stable tripod mooring was deployed by the Buoy Project at $27^{\circ} 43^{\prime} \mathrm{N}, 69^{\circ} 51^{\prime} \mathrm{W}$ in $5455 \mathrm{~m}$ water depth. The mooring was in place for 44 days. On the IWEX (for Internal Wave Experiment) mooring were mounted 17 VACMs, 9 temperature/pressure recorders, and 4 model 850 current meters. The VACMs were modified to measure temperature difference between thermistors mounted in pods at the top and bottom of each instrument as well as absolute temperature. Because of the temperature difference measurements extensive calibration operations were performed. These calibration operations, combined with the stability of the mooring and the close spacing of a cluster of 7 VACMs at the top, offered an excellent chance to determine the achievable accuracy in the VACM measurement of absolute temperature in situ.

Figure 6 illustrates the configuration of the IWEX mooring. The depths of the levels and the horizontal separations of instruments on two different legs but at the same level are given in Table 5 as well as the temperature gradient at each level derived from a mean temperature profile (Millard, 1974; Tarbel1, Briscoe and Chausse, 1975). Calibrations

The thermistors used in the absolute temperature circuit of the IWEX VACMs were manufactured by Thermometrics, Inc. Mechanically and electrically they are quite similar to the YSI thermistors we had used previously. Instead of being mounted within the current meter, they were mounted externally in pods to decrease the time constant.

Before delivery the thermistors were stabilized by temperature cycling and then tested for maximum stability by repeated calibrations at regular intervals by the manufacturer. In addition, they were calibrated in our own facility (see section 4. of this report) before and after the experiment and twice more in the two years since. We have not included these in the thermistors reported on in section 5 because of this limited calibration history.

Because of the stringent requirements of the temperature difference measurements the thermistor pods were immersed, several at a time, in a constant temperature bath before and after the experiment for system calibration. The bath was run at $0,15,30^{\circ} \mathrm{C}$ while the thermistors remained 
connected to the current meters. These data were recorded on the IWEX data tape for each instrument.

The constant temperature bath was a Tronac Model 400, modified by the addition of one inch of urethane insulation on all sides. The temperature controller was a Tronac Model 40 used in conjunction with an external cooling unit. These provided excellent temperature control for the calibrations, maintaining control to within $2 \mathrm{~m}^{\circ} \mathrm{C}$ (averaged over 225 seconds) for periods of hours with temperature differences through the tank of less than $.2 \mathrm{~m}^{\circ} \mathrm{C}$. Absolute temperature of the tank was measured with a platinum resistance thermometer with calibrations traceable to the National Bureau of Standards.

The noise level and short-term stability of the instruments, and the stability of the calibration bath were within design specifications. As a test five instruments were run overnight in the bath. The absolute temperatures recorded by the current meters were constant within \pm 1 data count $\left( \pm .2 \mathrm{~m}^{\circ} \mathrm{C}\right)$ averaged over 225 seconds.

Results

Biases and drift rates of the thermistors were computed from the bath tests and our standard thermistor calibrations. Bias is the error in measurement of absolute temperature by a current meter and thermistor at the time of the pre-mooring bath test. Drift rate is computed from the difference in error of measurement between the pre-mooring and post-mooring bath tests and the pre-mooring and post-mooring thermistor calibrations. Only two of the seventeen thermistors, those at the positions B2 and C5, showed significant drift and needed to be corrected but the magnitudes of these two drift rates, 9 and $11 \mathrm{~m}^{\circ} \mathrm{C} /$ month, were surprisingly large in view of the pretesting performed by the manufacturer.

Table 6 lists means of absolute temperature for all the levels where there was more than one current meter. They are listed as ten consecutive 4-day means and the overall 40-day mean. The B2 and C5 temperatures have been corrected for bias and drift. No corrections were required for the rest of the temperatures. 
In Table 7 are the temperature differences at each level for the 4-day means, the 40-day mean, and the 40-day mean divided by the temperature gradient at that level from Table 5. If we assumed that the temperature sensors were all perfect then this last quantity would be the mean depth difference between sensors on one level.

Now look at Table 7 in detail keeping in mind our stated temperature accuracy of $10 \mathrm{~m}^{\circ} \mathrm{C}$. Sensors $\mathrm{Al}$ and $\mathrm{Cl}$ are only 6.1 meters apart and the temperatures agree within, at most, $2 \mathrm{~m}^{\circ} \mathrm{C}$. At level 2, with a separation of 8.5 meters, A2 and C2 agree to no worse than $3 \mathrm{~m}^{\circ} \mathrm{C}$. B2 is one of the two thermistors which had a rather large drift rate and is, therefore, not as reliable as the others. In spite of this, it agrees with $\mathrm{A} 2$ and $\mathrm{C} 2$ within $5 \mathrm{~m}^{\circ} \mathrm{C}$ except for one of the 4-day periods. $\mathrm{A} 4$ and $\mathrm{B} 4$ agree within $5 \mathrm{~m}^{\circ}$ C. At levels 5, 6, 10 with substantially larger sensor separations the B leg temperatures are substantially higher than for legs A or C. To explain this requires that the sensors on the B leg be 1, 2, 3 meters higher for the 5, 6, 10 levels than the sensors on the other two legs. Although there were not enough working pressure sensors on the mooring to define the motions we can rationalize the direction if not the magnitude, of the leg motions.

Anchors at the base of legs $A$ and $C$ were lined up along a northsouth line. The currents in the top $1500 \mathrm{~m}$ were predominantly from west to east during the whole 40 days. This would cause legs $A$ and $C$ to be depressed relative to leg $B$. The current veered somewhat about the easterly direction with time, however, so we cannot say much about the relative depths of sensors on legs $A$ and C. It is apparent from Table 7 that the $\mathrm{B}-\mathrm{A}$ and $\mathrm{B}-\mathrm{C}$ temperature differences are substantially larger than the C-A at levels.5, 6, and 10 .

The absolute temperature data from the IWEX mooring are consistent with our claimed temperature accuracy of $10 \mathrm{~m}^{\circ} \mathrm{C}$. They are particularly supportive where the horizontal separations are small and we can expect the vertical separations to be less than about $50 \mathrm{~cm}$. 
Table 5

\section{IWEX Mooring Data}

Lev
1
2
4
5
6
8
10
14

Horizontal
Separation
of

Depth

Instruments

Level

(m)

(m)

6.1

8.5

14.0

44.0

139

441

Temperature

Gradient

$\left(\mathrm{m}^{\circ} \mathrm{C} / \mathrm{m}\right)$

2

603.6

605.7

610.6

639.5

730.6

1014.4

450

18.6

18.6

18.8

19.8

22.5

$8 \quad 1014.4$

1023.1

12.2

1600

11.7

1.4 
Table 6

IWEX 4-Day Mean Temperatures, B2 and C5 Corrected for Thermistor Drift

$\begin{array}{lccccccccccc} & 1 & 2 & 3 & 4 & 5 & 6 & 7 & 8 & 9 & 10 & \begin{array}{c}40-\text { Day } \\ \text { Mean }\end{array} \\ \text { A1 } & 14.029 & 13.964 & 13.968 & 14.015 & 14.116 & 14.158 & 14.180 & 14.186 & 14.181 & 14.173 & 14.097 \\ \text { C1 } & 14.027 & 13.962 & 13.967 & 14.014 & 14.116 & 14.157 & 14.179 & 14.184 & 14.180 & 14.172 & 14.096 \\ \text { A2 } & 13.995 & 13.927 & 13.930 & 13.975 & 14.079 & 14.120 & 14.144 & 14.152 & 14.144 & 14.141 & 14.061 \\ \text { B2 } & 13.988 & 13.922 & 13.925 & 13.972 & 14.075 & 14.117 & 14.141 & 14.150 & 14.141 & 14.139 & 14.057 \\ \text { C2 } & 13.995 & 13.926 & 13.930 & 13.974 & 14.078 & 14.119 & 14.142 & 14.149 & 14.141 & 14.138 & 14.059 \\ \text { A4 } & 13.865 & 13.798 & 13.793 & 13.836 & 13.946 & 13.985 & 14.008 & 14.024 & 14.005 & 14.015 & 13.927 \\ \text { B4 } & 13.866 & 13.800 & 13.794 & 13.839 & 13.949 & 13.990 & 14.011 & 14.027 & 14.009 & 14.017 & 13.930 \\ \text { A5 } & 13.288 & 13.231 & 13.181 & 13.241 & 13.358 & 13.429 & 13.452 & 13.461 & 13.429 & 13.463 & 13.353 \\ \text { B5 } & 13.301 & 13.249 & 13.198 & 13.262 & 13.380 & 13.453 & 13.473 & 13.484 & 13.448 & 13.482 & 13.373 \\ \text { C5 } & 13.289 & 13.237 & 13.188 & 13.250 & 13.367 & 13.436 & 13.457 & 13.467 & 13.430 & 13.468 & 13.359 \\ \text { A6 } & 11.254 & 11.155 & 11.142 & 11.134 & 11.264 & 11.389 & 11.383 & 11.413 & 11.431 & 11.442 & 11.301 \\ \text { B6 } & 11.293 & 11.198 & 11.184 & 11.183 & 11.317 & 11.447 & 11.435 & 11.464 & 11.488 & 11.496 & 11.350 \\ \text { C6 } & 11.260 & 11.162 & 11.150 & 11.147 & 11.276 & 11.387 & 11.371 & 11.402 & 11.410 & 11.434 & 11.300 \\ \text { A10 } & 6.196 & 6.219 & 6.244 & 6.269 & 6.271 & 6.317 & 6.437 & 6.594 & 6.617 & 6.583 & 6.375 \\ \text { B10 } & 6.219 & 6.247 & 6.278 & 6.303 & 6.315 & 6.365 & 6.476 & 6.635 & 6.669 & 6.627 & 6.413 \\ \text { C10 } & 6.192 & 6.222 & 6.252 & 6.280 & 6.278 & 6.312 & 6.422 & 6.575 & 6.594 & 6.572 & 6.370 \\ \text { A14 } & 3.538 & 3.563 & 3.605 & 3.605 & 3.580 & 3.581 & 3.620 & 3.635 & 3.629 & 3.619 & 3.597 \\ \text { B14 } & 3.554 & 3.589 & 3.628 & 3.629 & 3.615 & 3.602 & 3.641 & 3.664 & 3.655 & 3.639 & 3.622 \\ \text { C14 } & 3.547 & 3.597 & 3.622 & 3.621 & 3.598 & 3.592 & 3.626 & 3.641 & 3.626 & 3.619 & 3.609\end{array}$


Table 7

IWEX Temperature Differences

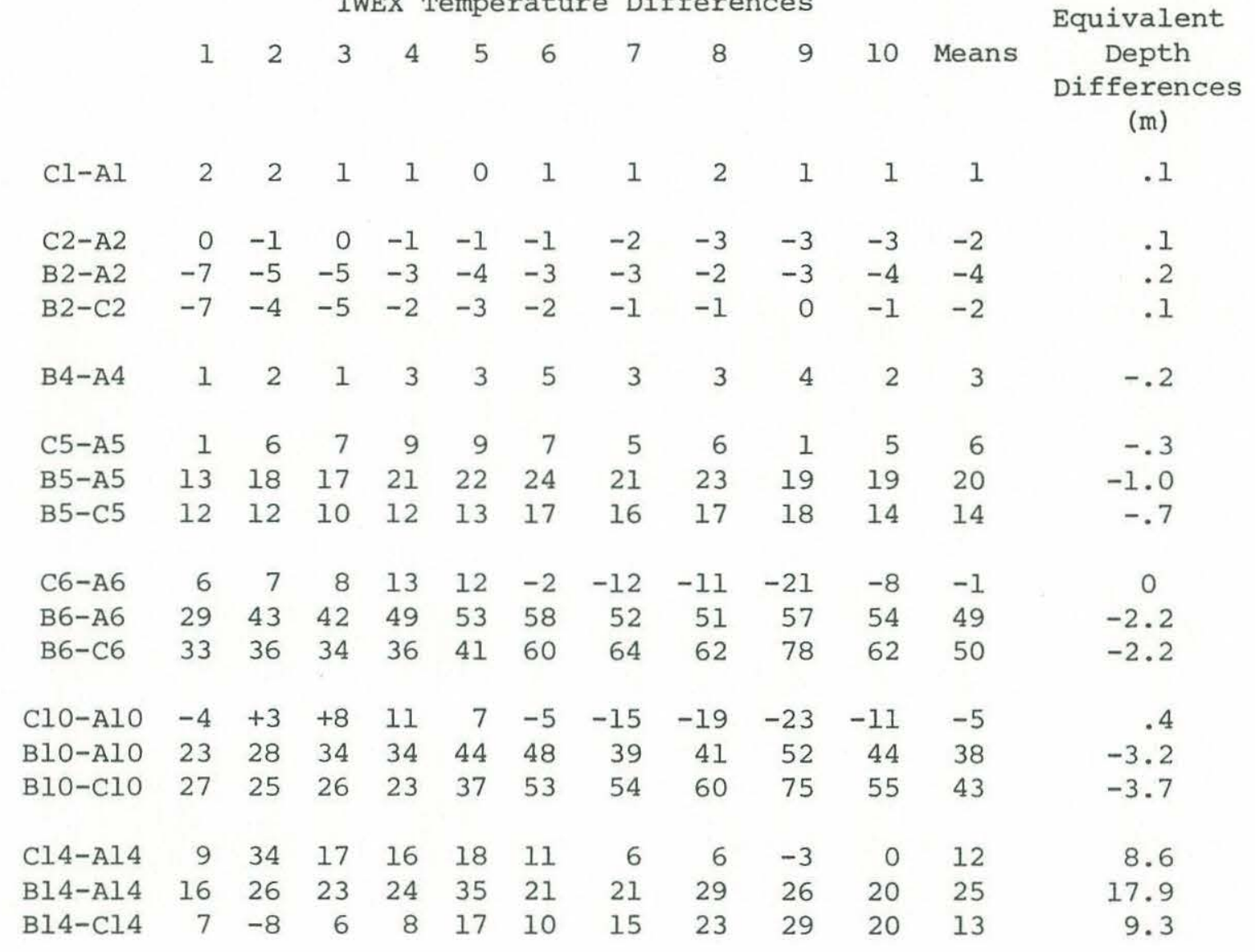




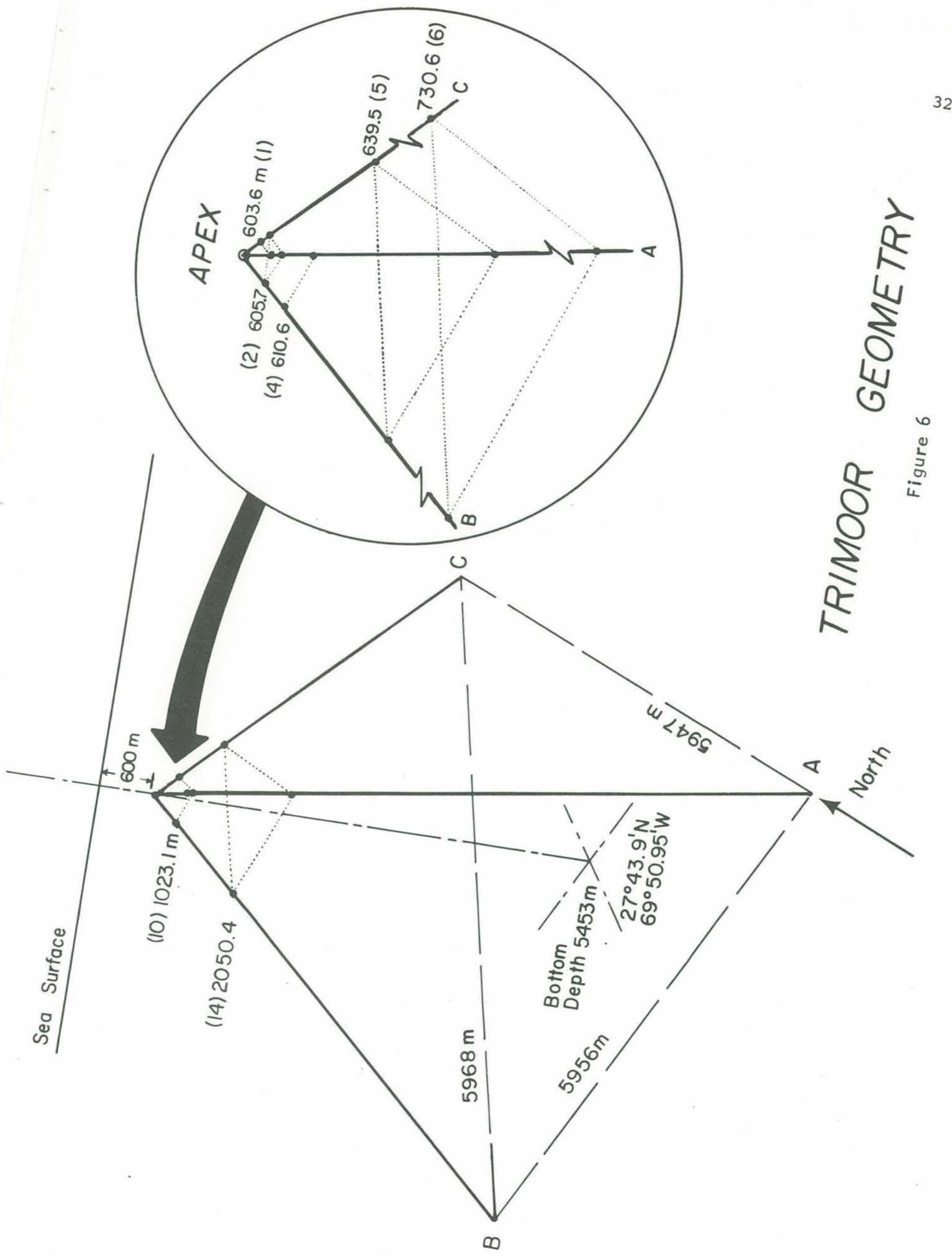


6. C. Mooring 551 Intercomparison

In December 1974, a mooring was implanted at Site J, $36^{\circ} \mathrm{N}, 70^{\circ} \mathrm{W}$, with four VACMs rigidly shackled together at a nominal $2000 \mathrm{~m}$ depth. Mooring 551 was in place for 128 days during which all four instruments worked satisfactorily. A fifth instrument, containing a pressure sensor, did not work. Because of this, the depths of the VACMs are known only to about $\pm 20 \mathrm{~m}$.

Since the mooring's purpose was a detailed comparison of the VACMs, the depth of the instrument grouping was chosen to be in a region of low gradients. Figure 7 shows temperature vs. depth from a CTD station made at the mooring location when it was set. The inset shows a more detailed plot for the depth range $1900-2100 \mathrm{~m}$, a straight line least squares fitted to the CTD data, and four points representing the 128 day temperature means for the four VACMs. The straight line has a slope of $-0.71 \mathrm{~m}^{\circ} \mathrm{C} / \mathrm{m}$, or the equivalent of a $4.3 \mathrm{~m}^{\circ} \mathrm{C}$ spread in temperature over the $6 \mathrm{~m}$ between the top and bottom thermistors.

Table 8 shows the 128 day temperature means from the four VACMs and their standard deviations. For each 7.5 minute recording interval a mean temperature was computed from the four individual temperatures and the difference between the mean and the individual temperatures computed to see how well the four instruments tracked. Row 4 is the 128 day time mean of these differences for each instrument and row 5 is the standard deviation of this quantity. The results show that the instruments track very well and that the agreement of the means is not fortuitous.

Table 8

Mooring 551 Temperatures Averaged over 128 Days

$\begin{array}{lllll}\text { 1. Instrument } & 5512 & 5513 & 5514 & 5515 \\ \text { 2. Mean temperature } & 3.935^{\circ} \mathrm{C} & 3.933^{\circ} \mathrm{C} & 3.936^{\circ} \mathrm{C} & 3.932^{\circ} \mathrm{C} \\ \text { 3. Standard deviation } & 0.024 & 0.024 & 0.024 & 0.024 \\ \text { 4. Mean difference } & 0.001 & -0.001 & 0.002 & -0.002 \\ \text { 5. Standard deviation } & 0.002 & 0.001 & 0.001 & 0.002\end{array}$


TEMPERATURE $\left({ }^{\circ} \mathrm{C}\right)$

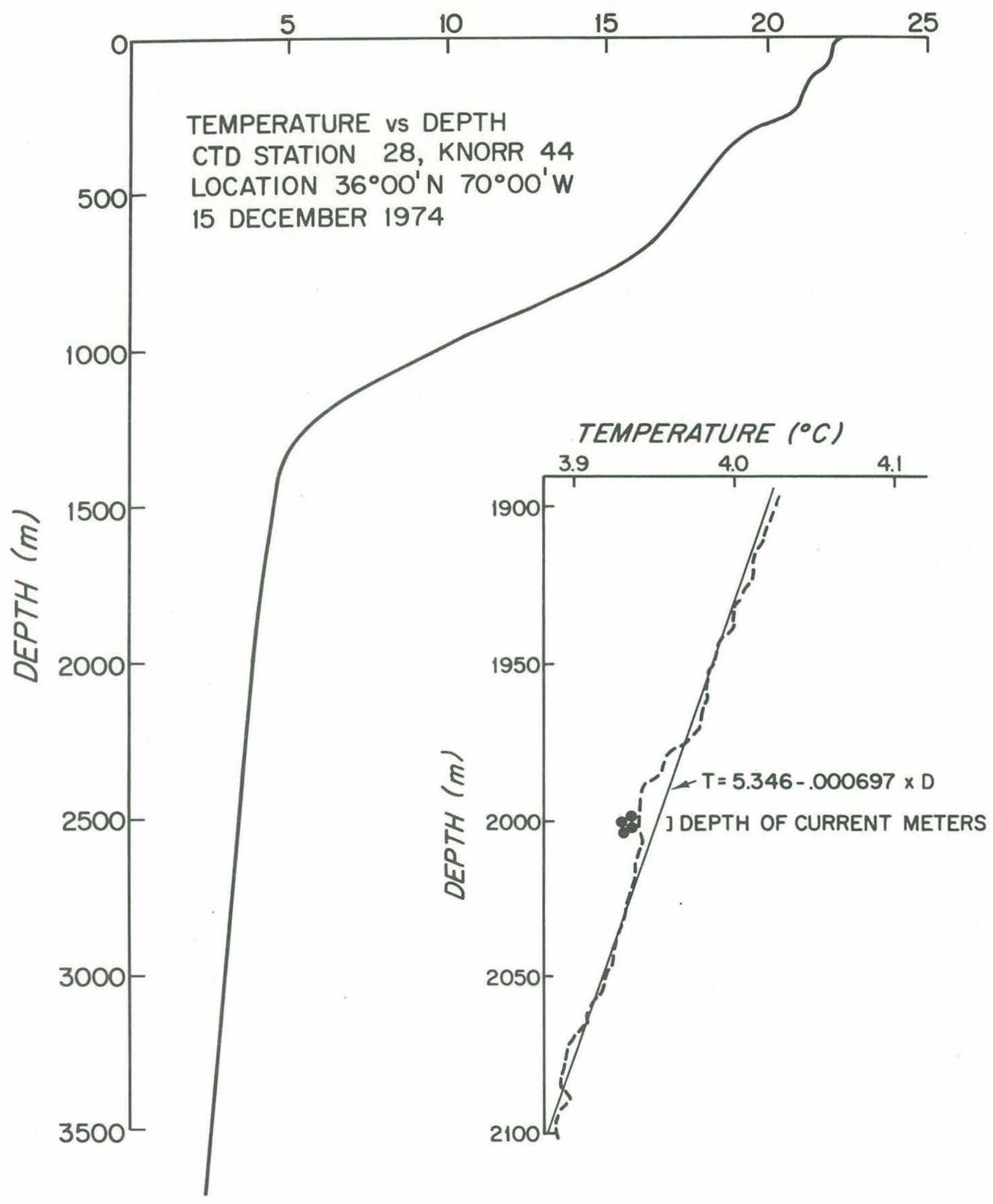


It would be appealing to attempt some kind of a direct comparison between absolute temperatures from VACMs and CTD but the uncertainty in current meter depth rules this out. The CTD data allow us to say that the time averaged temperature gradient in the vicinity of $2000 \mathrm{~m}$ is probably very close to $-0.7 \mathrm{~m}^{\circ} \mathrm{c} / \mathrm{m}$. The absolute temperatures are consistent with the CTD temperatures to within the accuracy of the VACM depths. 
6. D. Error Analysis

In the previous sections of this report we have described the components of the VACM temperature measuring system, some of the errors in those systems, and intercomparisons which have indicated some of the relative uncertainties in our temperature measurements. We have not been able to make an in situ comparison with a different, and preferably certifiably accurate, instrument, nor have we been able to test the absolute accuracy in the laboratory. In this section we will compute analytically the accuracies of both relative and absolute temperature measurements. To the extent that our computed accuracy of relative measurements agrees with the intercomparison results we may have some confidence in the computed absolute accuracy.

In Table 9 is a list of possible sources of error with an estimate of the contribution of each to the instrument bias in the measurements and the measurement variation.

Table 9

Error Sources in VACM Temperature Measurements

Instrument Measurement

Bias Variation

Thermistor
a. Calibration and drift rate
b. Linearity
c. Self heating

V/F Converter
a. Stability
b. Linearity

Rest of VACM

a. Time base stability (900 second recording interval)

b. Integrator

$\begin{array}{rc} & \pm 4 \mathrm{~m}^{\circ} \mathrm{C} \\ +.3 \mathrm{~m}^{\circ} \mathrm{C} & 0 \\ +1 \mathrm{~m}^{\circ} \mathrm{C} & 0\end{array}$

$1 \mathrm{~m}^{\circ} \mathrm{C}$

$1 \mathrm{~m}^{\circ} \mathrm{C}$

$\pm .3 \mathrm{~m}^{\circ} \mathrm{C}$

$\pm .06 \mathrm{~m}^{\circ} \mathrm{C}$ 
The following describes the terms in the table in more detail and justifies the uncertainties given.

Thermistor

a. Calibration and drift rate - From the NBS intercomparison we feel sure that the absolute accuracy of each of our calibrations is about $\pm 3 \quad \mathrm{~m}^{\circ} \mathrm{C}$. The scatter about the line fitting calibration vs. time data is $\pm 1 \mathrm{~m}^{\circ} \mathrm{C}$ or less. The total uncertainty in expressing $\mathrm{T}$ as a function of $R$ by the equation

$$
\mathrm{T}^{-1}=\mathrm{A}+\mathrm{B}(\ln \mathrm{R})+\mathrm{C}(\ln \mathrm{R})^{3}
$$

is then about $\pm 4 \mathrm{~m}^{\circ} \mathrm{C}$.

b. Linearity - Thermistors are nonlinear sensors. Computing a mean temperature from a mean thermistor resistance introduces an error which depends on the amplitude of fluctuations during the averaging interval. Typical temperature records, both in and below the thermocline show temperature standard deviations of about $200 \mathrm{~m}^{\circ} \mathrm{C}$. For a sine wave fluctuation of this amplitude the error would be $+.3 \mathrm{~m}^{\circ} \mathrm{C}$. This is a systematic and not a random error so it contributes to the instrument bias.

c. Self heating - In the input circuit of the V/F converter, a precise 3.9 volts is impressed across the thermistor and a precision $37.3 \mathrm{~K} \Omega$ fixed resistor is connected in series with the thermistor. In Table 10 are shown:

$$
\begin{aligned}
& \text { T - nominal temperature } \\
& \mathrm{R} \text { - mean resistance and standard deviation for the thermistors } \\
& \text { in Table } 3 \text { with drift rates less than } 3.5 \mathrm{~m}^{\circ} \mathrm{C} / \text { year. } \\
& \mathrm{P}-\text { power dissipated in thermistor with standard deviation } \\
& \text { due to deviation in } \mathrm{R} \text {. } \\
& \mathrm{T}-\text { thermistor self-heating with assumed dissipation constant of } \\
& \quad 3 \mathrm{mw} /{ }^{\circ} \mathrm{C} \text { and standard deviation due to deviation in R. } \\
& \mathrm{V}_{\text {th }}-\text { volts across thermistor resistance } \mathrm{R} \text { in current meter } \\
& \quad \text { circuit with standard deviation due to deviation in R. } \\
& \mathrm{V} \text { calib - volts applied across thermistor in calibration equipment. } \\
& \mathrm{dT} / \mathrm{dV} \text { - sensitivity of indicated temperature to an error in the } \\
& \text { voltage applied across the thermistor. }
\end{aligned}
$$


Table 10

Thermistor Self-Heating

$\begin{array}{ccccccc}\mathrm{T} & \mathrm{R}(\mathrm{ohms}) & \mathrm{P}(\mu \mathrm{w}) & \Delta \mathrm{T}\left(\mathrm{m}^{\circ} \mathrm{C}\right) & \mathrm{V}_{\mathrm{th}} \text { (volts } & \mathrm{V}_{\text {cal }} \text { (volts } & \frac{\mathrm{dT}}{\mathrm{dV}}\left(\frac{\mathrm{m}^{\circ} \mathrm{C}}{\mathrm{volt}}\right) \\ 0^{\circ} \mathrm{C} & 95080 \pm 377 & 82.52 \pm .14 & 27.51 \pm .05 & 2.801 \pm .003 & 2.80 & 20 \\ 5 & 74453 \pm 286 & 90.68 \pm .12 & 30.23 \pm .04 & 2.598 \pm .003 & 2.60 & 23 \\ 10 & 58712 \pm 220 & 96.87 \pm .08 & 32.29 \pm .03 & 2.385 \pm .003 & 2.39 & 27 \\ 15 & 46611 \pm 171 & 100.69 \pm .04 & 33.56 \pm .01 & 2.166 \pm .004 & 2.17 & 31 \\ 20 & 37244 \pm 135 & 101.94 \pm .0003 & 33.98 \pm .0001 & 1.949 \pm .004 & 1.95 & 35 \\ 25 & 29947 \pm 106 & 100.73 \pm .04 & 33.58 \pm .01 & 1.737 \pm .003 & 1.74 & 39 \\ 30 & 24222 \pm 84 & 97.34 \pm .07 & 32.45 \pm .02 & 1.535 \pm .003 & 1.54 & 42\end{array}$

Since the same voltage is applied to the thermistor during calibration as in the current meter, the bias due to self-heating is very nearly the same in the two situations. This net bias, therefore, does not appear in Table 9. There are three kinds of errors that can occur through the self-heating:

1. An error in the volts applied to the thermistor during calibration can cause an amount of self-heating differing from that in the current meter. An error of 0.1 volt would cause up to $5 \mathrm{~m}^{\circ} \mathrm{C}$ error, indicating that a modicum of care is required.

2. Because various thermistors have somewhat different resistances at the same temperature, the voltage across them, and thus the self-heating varies. For the range of thermistors in this study, however, the difference is at most $.05 \mathrm{~m}^{\circ} \mathrm{C}$, a negligible amount.

3. The assumed dissipation constant of $3 \mathrm{mw} /{ }^{\circ} \mathrm{C}$ is a nominal value. The important thing is to have the dissipation constant the same in the current meter and in the calibration setup. We have not been able to measure either dissipation constant but have tried to make the situations quite similar physically. We feel confident that the error due to difference in self-heating is less than $\pm 1 \mathrm{~m}^{\circ} \mathrm{C}$.

$\mathrm{V} / \mathrm{F}$ Converter

a. Stability - We saw in Section 3 that the $V / F$ converter is stable to 3 parts in $10^{5}$, equivalent to about $\pm 1 \mathrm{~m}^{\circ} \mathrm{C}$.

b. Linearity - We saw, also in Section 3, that the period of the $\mathrm{V} / \mathrm{F}$ converter output signal is a linear function of thermistor resistance to within the equivalent of $\pm 1 \mathrm{~m}^{\circ} \mathrm{C}$. 
Rest of VACM

a. Time base stability. The stability of the crystal oscillator which provides the time base in the VACM is stable to 1 part in $10^{5}$, equivalent to $.009 \mathrm{sec}$ for a recording interval of $900 \mathrm{sec}$. The uncertainty in temperature due to this uncertainty can be derived from the three equations:

$$
\begin{aligned}
& T=\left[A+B(\ln R)+C(\ln R)^{3}\right]^{-1} \\
& R=\frac{\left(\frac{1}{P}+K_{2}\right) R_{S}}{K_{1}-K_{2}-\frac{1}{P}} \\
& P=\frac{t}{N}
\end{aligned}
$$

where:

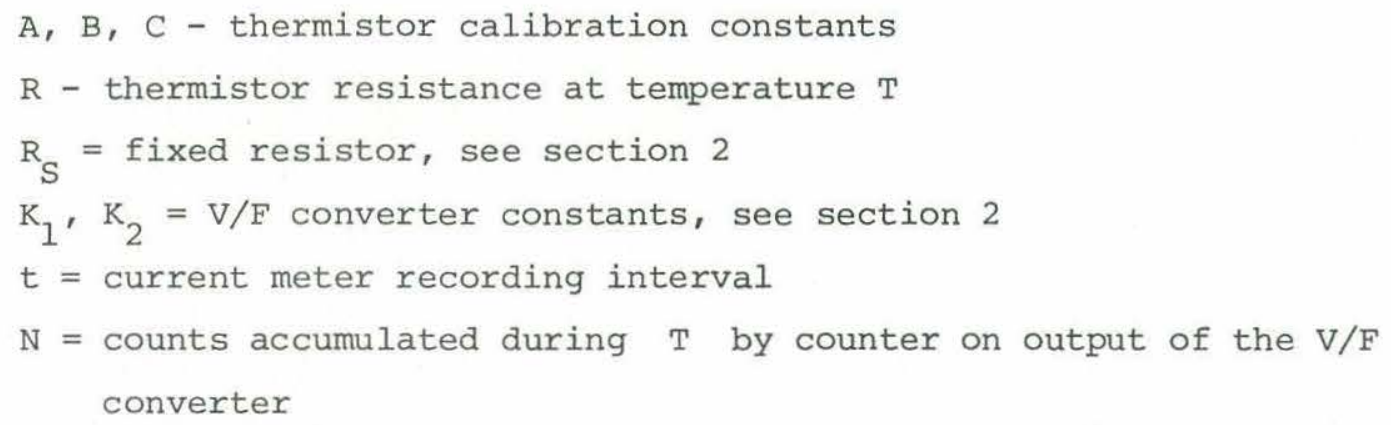

The uncertainty in temperature due to variations in the time base is given by:

$$
\begin{aligned}
& \left.\Delta T\right|_{N}=\frac{\partial T}{\partial R} \frac{\partial R}{\partial P} \frac{\partial P}{\partial t} \Delta t \\
& \frac{\partial T}{\partial R}=-\frac{T^{2}}{R}\left[B+3 C(\ln R)^{2}\right] \\
& \frac{\partial R}{\partial P}=\frac{R_{S}\left(K_{2}-K_{1}\right)}{\left[P\left(K_{1}-K_{2}\right)-1\right]^{2}} \\
& \frac{\partial P}{\partial t}=\frac{1}{N}
\end{aligned}
$$


Typical values of the variables at $10^{\circ} \mathrm{C}$ are:

$$
\begin{aligned}
& T=283.15^{\circ} \mathrm{C} \\
& \mathrm{R}=58712 \Omega \\
& \mathrm{B}=.22519048 \times 10^{-3} \\
& \mathrm{C}=.114084 \times 10^{-6} \\
& \mathrm{~N}=575117
\end{aligned}
$$

$$
\begin{aligned}
\mathrm{R}_{1} & =24270 \Omega \\
\mathrm{R}_{2} & =94980 \Omega \\
\mathrm{P}_{1} & =1.0036 \times 10^{-3} \mathrm{sec} \\
\mathrm{P}_{2} & =2.1548 \times 10^{-3} \mathrm{sec} \\
\Delta t & =.009 \mathrm{sec}
\end{aligned}
$$

Substituting these

$$
\left.\Delta \mathrm{T}\right|_{\mathrm{N}}= \pm .3 \mathrm{~m}^{\circ} \mathrm{C}
$$

b. Integrator - The integrator is just a counter and has an uncertainty of \pm 1 count. From Table 1 we see that this is equivalent to $\pm .06 \mathrm{~m}^{\circ} \mathrm{C}$, a negligibly small uncertainty.

The total variance of temperature is the sum of the squares of the uncertainties. For the measurement variations,

$$
\operatorname{Var}_{\mathrm{T}} \simeq 18\left(\mathrm{~m}^{\circ} \mathrm{C}\right)^{2}
$$

The relative uncertainty we expect in the temperature measurements is then of the order of $\pm 4.2 \mathrm{~m}^{\circ} \mathrm{C}$ which agrees well with the results of the IWEX intercomparison.

Adding the contributions of instrument biases to the variance,

$$
\operatorname{Var}_{\mathrm{T}} \simeq 19\left(\mathrm{~m}^{\circ} \mathrm{C}\right)^{2}
$$

the uncertainty we expect in the absolute temperature measurements is then about $\pm 4.4 \mathrm{~m}^{\circ} \mathrm{C}$.

We feel that this uncertainty estimate is a little optimistic but not completely out of line. Nelson Hogg (personal communication) after contouring, separately, temperatures recorded during MODE by current meters and CTDs, stated that the two sets appeared to agree within $\pm 10 \mathrm{M}^{\circ} \mathrm{C}$. Our best guess as to the achievable accuracy of absolute temperatures with the VACM then, is perhaps better than $\pm 10 \mathrm{~m}^{\circ} \mathrm{C}$ but no better than $\pm 4.5 \mathrm{~m}^{\circ} \mathrm{C}$. 


\section{References}

Bennett, A. S., 1972. The calibration of thermistors over the temperature range $0-30^{\circ}$ C. Deep-Sea Res., 19, 157-63.

Bradshaw, A., and K. E. Schleicher, 1970. Direct measurement of thermal expansion of sea water under pressure. Deep-Sea Res., 17, 691-706.

Millard, R., Jr., 1974. CTD averages from IWEX. MODE Hot Line News, no. 52, 3. (unpublished manuscript).

Steinhart, J. S., and S. R. Hart, 1968. Calibration curves for thermistors. Deep-Sea Res., 15, 497-503.

Tarbell, S., M. G. Briscoe, and D. Chausse, 1975. A compilation of moored current data and associated oceanographic observations, Volume IX (1973 Internal Wave Experiment (IWEX)) . W.H.O.I. Ref. 75-68 (unpublished manuscript).

Vector Averaging Current Meter Technical Manual, AMF Publication \#SLS 106-11419. AMF Electrical Products, Development Division, 1025 North Royal Street, Alexandria VA. 
Appendix I

Some Useful Numbers

Some useful information is summarized in Table I-1.

Column 1 - The seven nominal temperatures at which we monitor thermistor and $\mathrm{V} / \mathrm{F}$ converter characteristics.

Column 2 - Nominal resistances at these temperatures of the YSI

44032 thermistor.

Column 3 - Nominal dT/dR for YSI 44032 thermistors.

Column 4 - Nominal period of the $V / F$ converter output signal for

the Column 2 resistances. Our V/Fs are normally adjusted to agree with

the nominal periods within $\pm .01 \mu$ s at $74,440 \Omega$.

Column 5 - Some typical VACM recording intervals.

Column 6 - Numbers of counts which would be accumulated during the

various recording intervals with thermistor resistances of Column 2 .

Column 7 - Temperature resolution due to 1 count resolution in the total counts.

Column 8 - Uncertainty in temperature due to uncertainty in either P1 or P2 of $\pm 1 \mu \mathrm{s}$.

Column 9 - Accuracy requirement for P1, P2 for a $\pm 1 \mathrm{~m}^{\circ} \mathrm{C}$ accuracy

in temperature.

Columns 10, 11, 12 - Accuracy requirements in A, B, C thermistor

constants for $\pm 1 \mathrm{~m}^{\circ} \mathrm{C}$ temperature accuracy. See section 5 for definition of $A, B, C$. 


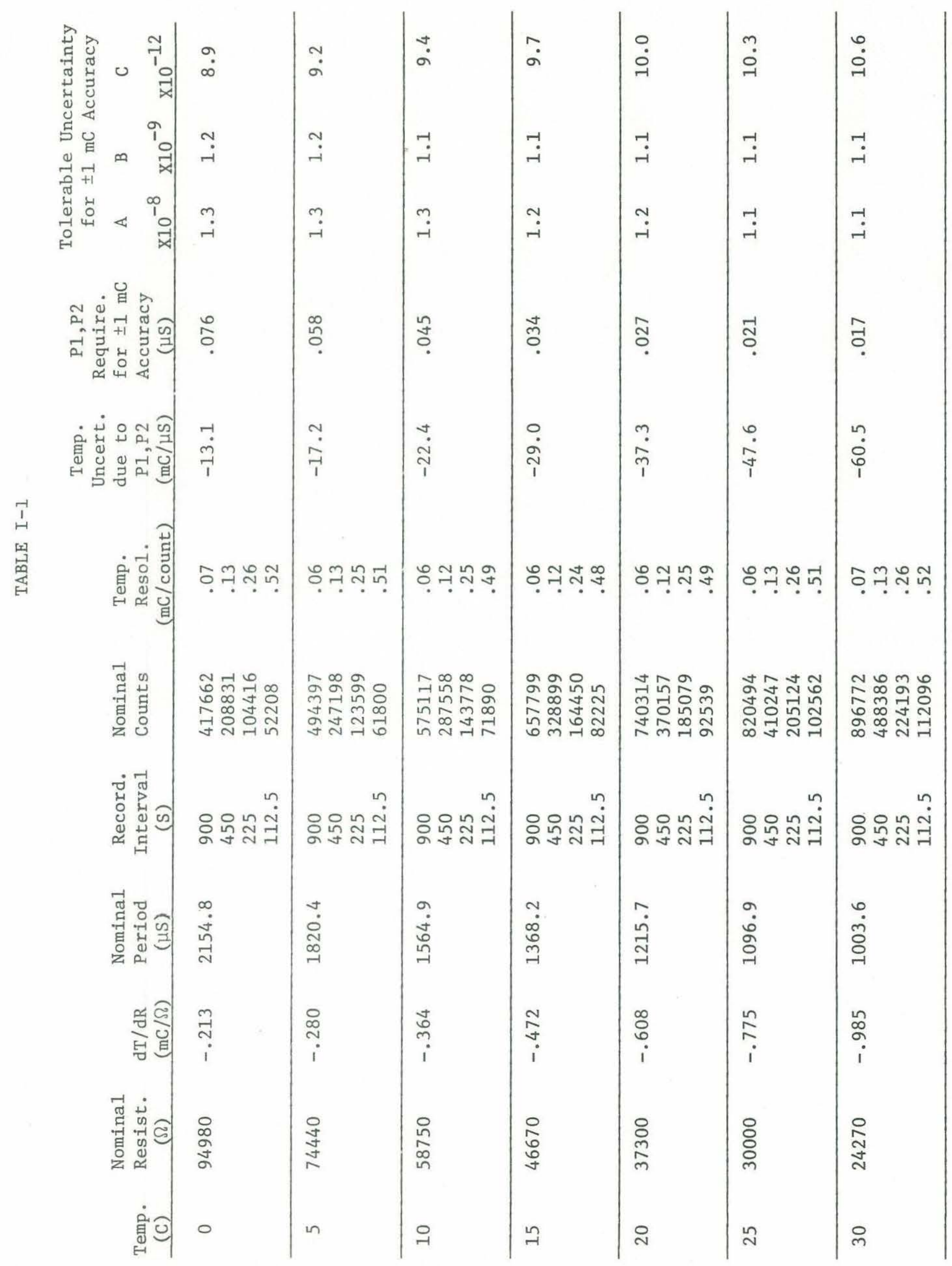




\section{Appendix II \\ CALIBB Program}

Included in this appendix are a description of the CALIBB program, a listing of the program, and an example of input and output data from a calibration. CALIBB was written using Xerox FORTRAN IV and contains some statements which are not compatible with other versions of FORTRAN IV. 
CALIBB , 1

NAME: CALIBB

TYPE: Main program - processor

PURPOSE: TO process thermistor calibration data

MACHINE: XDS Sigma 7

SOURCE LANGUAGE: XerOX FORTRAN IV

PROGRAM CATEGORY: Utility

DESCRIPTION:

CALIBB was written to fit thermistor calibration data to the equation

$$
1 / T=A+B * L N(R)+C *(L N(R)) * * 3
$$

where $T$ is absolute temperature in ${ }^{\circ} \mathrm{K}$ and $\mathrm{R}$ is thermistor resistance.

CALIBB provides a choice of three inputs;

1. Direct values of temperature and corresponding thermistor resistance.

2. Output of a Guildline bridge connected to a platinum resistance thermometer is converted to temperature. Thermistor resistance has corrections applied for lead resistance and bridge dial resistance.

3. Output of a Mueller bridge connected to a platinum resistance thermometer is converted to temperature.

The result of all three types of input data is a set of temperatures and thermistor resistances for each thermistor. These are then fitted to the above equation by the method of least squares. The resulting A, B, C constants are used for computing temperature from thermistor resistance.

CALIBB was written particularly to process the calibration data produced by K. Schleicher and A. Bradshaw for Buoy Project thermistors used in current meters.

INPUT: By cards

For each batch

Card 1 is the same for all three types of input data.

1 card - Batch number, type of input (DIRECT, GUILD,MUELL), number of thermistors in batch, number of nominal temperatures per thermistor, date of calibration, source of calibration data $(\mathrm{T} 7, \mathrm{I3}, \mathrm{T} 16, \mathrm{~A} 4, \mathrm{~T} 36,12, \mathrm{~T} 51,12,2 \mathrm{X}, \mathrm{A} 2,1 \mathrm{X}, \mathrm{A} 3,1 \mathrm{X}, \mathrm{A} 2,1 \mathrm{X}, 3 \mathrm{~A} 4)$ 
CALIBB , 2

Type 1, Direct

For each thermistor

1 card - Header card - thermistor number, batch number (T13,I4, T25, I3)

1 or more cards - Data - 4 pairs of temperature, resistance $(4(2 F))$

Type 2, Guildline bridge

For each batch

1 or more cards - list of thermistor number in calibration batch in order of subsequent data appearance

(16I)

1 card - Platinum probe identifier, zero ratio of bridge $(\mathrm{T} 9, \mathrm{~A} 4, \mathrm{~T} 25, \mathrm{~F})$

For each nominal temperature

'I card - nominal temperature, data date, initial bridge ratio, volts across thermistor, number of book containing original data, page in book

(T9,F4.1, T14,3A4, T36,F, T52,F, T63I, T74,I)

1 or more cards - data pairs consisting of position in bath, bridge ratio, and uncorrected resistance

(T8,I2, T10, 2F)

Type 3, Mueller bridge

For each batch

1 or more cards - list of thermistor numbers in calibration batch in order of subsequent data appearance (16I)

For each nominal temperature

2 cards - nominal temperature, data date, zero error of bridge, volts across thermistor, book containing original data, page in book

(T9,F, T13,3A4, T34,F, T52,F, T63,I, T74,I)

1 card - NRMLIMA, RVRSIMA, RVRSI4MA, COEFF, RZERO (For definitions see program listing)

(T9, F, T26,F, T44,F, T59,F, T73,F)

For each thermistor

I card - data for this nominal temperature; BRIJNIMA, NULLNIMA, BRIJRIMA, NULLRIMA , BRIJMI4MA, NULLMI4MA, RES

$(\mathrm{T} 9,7 \mathrm{~F})$ 
CALIBB, 3

OUTPUT:

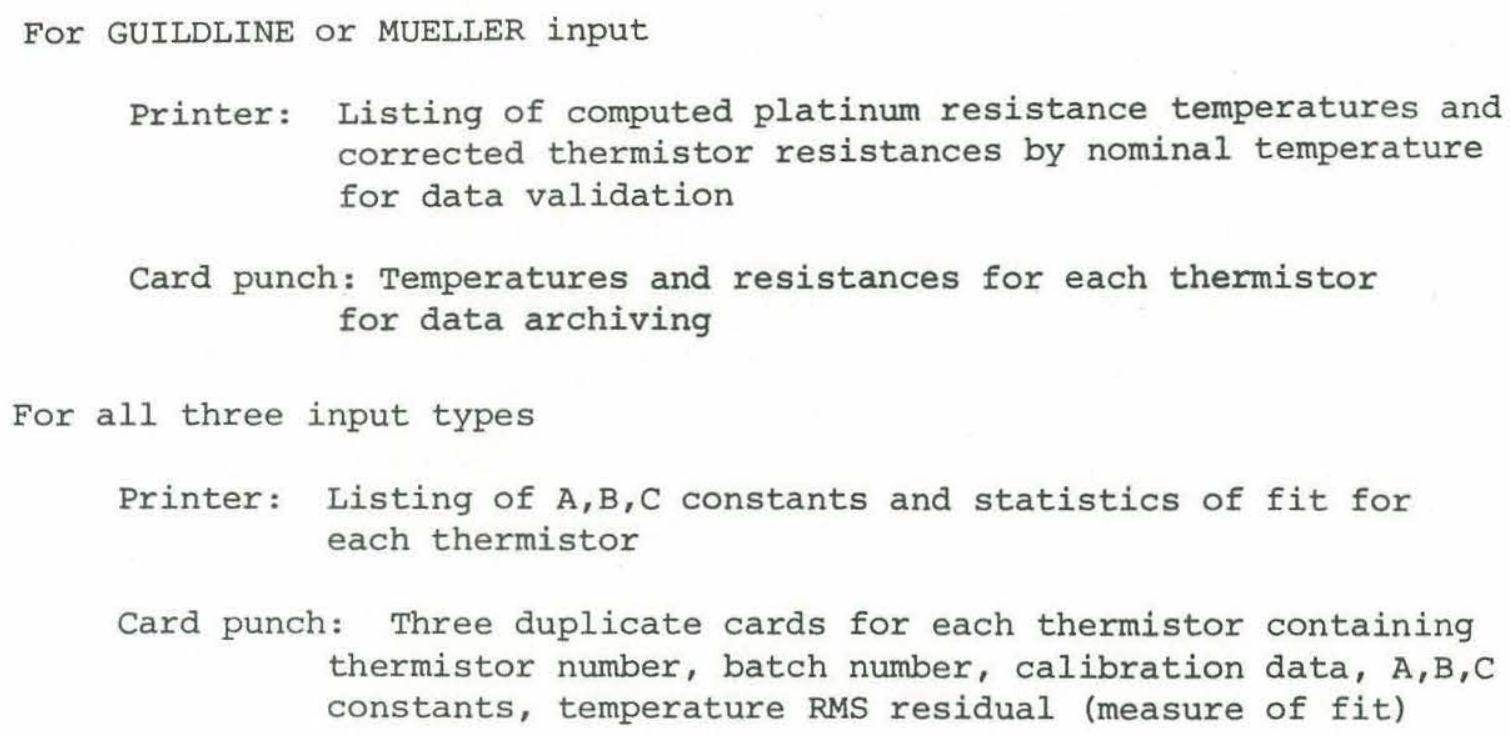

USEAGE:

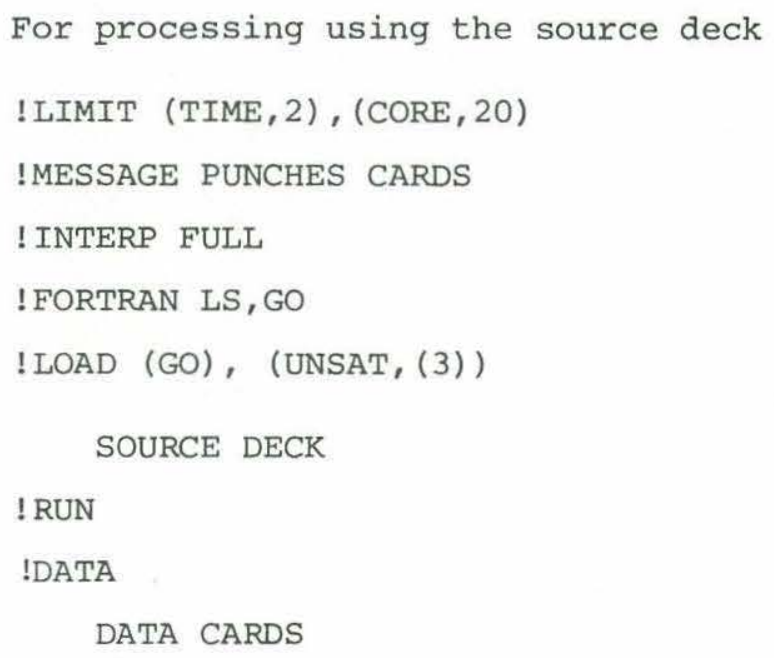

Batch of 24 thermistors and 7 nominal temperatures requires about 3.9 charge units when run with the source deck, 2.2 charge units when run with an object deck 


\section{CALIBB , 4}

ERRORS AND DIAGNOSTICS:

1. NUMTHERM TOO LLARGE

Number of thermistors on first data card greater than 25

2. NUMNOMTEMP TOO L.ARGE

Number of nominal temperatures on first data card greater than 10

PROGRAMMER: R. E. Payne

ORIGINATOR: Buoy Project

DATE: August 1976

REFERENCES: None 







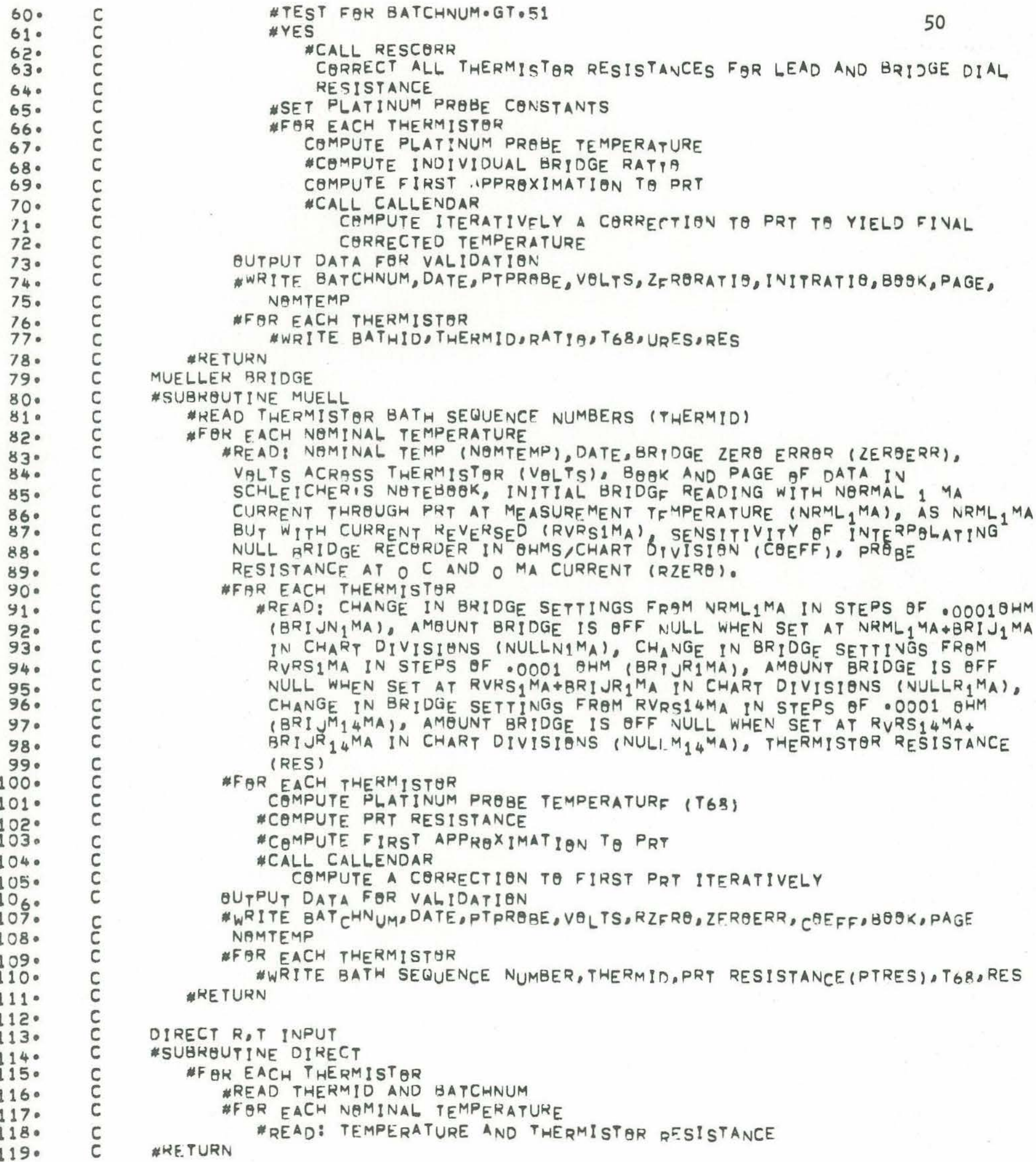


SUEREUTINE CALLENDAR

CALLENDAR CQMPUTFS A CQRRECTION TO THE CAMPIITEO PRT TEMPERATURE $3 Y$ AN ITERATIVE TECHNIQUE SPECIFIED IN THE PRT PRAAE MANUAL. \#CEMPUTE CARRECTION (CERK) BASED ON DELTA (PRT CANSTANT) AND TEMPERATURE. IS LESS THAN • 00001 \#CAMPUTE ANATHEK CORRECTION (DELTAT) BASED AN THUS FAR CORRECTED TEMPERATURE AND SOME. CONSTANTS. \#FINAL TG\& HAS BATH CQRRECTIANS INCQRPORATED. \#RETURN

SUBROUTINE RESCARR RESCARK CQRRECTS THE THERMISTUR RESISTANCESIURESI FOR THE RESISTAVCE OF THE BATH THERMISTHR LEADS AND THE BRIDGE DIAL RESISTANCES. \#TEST FOR GMD.EQ. 4 HERBR (ER BRIDGE)

YES-GQ TO LEAD RESISTANCE CORRECYIONS

NG.PRACEED WITH GUILDLINE BRIDGE DIAL CORRECYIONS

\#FHL EACH THERMISTUL

* TEST FAR URES・LT•100。

YES.SE,T CARRECTION EQUAL TO O

NG.PRACEED WITH COMPUTING CORRECTION

\#CALL GETDIG!TS

\#CAMPUTE. CQRRFCTION FGR EACH DIAL (LEAD a DIGITS ONLY)

"APPLY TATAL CORRECTION TO URES, GBTAINING RES

HF AR EACH THERMISTOR

WAPPLY LEAD CARRECTION TU RES

\#RETURN

SUERTUTINE GETDIGITS

GETDIGITS CONVERTS A G DIGIT INUMBER, INTA A, DIMENSIONAL ARRAY, ISTORE'. \#LELO THE ARRAY 'STORE'

*CONVERT THE $S$ DIGITS OF THE RESISTANCE INTA AN INTEGER

\#PUT THE DIGITS OF THE INTEGER RFSISTANCE INTO ISTORE! \#RETURN

SUBRAUTINE ABCFIT

ABCFIT PERFARMS A LEAST SQUARES FIT OF THE CALIBRATION DATA TO THE FUNCTIEN $Y=A+B * X+C * X * * 3$

WHERE $Y=1 / T 68, X=L O G$ (RES)

ABCFIT IS RIN ONCE FOR EACH THERMISTOR IN PHE BATCH

\#FHL EACH NOMINAL TEMPERATURE \#COMPUTE MEANS $\theta F \quad x, y, x * 3$

\#FQR EACH NAMINAL TEMPERATURE "SULPRACT MEANS FRAM EIJUATION TO BE FITTFD AND COMPUTE SUMMATIONS NECESSARY FBR DETERMINING B,C. REMUVING THE MEANS REDUCES THE KEUNDEFF ERRER. \#CUMPUTE B.COA CANSTANTS \#FOH EACH NAMINAL TEMPERATURE \#COMPUTF ESTIMATED VALUES OF Y AND T USING A,B,C AND $X$, AND RESIJUALS \#RETURN

SUBROUTINE PRINTOUT

PRINT OUTPUT OF LEAST SQUARES FIT FGR ONE THERMISTOR

\#PRINT THERMID, BATCHNUM

\#PRINT TIME OF CALIY RUN(ICLK) OCALIBOATE, CAI. IBPLACE

\#PRINT $A, B, C$ CONSTANTS

\#PR!NT Y, YHAT, RESIOY FUR EACH NOMINAL TEMPERATURE

\#PRINT RES T68. THATORESIUT FGR EACH NOMINAL TEMPERATURE \#RETURN 


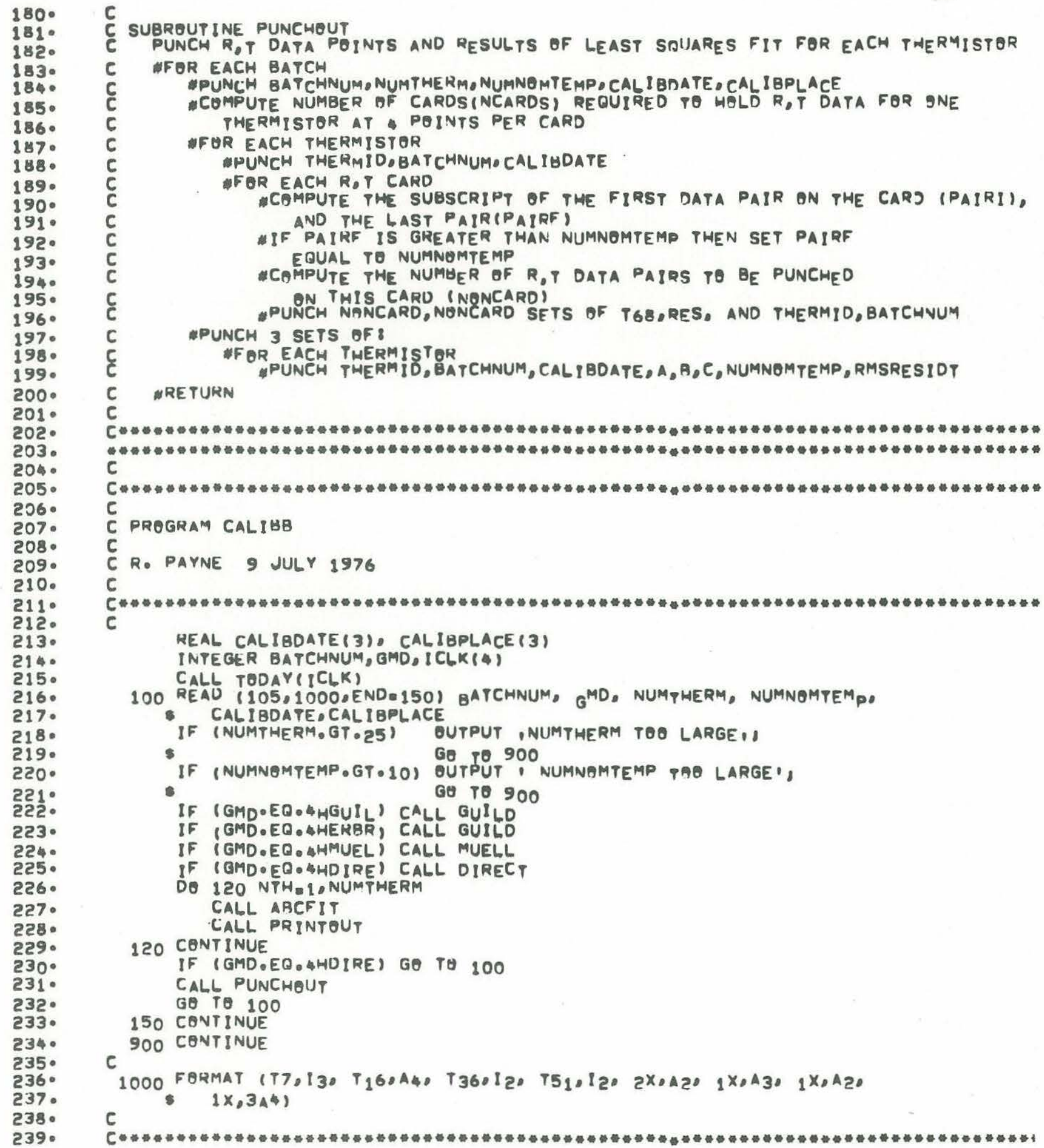




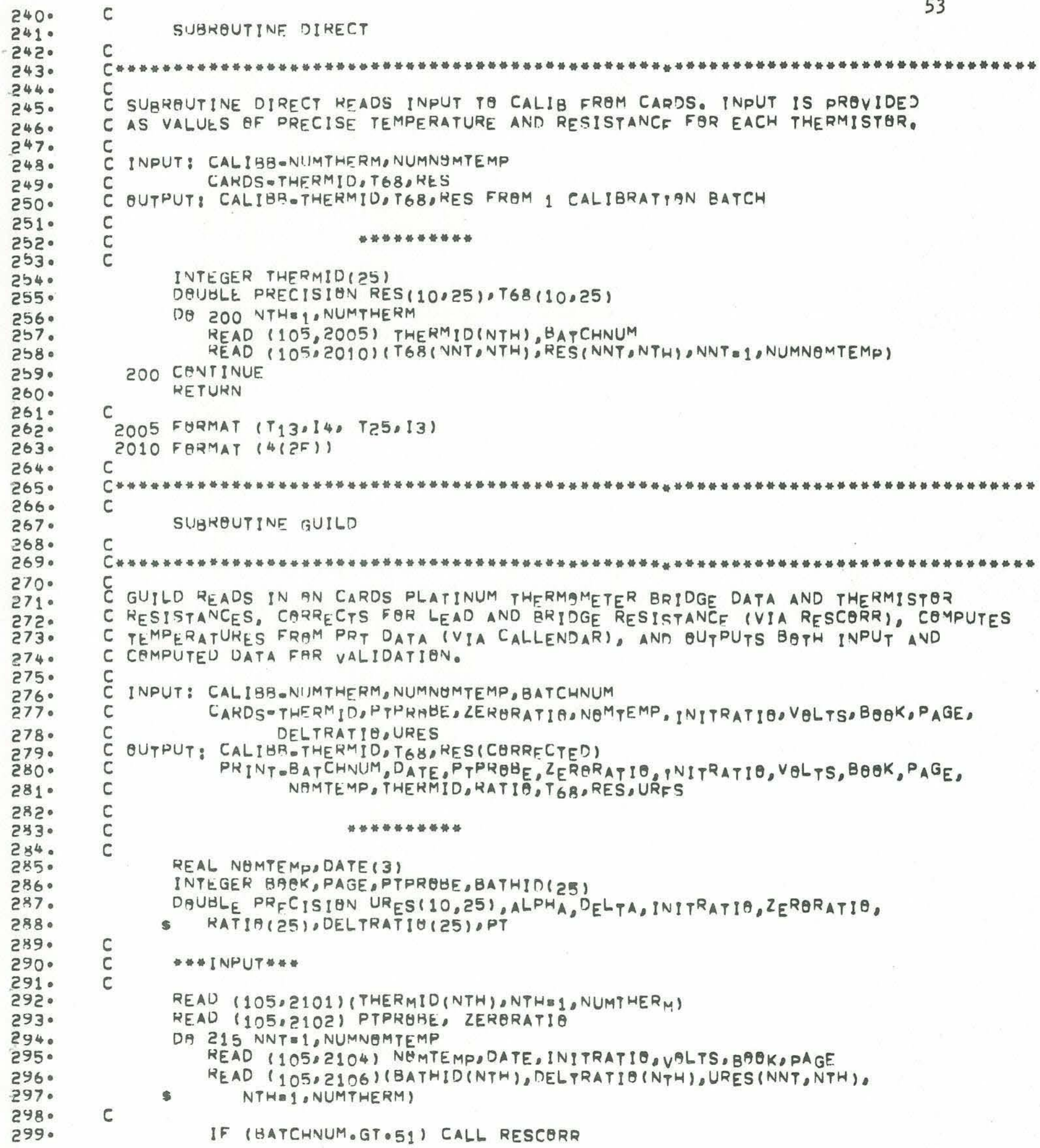

240. C SUBROUTINF. DIRECT

C C

C

C SUBRQUTINE DIRECT KEADS INPUT TO CALIB FROM CARDS. INPUT IS PROVIDEJ

C AS VALUES OF PRECISE TEMPERATURE AND RESISTANCF FOR EACH THERMISTER.

c

C INPUT: CALIBB-NUIMTHERM,NUMNYMTEMP

C CAKDS - THERMID,T68,RES

C OUTPUT: CALIBR.THERMIU, T68,KES FROM I CALIBRATIAN BATCH

C

c

C

2005 FURMAT (T13.140 T25.13)

INTEGER THERMID(25)

DQUULE PRECISION RES $(10.25), T 68(10.25)$

DO 200 NTHE 1 , NUMTHERM

READ (105,2005) THERMID(NTH),BAPCHNUM

READ (105:2010) (T68) (NNT, NTH), RES (NNT, NTH), NNT 1 , NUMNOMTEMP)

2010 FARMAT (4(2F))

C

C

C

SUBROUTINE GUILD 
300. 301. 302.

$303^{\circ}$ 304. 305. 306. $307^{\circ}$ 308 .

309.

310.

311.

312.

313.

314.

315 。

316.

317.

318.

319.

320.

321.

322.

$323^{\circ}$

$324 \circ$

325.

326.

327.

328.

329.

330.

331.

332.

$333^{\circ}$

$334^{\circ}$

335 .

$336^{\circ}$

337.

338.

$339^{\circ}$

340.

$341^{\circ}$

$342^{\circ}$

343.

$344^{\circ}$ 345.

3460

$347^{\circ}$

348 .

$349^{\circ}$

$350^{\circ}$

$351^{\circ}$

$352^{\circ}$

$353^{\circ}$

354 .

355 .

356.

$357^{\circ}$

358 。

$359^{\circ}$ c

c

$$
215 \text { CONTINUE }
$$

Continue

2101 FQRMAT (16!)

2102 FQRMAT $(T 9,44, T 25,5)$

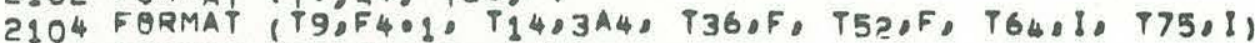

2106 FORMAT (T8,120 TIO०2F)

2190 FBRMAT (1H1,9X,'BATCHNUMEI, I3/

- jOXPDATE DQNE:I, 3A4/

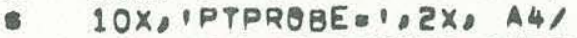

- iox, ivolts across thermai, FG.3l

- jox,izergratiogi, F10.6I

- IOX.IINITRATIOEI, FIO.6I

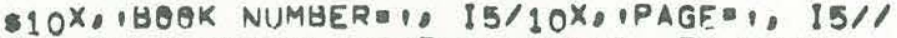

- 2X, INOMPNAL PEMPERATURE 1 , FG.2111

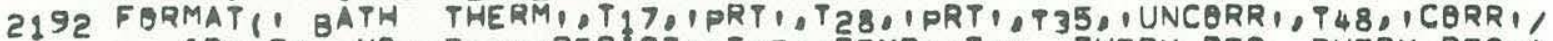

I ID, T8, NO, , T, 60, RESIST,OT27, TEMP, T34, TTHERM RES THERM RES I)

2194 FORMAT $(1 x, 13,17, F 1106,59.4,2 F 11.2)$

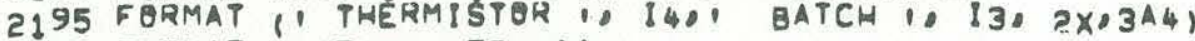

2196 FQRMAT $\left(4\left(F_{12} \cdot 40 F 8 \cdot 2\right)\right)$

c

c

C

SUBROUTINE MUELL

C

C

SUBRUUTINE MUELL READS IN ON CARDS PRT BRIDGE DATA AND THERMISTOR

C RESISTANCES, CQMPUTES TEMPERATURES FRGM PRT DATA (VIA CALLENDAR), AND

C OUTPUTS BOTH INPUT AND COMPUTED DATA FQR VALIDATION. ONL" PHE BRADSHAW PROBE

C HAS BEEN USED WITH THE MUELLFR BRIDGE. MUELL IS FAR HISTORICALL DATA ONLY.

C THE MUELLER BRIDGE IS NO LONGER USED.

C

C INPUT: CALIBE.NUMTHERM,NUMNOMTEMP

C CARDS THERMIDONOMTEMP, DATE, ZFROERR, VOL TS\&BOOK, PAGE ONRMLIMAQRVRSIMAO

C RURS I $4 M A, C O E F F, R 2 E R O, B R$ I JN I MA, NULL NIMA, BR I JR I MA, NULLRI MA,

C BRIJMILMAONULLMILMAORES

OUPPUT\& CALIBB.THERMIO,TGB,RES

PRINT -BATCHNUM,DATE,PTPRBBE, VOLTS,RZERA, ZERAERR, COEFF, BOOK, PAGE, NAMTEMP, THERMIO,PTRES, T 68 , RES 


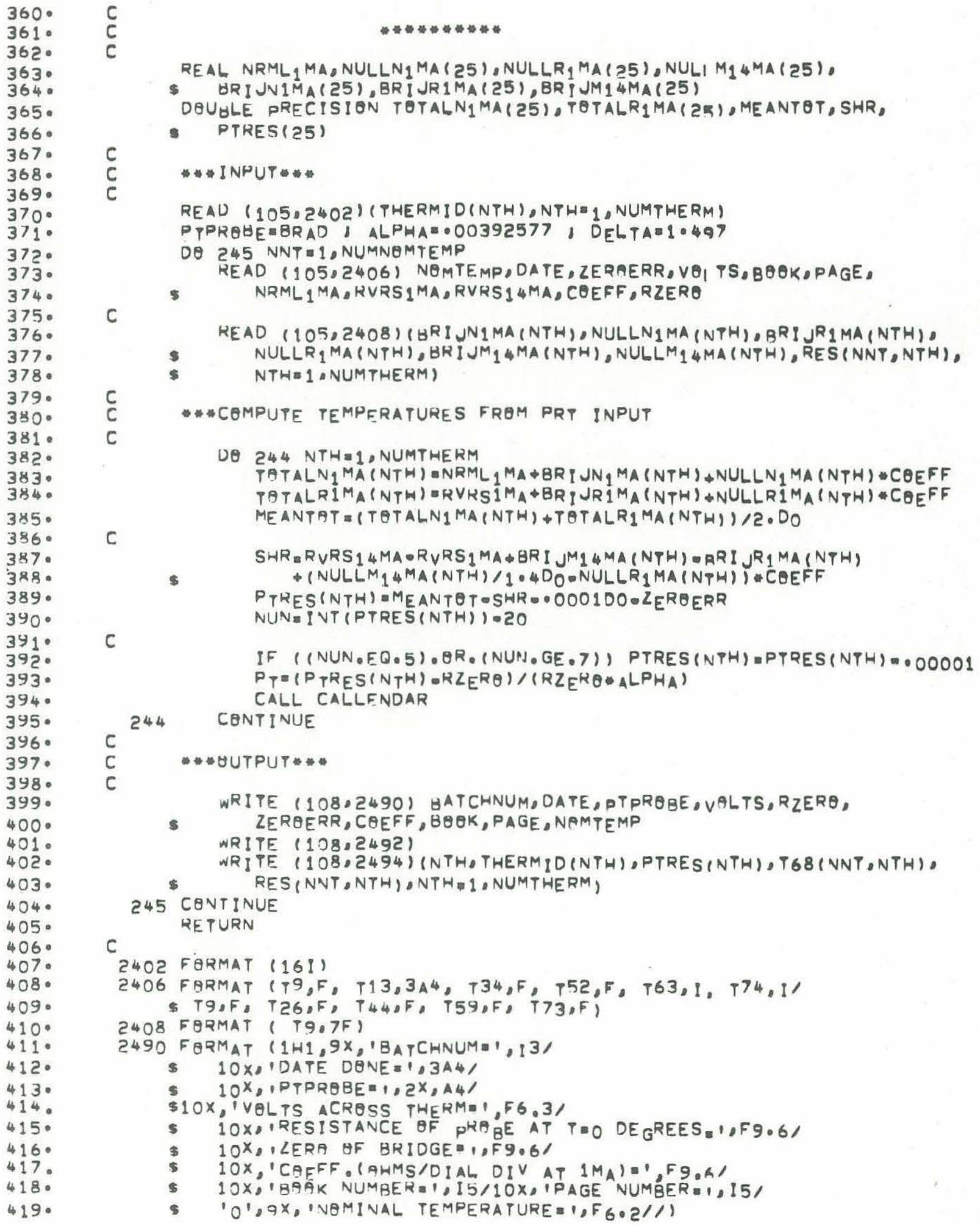


420. 421. परे० 423. 4240 425. 426. 427. 428. 429. 430. 431. 432 . 4330 4340 435.

436. 437.

438. 439.

440 . 441. 4420 443 . 444. 445. 446. 447. 448 . 449. $450^{\circ}$ «b 1. पेट० 453. 4540 455. 456. $457^{\circ}$ 458. 459. 460. $461^{\circ}$ $462^{\circ}$ $463^{\circ}$ 4640 465. 466. $457^{\circ}$ 468. 469. $470^{\circ}$ $471^{\circ}$ 472 . 473 . 474. $475^{\circ}$ 476 . 477. $478^{\circ}$ 479.

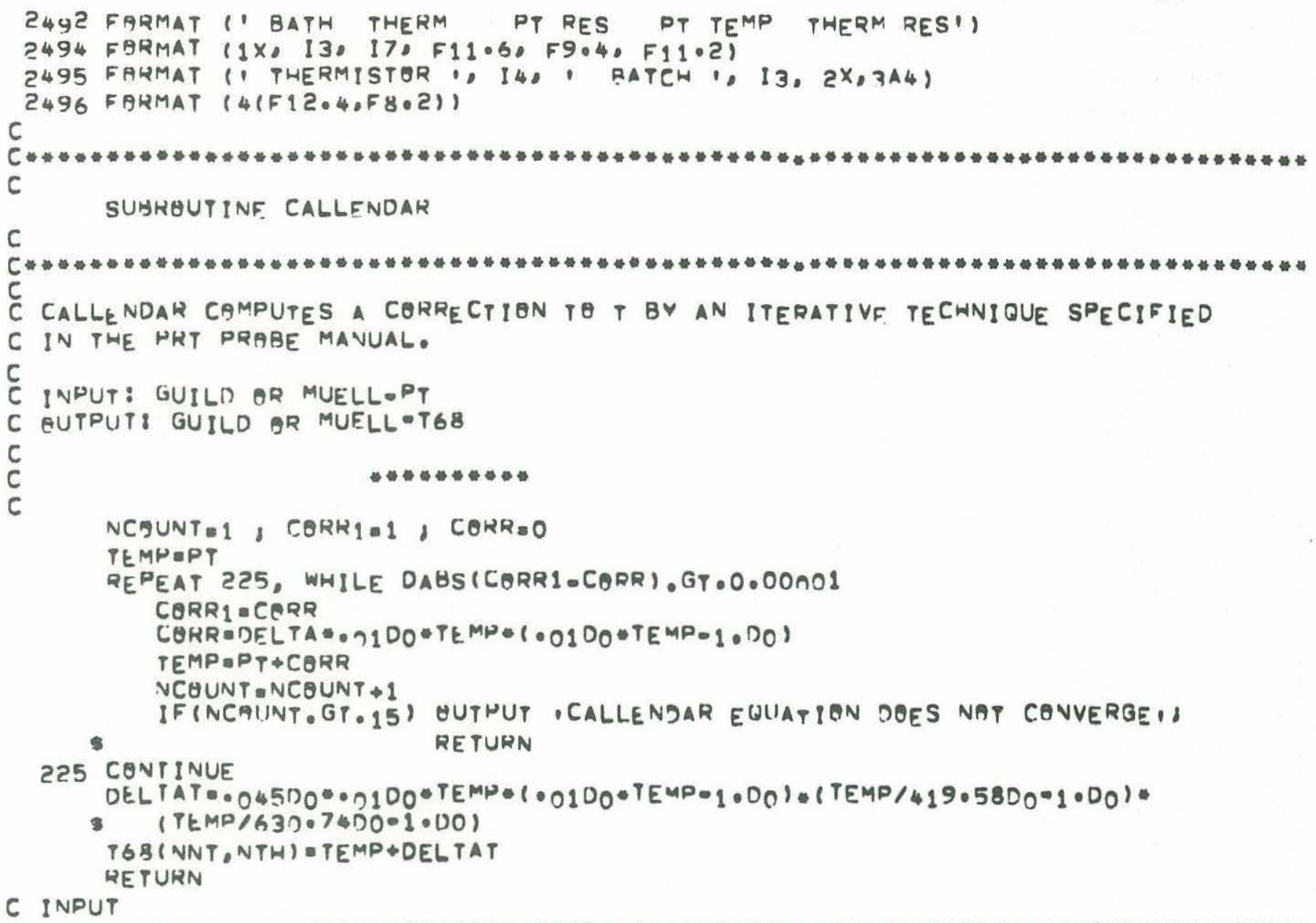




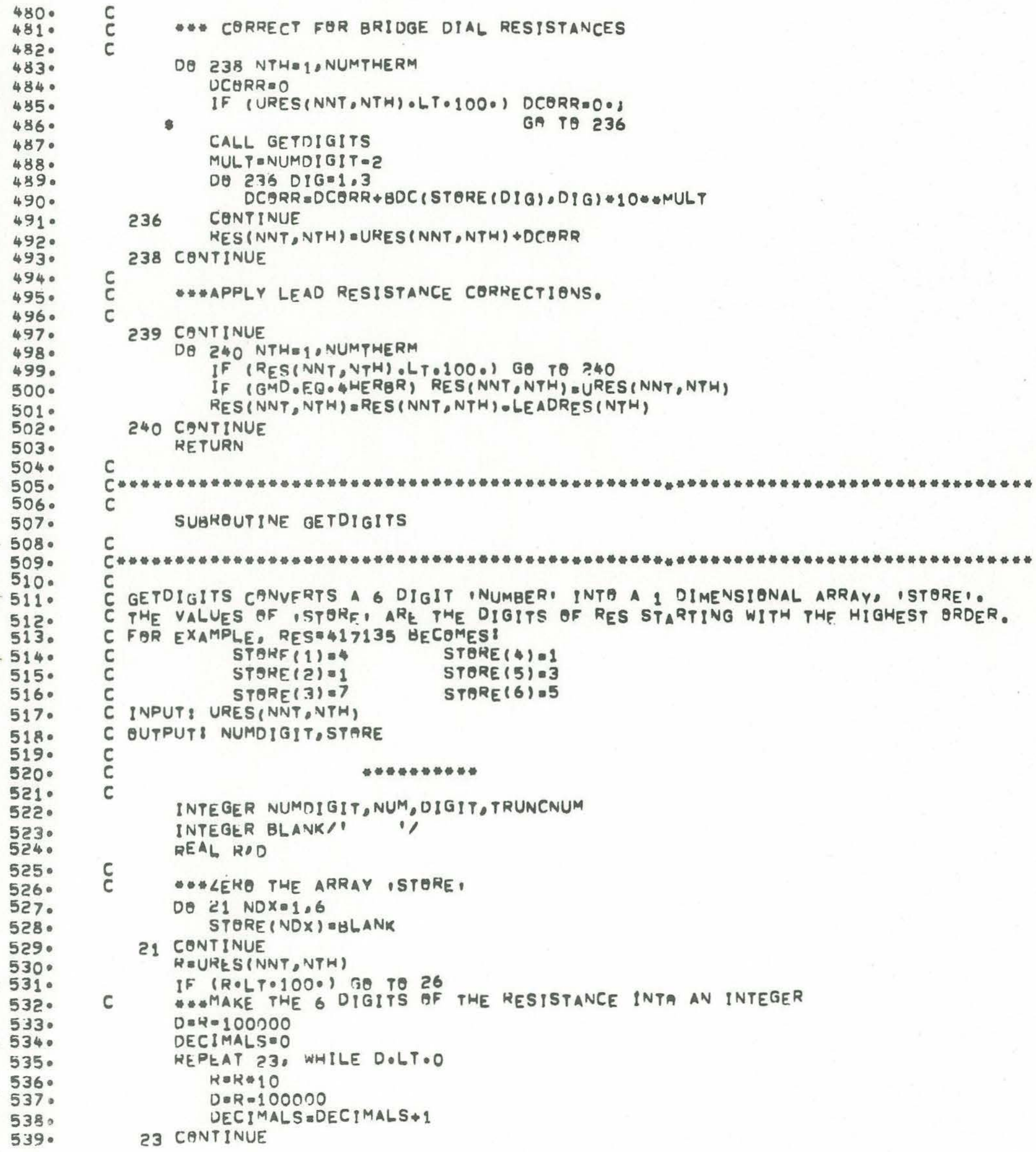

C W CORRECT FUR BRIDGE DIAL RESISTANCES

c

DO 238 NTH®1, NUMTHERM

$U C \theta R R=0$

IF (URES(NNT,NTH) $L T \cdot 100 \bullet$ ) DCORR=0.\&

$\$$

CALL GETDIG!TS

GA TO 236

MUL $P=N U M O ! G ! T=2$

DO 236 DIG $=1.3$

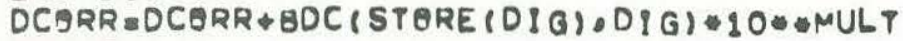

236 CENTINUE

238 CONTINUE

KES (NNT, NTH) $=U R E S$ (NNT,NTH) †DCQRR

c

C

239 CANTINUE

DQ 240 NTHE 1 ONUMPHERM

IF (RES(NNT,NTH) \&LT•lO0.) GO TO ?:\$O

IF (GMD.EQ. HERER) RES (NNT,NTH) EURES (NNT,NTH)

240 CANTINUE

RES (NNT, NTH) ®RES (NNT,NTH) •LEADRES (NTH)

C

RETURN

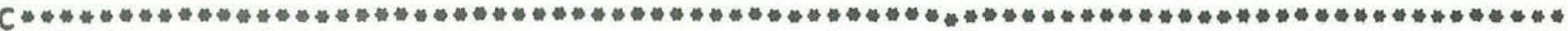

C

SUAROUTINE OETDIGITS

C

C

C GETDIGITS CANVERTS A 6 DIGIT ONUMBERI INTE A I DIMENSIONAL ARRAYO ISTOREI.

C THE VALUES OF ISTORF, ARE THE DIGITS OF RES STARTING WITH THE. HIGHEST ORDER.

C FOR EXAMPLE, RES 417135 HECOMES \&

C STBHF $(1)=\$ \quad$ STERE $(4) \approx 1$

C STORE $(2) \approx 1 \quad$ STORE $(5)=3$

C STORE $(3)=7 \quad \operatorname{STARE}(6)=5$

C INPUT: URES (NNT,NTH)

C OUTPUT\& NUMDIGIT,STARE

c

c

INTEGER NUMDIGIT, NUM, DIGIT, TRUNCNUM

INTEGER BLANK/I

REAL ROD

c

* LEHO THE ARRAY ISTERE,

DO 21 NDX 1.6 STORE $(N D X)=B L A N K$

21 CONTINUE REURES (NNT, NTH)

C

IF $(R \cdot L T \cdot 1000)$ GO TO 26

C MMAKE THE 6 DIGITS GF THE RESISTANCE INTA AN INTEGER

$D=H-100000$

DEC IMALS $\approx 0$

WEPLAT 23. WHILE D.LT.O

$K=R \cdot 10$

$D=R=100000$

DEC?MALS \&DEC?MALS +1

23 CANTINUE 


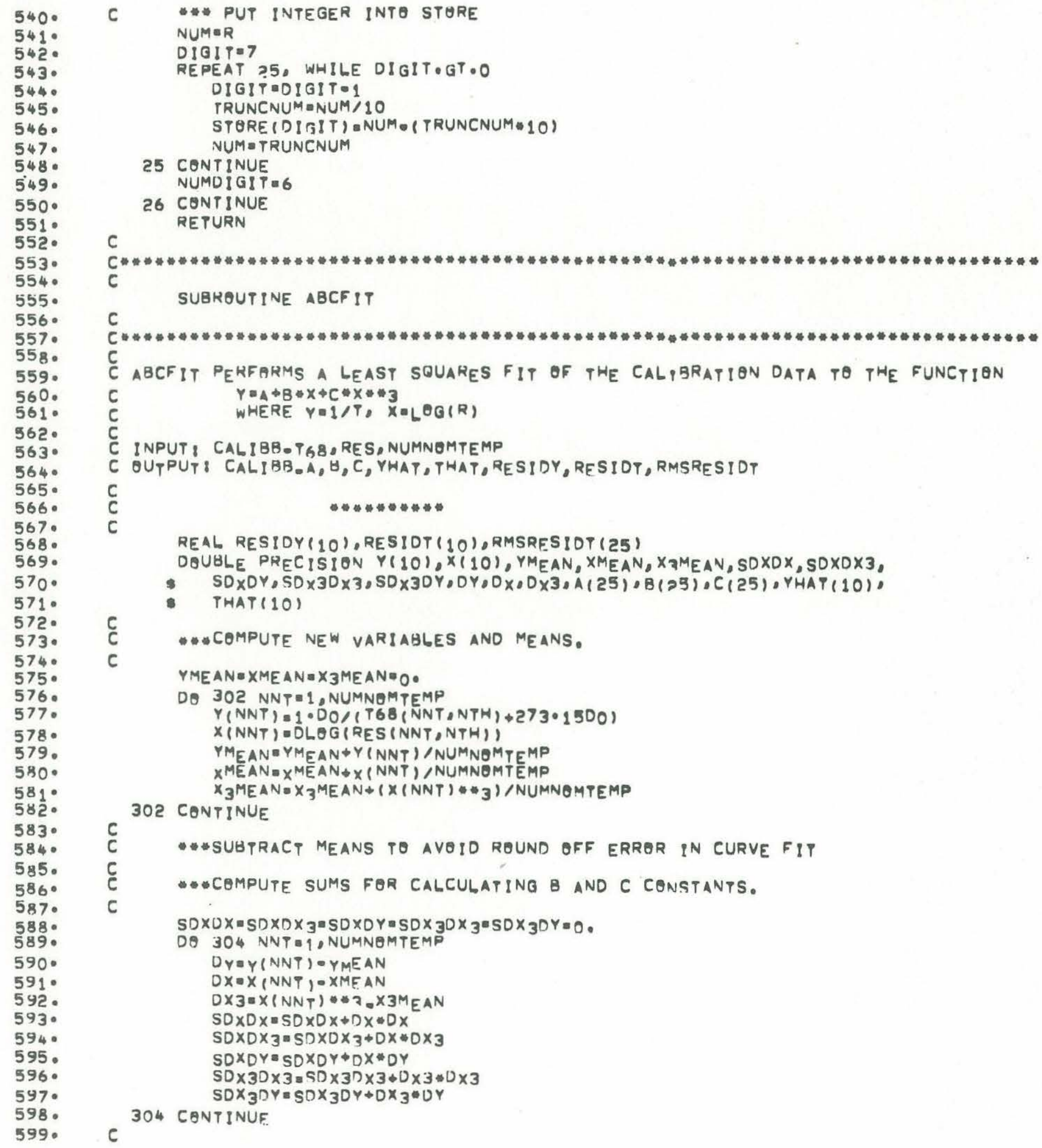




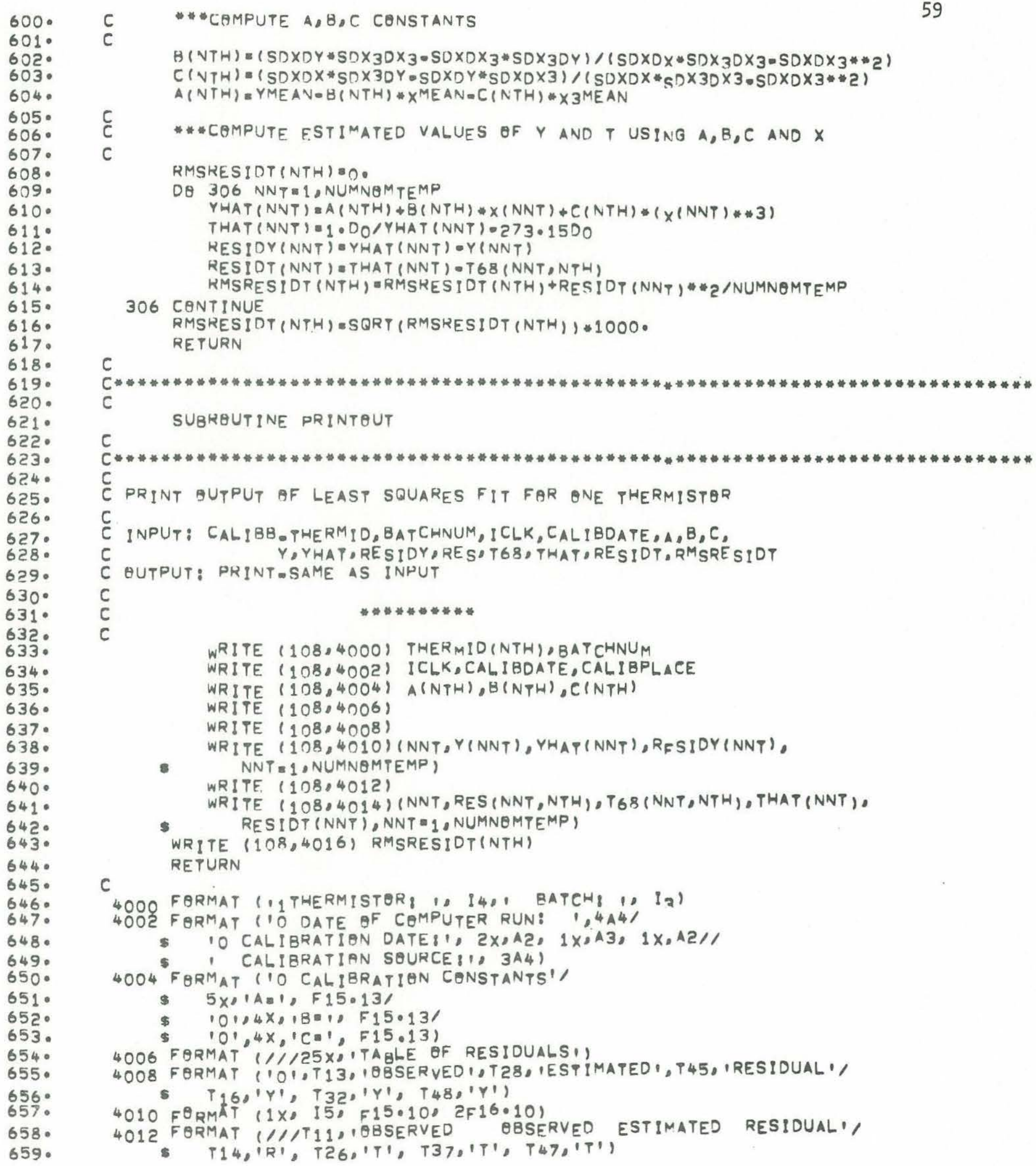




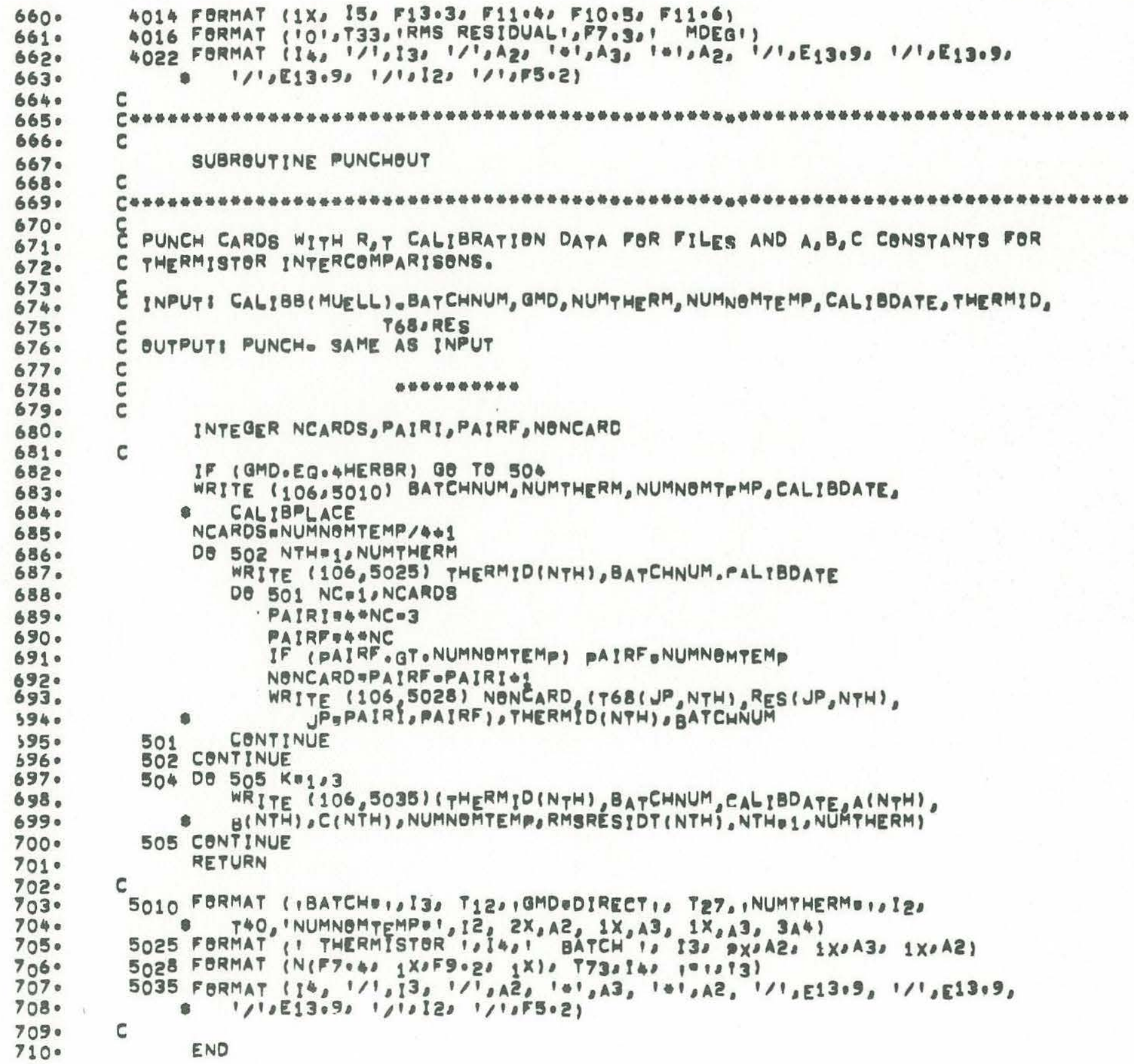




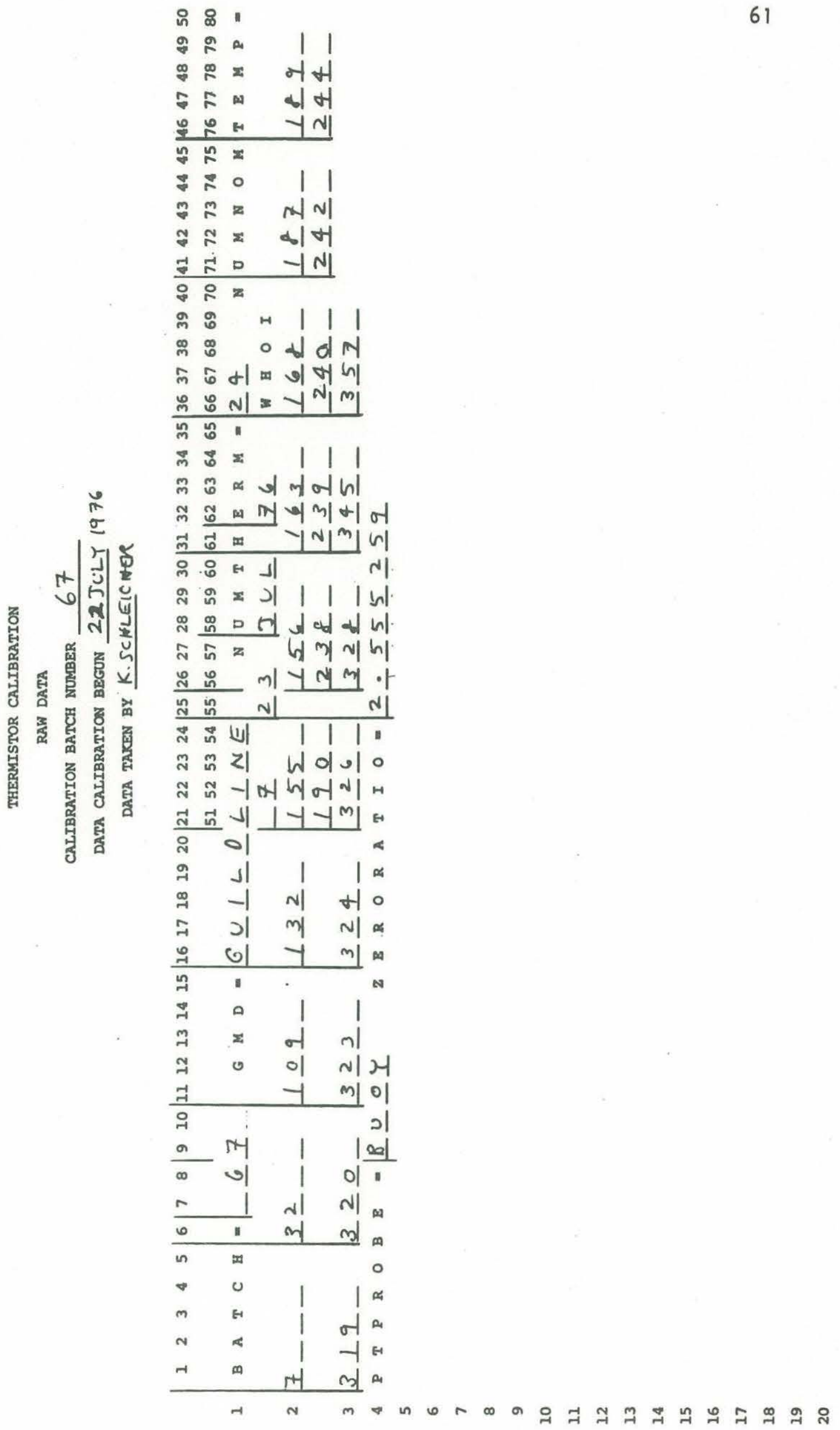




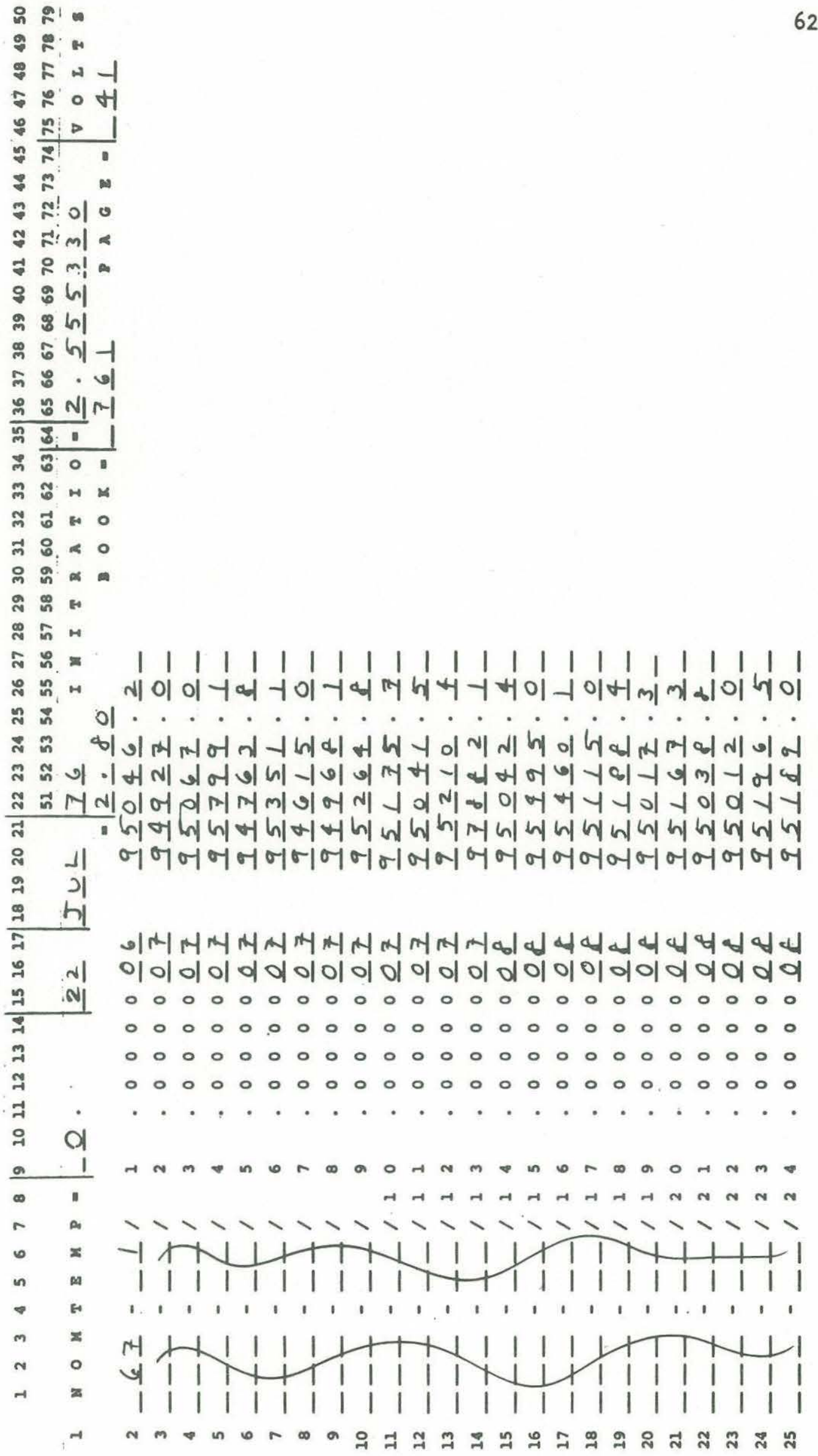




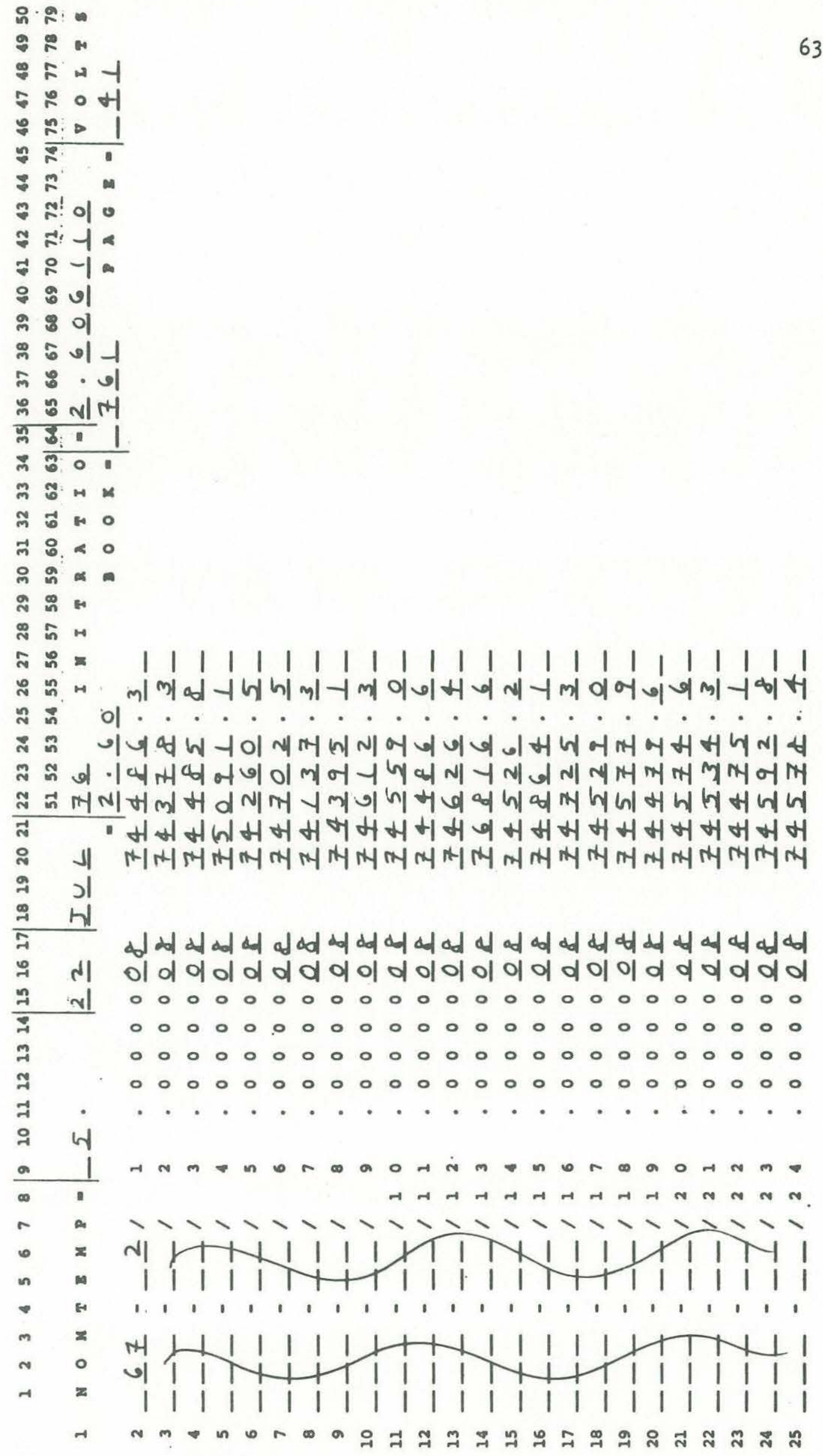




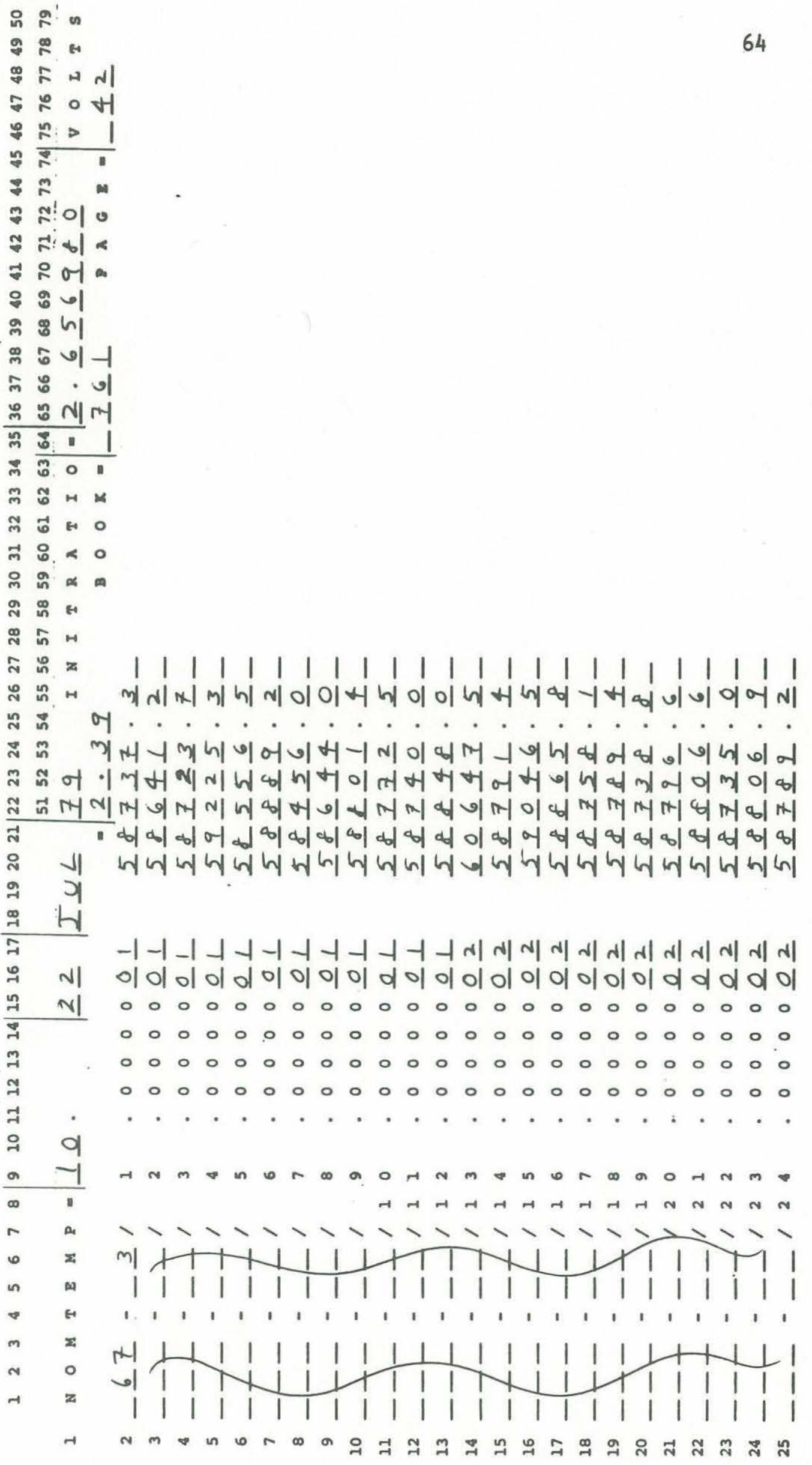




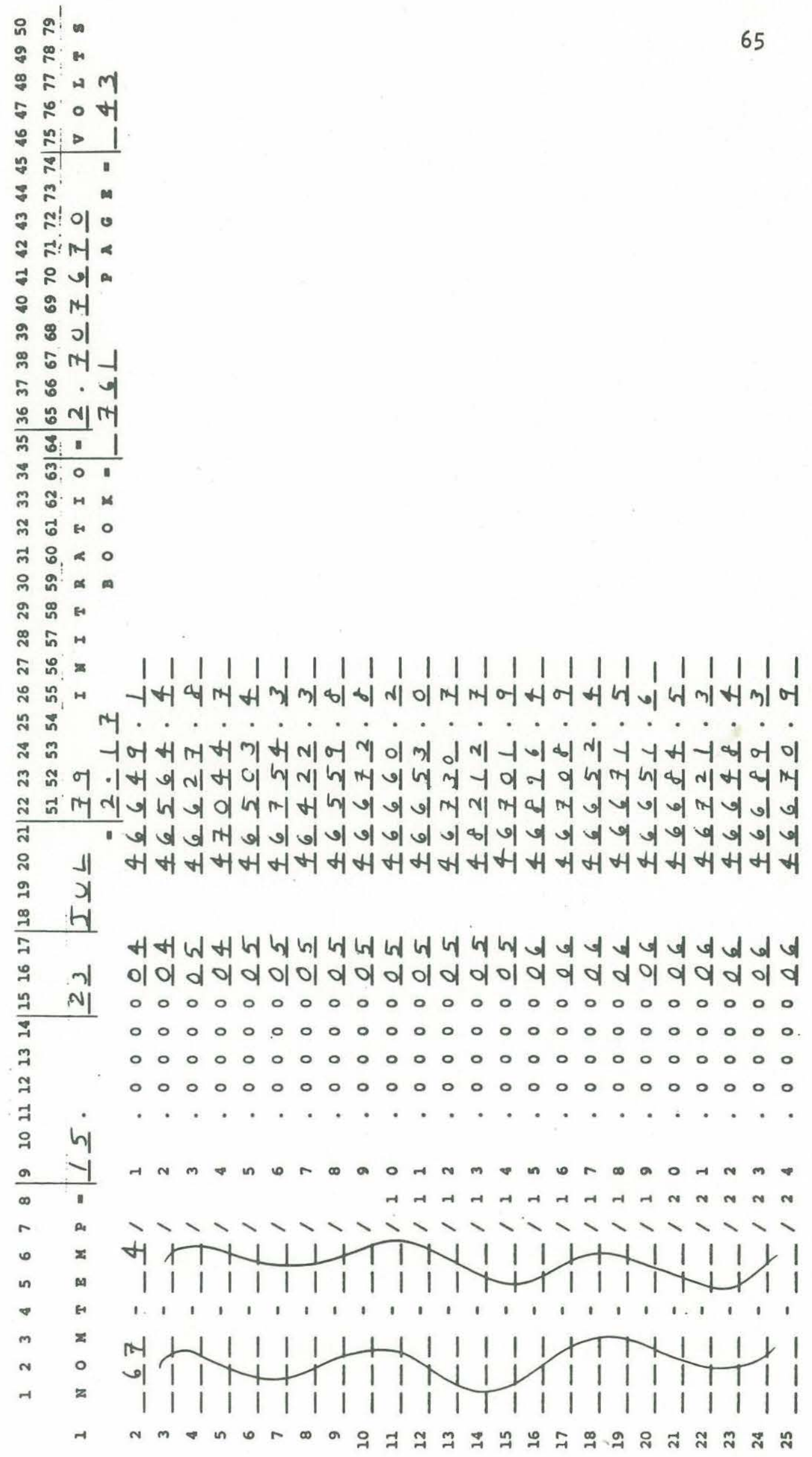




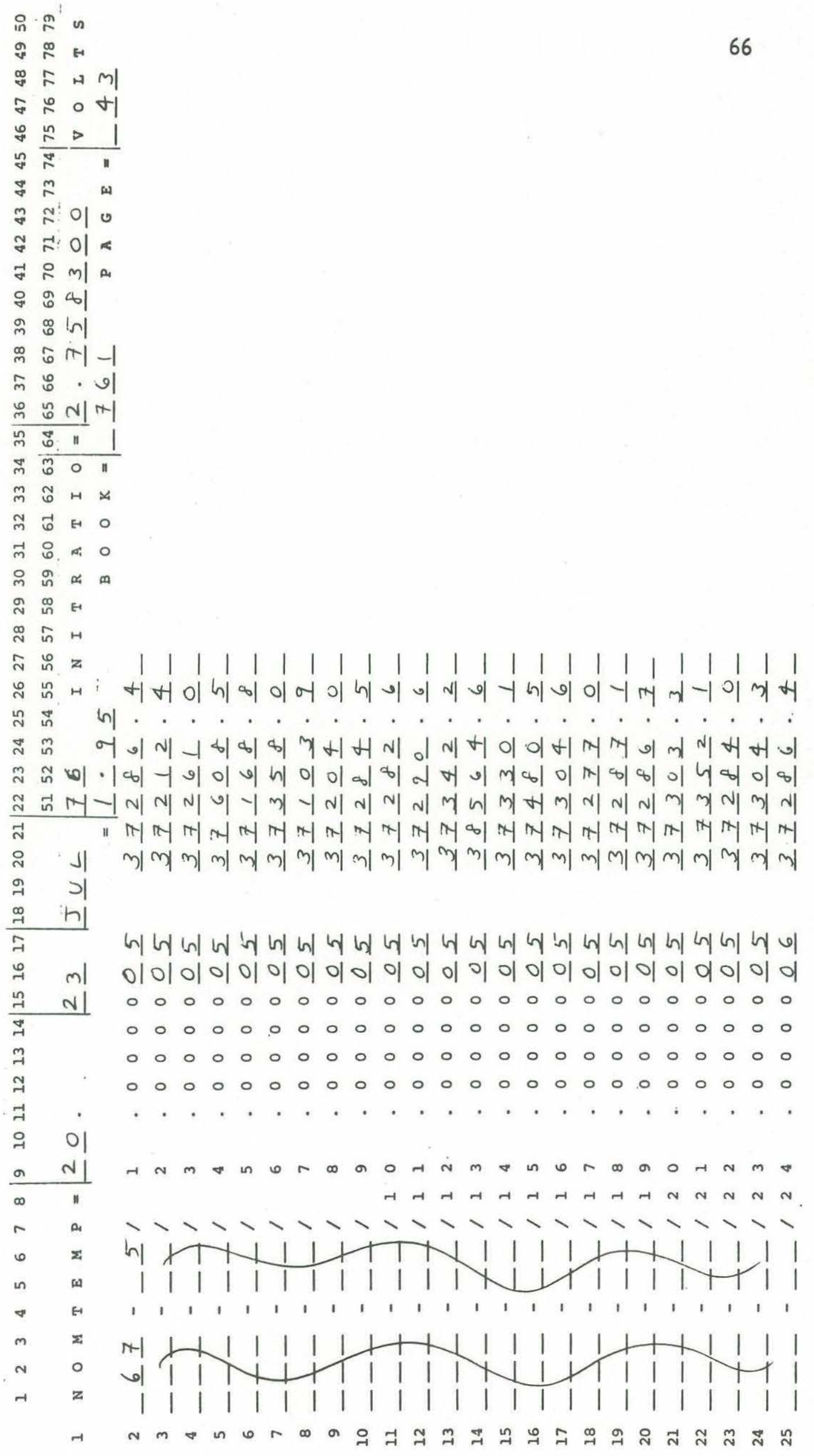




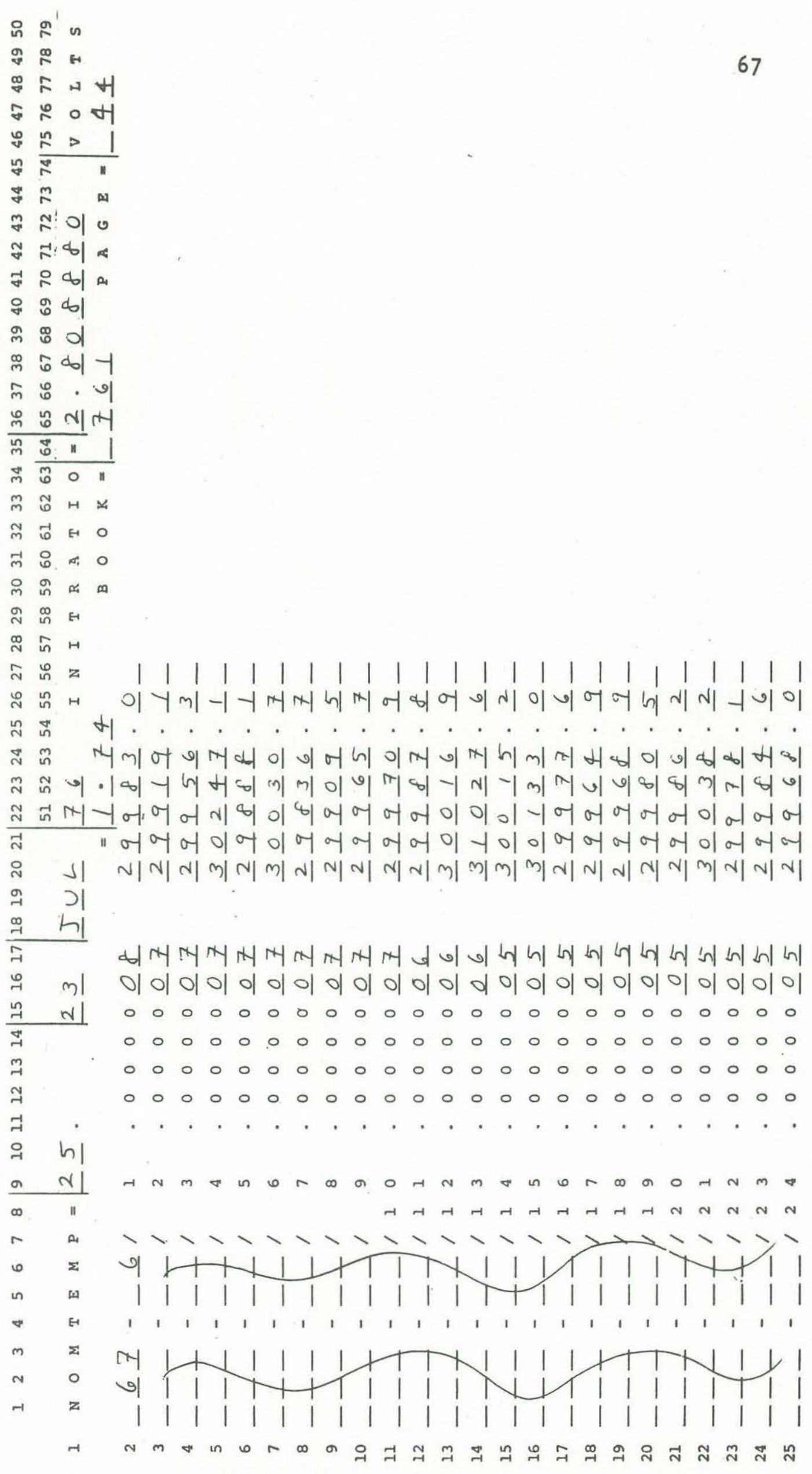




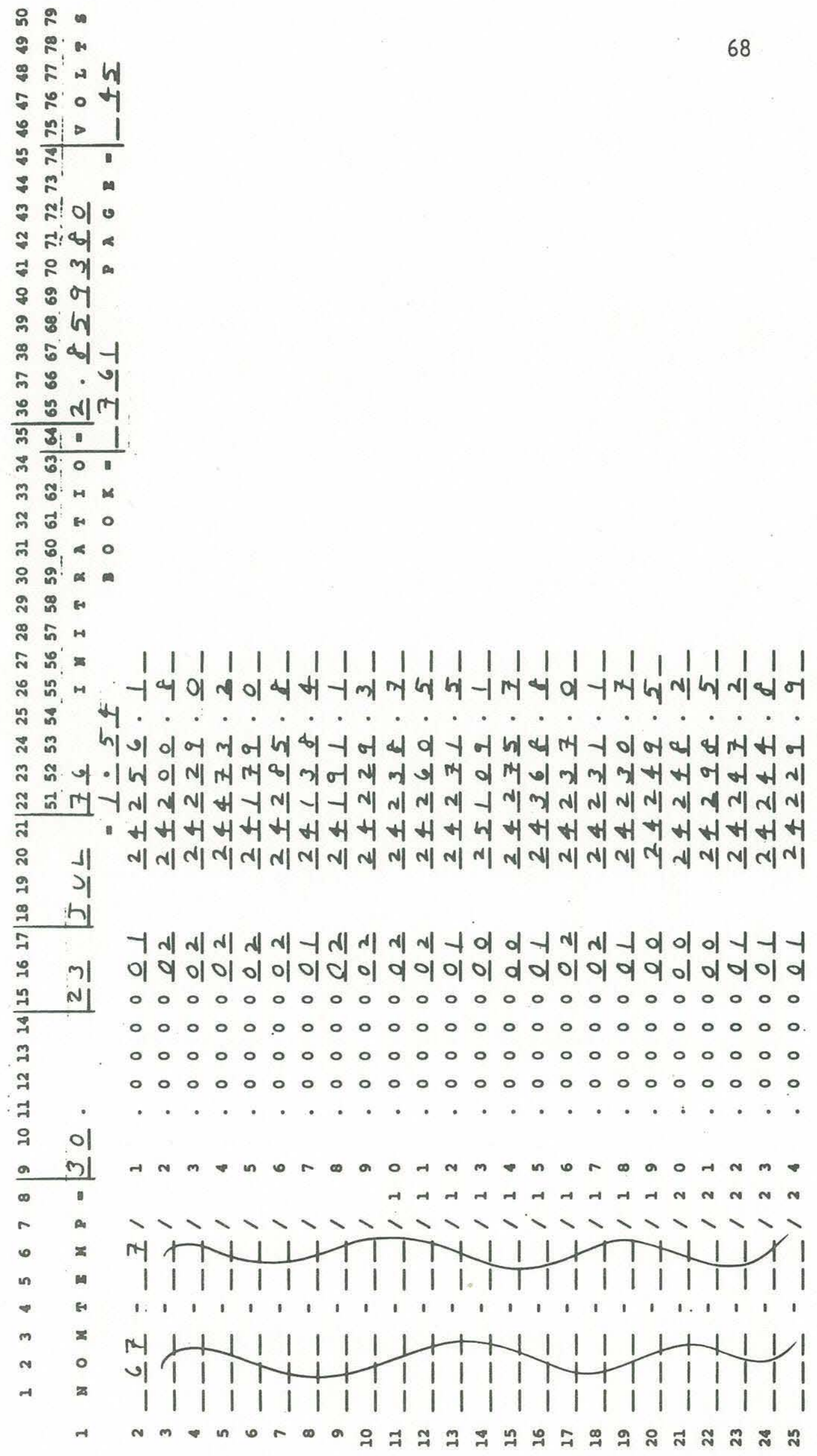


BATCHNUM $=67$

DATE DQNE 222 JUL 76

PTPROBE E BUOY

VOLTS ACROSS THERM 2.800

ZERORATIO= 2.555259

INITRATIOE 2.555330

BQOK NUMBER = 761

PAGE $=41$

\begin{tabular}{|c|c|c|c|c|c|}
\hline BATH & THERM & PRT & PRT & UNCORR & CORR \\
\hline ID & $N \theta$ & RESIST & TEMP & THERM RES & THERM RES \\
\hline 1 & 7 & $2 \cdot 555336$ & .0076 & $95046 \cdot 20$ & $95045 \cdot 15$ \\
\hline 2 & 32 & $2 \cdot 555337$ & .0077 & $94927 \cdot 00$ & $94925 \cdot 95$ \\
\hline 3 & 109 & $2 \cdot 555337$ & 0077 & $95067 \cdot 00$ & $\begin{array}{l}95065 \cdot 95 \\
95798 \cdot 05\end{array}$ \\
\hline 4 & $\begin{array}{l}132 \\
155\end{array}$ & $\begin{array}{l}2 \cdot 555337 \\
2 \cdot 555337\end{array}$ & $\begin{array}{l}.0077 \\
.0077\end{array}$ & $\begin{array}{l}95799 \cdot 10 \\
94763 \cdot 80\end{array}$ & $\begin{array}{l}95798 \cdot 05 \\
94762 \cdot 65\end{array}$ \\
\hline $\overrightarrow{6}$ & 156 & 2.555337 & .0077 & $95351 \cdot 10$ & $95350 \cdot 05$ \\
\hline 7 & 163 & 2.555337 & .0077 & $94615 \cdot 00$ & 94613.85 \\
\hline 8 & 168 & $2 \cdot 555337$ & .0077 & $94968 \cdot 10$ & 94967.05 \\
\hline 9 & 187 & $2 \cdot 555337$ & .0077 & $95264 \cdot 80$ & $95263 \cdot 75$ \\
\hline 10 & 189 & $2 \cdot 555337$ & .0077 & $95175 \cdot 70$ & $95174 \cdot 65$ \\
\hline 11 & 190 & $2 \cdot 555337$ & .0077 & $95042 \cdot 50$ & $95040 \cdot 45$ \\
\hline 12 & 238 & $2 \cdot 555337$ & 0077 & $95210 \cdot 40$ & $95209 \cdot 35$ \\
\hline 13 & 239 & $2 \cdot 555337$ & .0077 & $97882 \cdot 10$ & $97881 \cdot 20$ \\
\hline 14 & 240 & $2 \cdot 555338$ & .0078 & $95042 \cdot 40$ & $95041 \cdot 30$ \\
\hline 15 & 242 & $2 \cdot 555338$ & .0078 & $95495 \cdot 00$ & $95493 \cdot 9$ \\
\hline 16 & 244 & $2 \cdot 555338$ & .0078 & $95460 \cdot 10$ & $95459 \cdot 00$ \\
\hline 17 & 319 & $2 \cdot 555338$ & .0078 & $95115 \cdot 00$ & $95113 \cdot 9$ \\
\hline 18 & 320 & $2 \cdot 555338$ & .0078 & $95188 \cdot 40$ & $95187 \cdot 30$ \\
\hline 19 & 323 & $2 \cdot 555338$ & .0078 & $95017 \cdot 30$ & $95016 \cdot 2$ \\
\hline 20 & 324 & $2 \cdot 555338$ & .0078 & $95167 \cdot 30$ & $95166 \cdot 2$ \\
\hline 21 & 326 & $2 \cdot 555338$ & .0078 & 95038.80 & $95037 \cdot 70$ \\
\hline 2? & 328 & $2 \cdot 555338$ & .0078 & $95012 \cdot 00$ & $95010 \cdot 9$ \\
\hline 23 & 345 & $2 \cdot 555338$ & $\cdot 00^{78}$ & $95196 \cdot 50$ & $95195 \cdot 4$ \\
\hline 24 & 357 & $2 \cdot 555338$ & .0078 & $95189 \cdot 00$ & $95187 \cdot 9$ \\
\hline
\end{tabular}

Input data verification page for $0^{\circ} \mathrm{C}$ nominal temperature 
DATE GF COMPUTER RUN 14805 SEP 248176

CALIBRATIAN DATE: 23 JUL 76

CALIBRATION SOURCEI WHOI

CALIBRATION CONSTANTS

$A$ A. 0009087846954

B. .0002250005862

C. .0000001149649

TABLE OF RESIDUALS

$\begin{array}{cc} & \text { OBSERVED } \\ & Y \\ 1 & .0036608908 \\ 2 & .0035952332 \\ 3 & .0035316941 \\ 4 & .0034704710 \\ 5 & .0034113163 \\ 6 & .0033541115 \\ 7 & .0032988069\end{array}$

$$
\begin{gathered}
\text { ESTIMATED } \\
\text { Y } \\
.0036608901 \\
.0035952344 \\
.0035316951 \\
.0034704679 \\
.0034113182 \\
.0033541112 \\
.0032988070
\end{gathered}
$$

RESIDUAL $Y$

$\cdot .0000000007$ - 0000000012

.0000000010

.0000000031 .0000000019

.0000000003

.0000000000

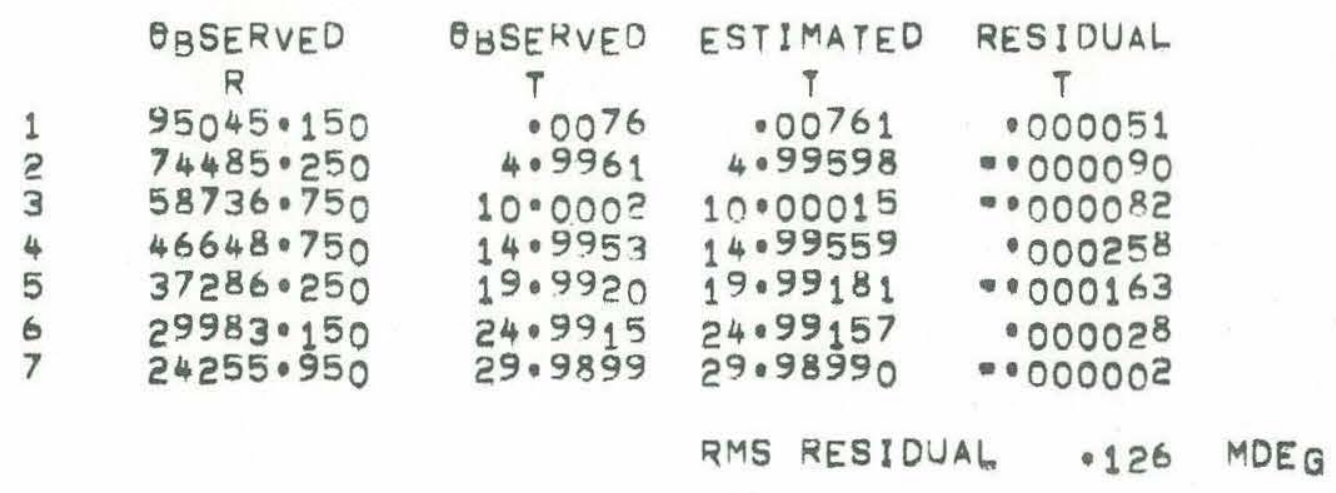

Output page for thermistor No. 7 


\section{Appendix III \\ CALCOLIN Program}

The CALCOLIN program is used to evaluate the calibration data and compare the results of several calibrations on a single thermistor. Its use over the last three years has allowed us to determine drift rates of thermistors, has helped us to detect errors in calibration data, and to evaluate the consistency of our calibrations. CALCOLIN is written in XerOX FORTRAN IV.

Following the listing of CALCOLIN is an example of the output of the program. There are two sets of numbers for each thermistor.

In the first set of numbers, the first four columns are, respectively, thermistor number, calibration batch number, r.m.s. calibration residual and calibration date. The numbers in the following seven columns are derived in the following way. The numbers at the tops of the columns, at the top of the page, are temperatures $(+0,+5$, etc. $)$ in ${ }^{\circ} \mathrm{C}$. The numbers directly below these are nominal resistances for this thermistor type at those temperatures from one of the input cards. The numbers for the individual thermistors and calibrations in Table $\mathrm{A}$ for each thermistor are the temperature differences which result from: (1) calculating a temperature using the nominal resistance at the head of the column and the A, B, C constants for that thermistor and calibration; (2) subtracting the temperature at the top of the column; (3) multiplying by 1000 to get the temperature difference in $\mathrm{m}^{\circ} \mathrm{C}$. The absolute value of one of these temperature differences has little meaning except to tell one whether an individual thermistor is within manufacturer's specifications or not. Comparing all the temperature differences at a given temperature for one thermistor can reveal several things. If the numbers stay quite constant over a period of several years as in thermistor 122 , we can say that the thermistor is stable and the random variations in the temperature difference give us a good idea of the repeatability of a given temperature in the calibration bath. If the numbers change with time as in thermistor 131 then we know the thermistor is drifting. If the temperature difference increases with time this indicates that the 
thermistor resistance at the specified temperature is increasing and vice versa.

The second table of numbers, for each thermistor, is an estimate of drift rate of the thermistor together with data which allow us to evaluate that drift rate. Each row in this second table is the result of computations on the numbers in the corresponding column of the first table.

The columns represent:

$T$ - The nominal temperature in ${ }^{\circ} \mathrm{C}$ as in the previous table

N - The number of calibrations performed on this thermistor

TIME - The elapsed time in days between the first and latest calibrations of this thermistor

YBAR - Mean of the temperature differences in the previous table for nominal temperature $T$ over all the calibrations

SEMV - The standard error of YBAR

YINTER $-\mathrm{b}$ in the equation

$\mathrm{y}=\mathrm{at}+\mathrm{b}$

where $y=$ temperature difference from Table $A$

$t=$ time in days from the first calibration to the calibration from which $y$ was obtained and a and $b$ are the result of the least squares fit of temperature difference vs. time

SLOPE - $\quad a$ in the above equation; the drift rate in $\mathrm{m}^{\circ} \mathrm{C} /$ day

DRIFT - The drift rate in $\mathrm{m}^{\circ} \mathrm{C} /$ year; SLOPE * 365

SELF - Standard error of the least squares fit

VSL - Variance due to the slope of the line

VAL. - Variance about the line

CORR - Correlation between temperature difference and time

SELF/SEMV - An indication of whether the least squares fit with time variation is better than a simple mean

CAL/VSL - An indication of how important the variance about the line is compared to the variance due to the slope of the line

- Following the seven lines at nominal calibration temperatures

is a final line with five numbers. These are, respectively,

the overall means of YBAR, SEMV and DRIFT, the square

root of the mean of VAL, and the overall mean of CORR

The final table is a listing of all the input cards. 
of the two examples shown, thermistor number 126 is stable with a standard deviation about the mean of $\pm 1.2 \mathrm{~m}^{\circ} \mathrm{C}$. Thermistor number 76 is drifting although the drift rate has decreased considerably in recent calibrations. 


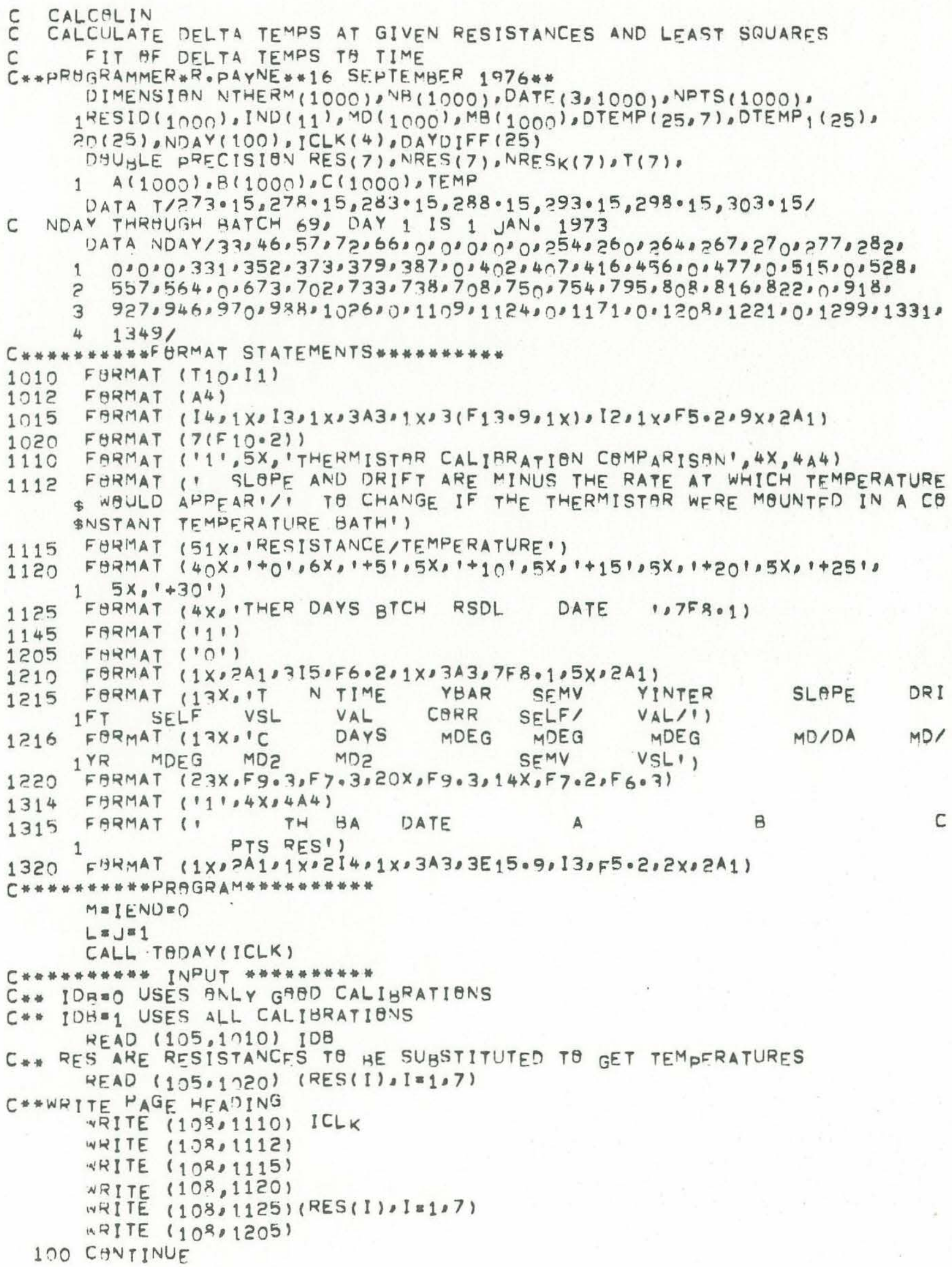




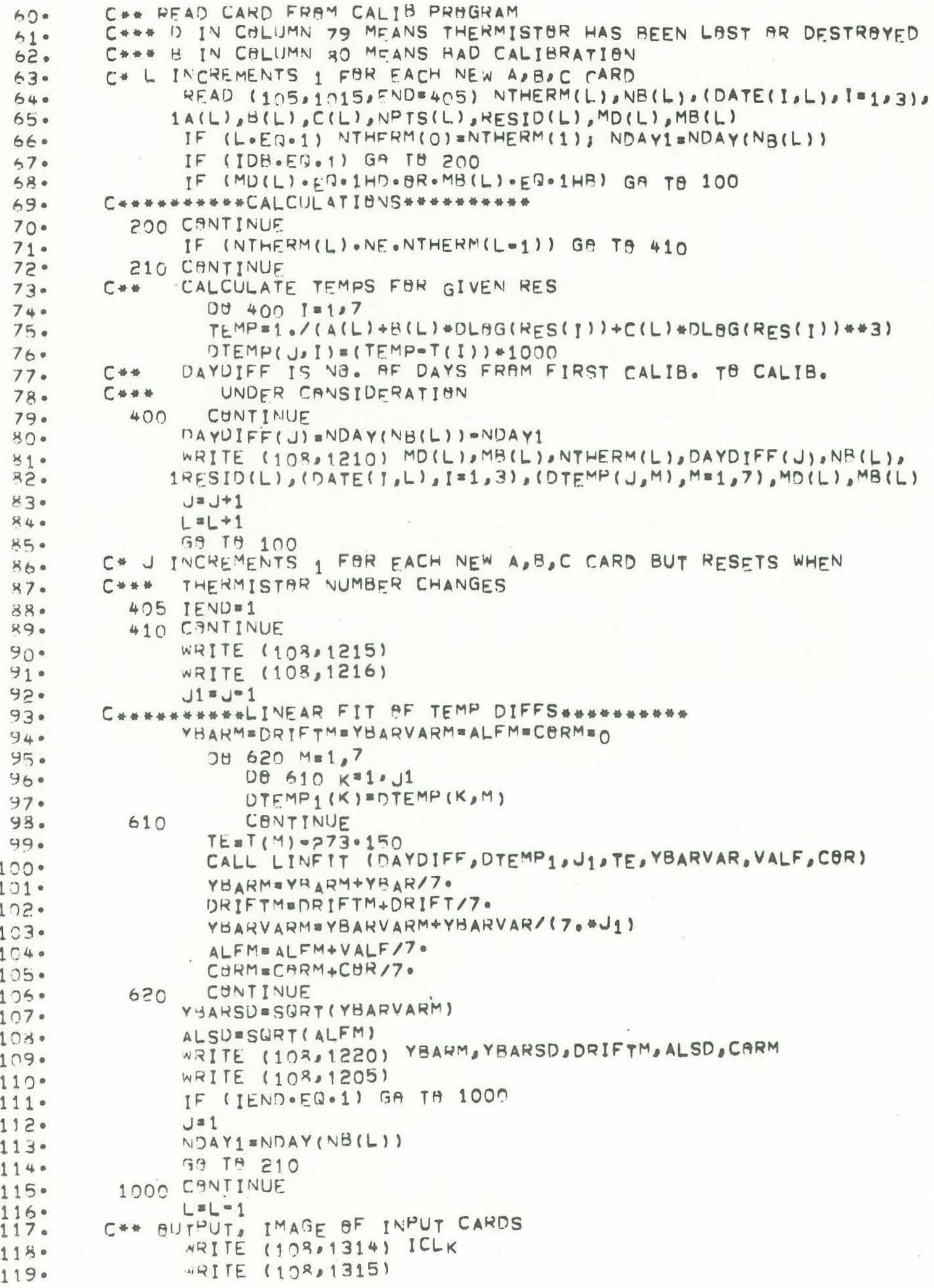




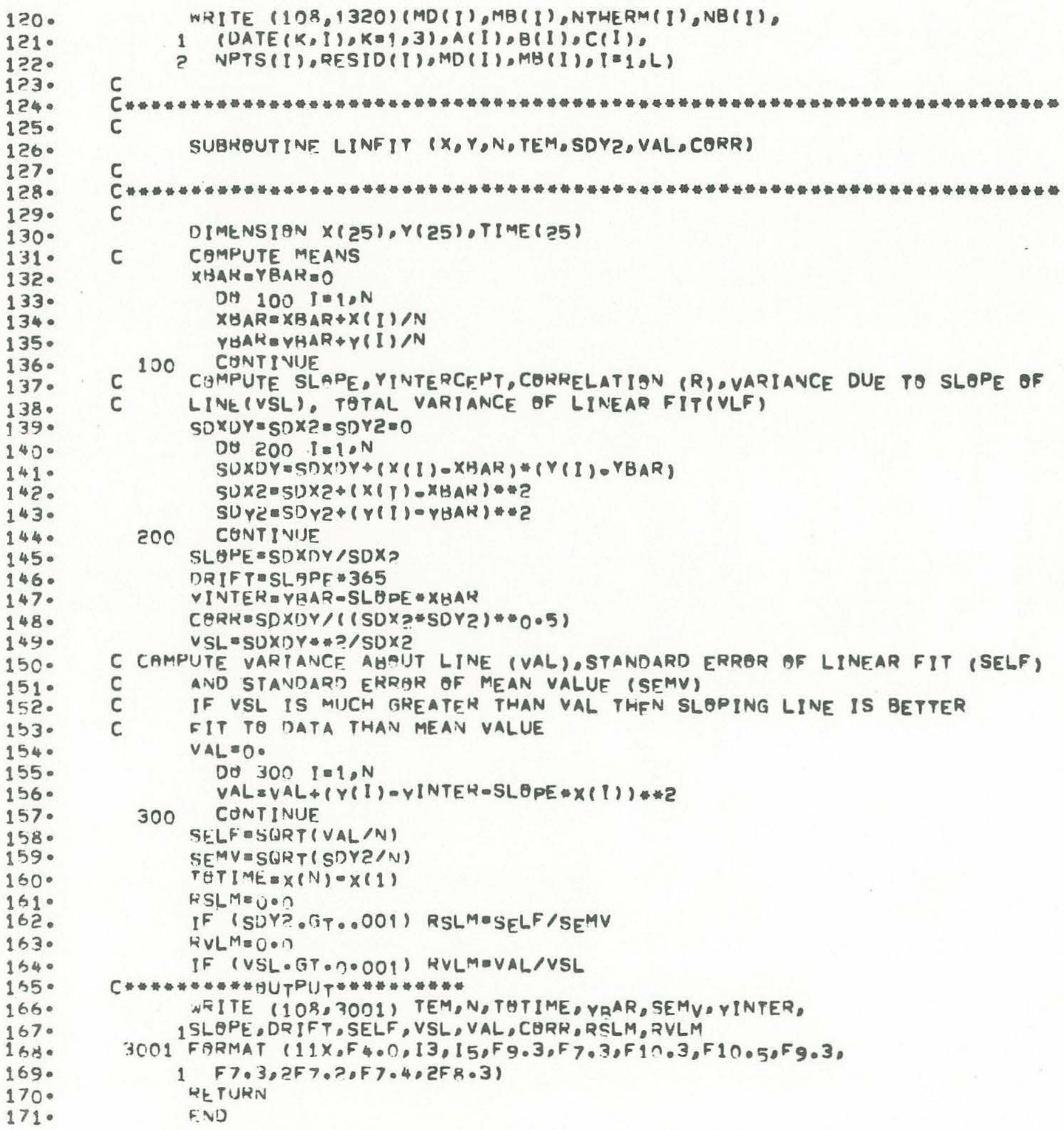

120 .

121.

1 ?2。

123.

1240

125.

126.

127.

128.

$129^{\circ}$

$130^{\circ}$

131.

132.

133.

134.

135 .

136.

137.

138.

$939^{\circ}$

140.

141.

142 .

143.

1440

145 .

146.

147.

148.

$149^{\circ}$

150.

$151^{\circ}$

152.

$153^{\circ}$

$154^{\circ}$

155 .

$156^{\circ}$

$157^{\circ}$

158 .

159.

$160^{\circ}$

161.

162 .

1630

1340

135.

$166^{\circ}$

$167^{\circ}$

1 करण

$169^{\circ}$

170.

171.

WRITE (108, 1320) (MD(I),MB( I),NTHERM(I),NB (I),

1 (DATE $(K, I), K=1,3), A(I), B(1), C(I)$,

? NPTS(I),RESID(I),MD(I),MB(I),I I,L)

C

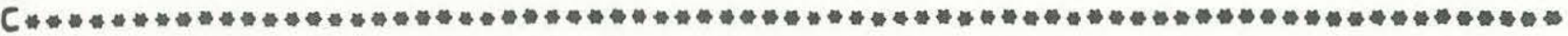

C

SUBHEUTINE LINFIT (X,Y,N,TEM,SDYZ,VAL,CORR)

C

C

C

C CAMPUTE MEANS

XHAK $=P B A R=0$

DH $100 I=1, N$

$X B A R=X B A R+X(I) / N$

$Y B A K \cong Y H A R \rightarrow Y(I) / N$

100 CONTIVUE

C CGMPUTE SLAPE, YINTERCEPT,CORRELATION (R), VARIANCE DUE TO SLOPE OF

C LINE(VSL), TOTAL VARIANCE OF LINEAR FIT(VLF)

SDXUY:SDX? SDYZ=0

DU 200 I $1=1 . \mathrm{N}$

$S U X D Y=S n X !) Y \leftrightarrow(X(I)=X H A R) *(Y(I)-Y B A R)$

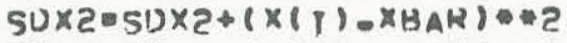

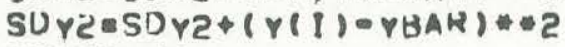

EOC CENTINIJE

SLOHE SSOXNY/SDX?

DRIF TSSLPPF $\$ 365$

$\checkmark I N T E R=Y B A R-S L Q D E * X B A R$

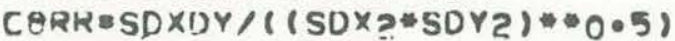

$\checkmark S L=S U X D Y * ? / S D \times 2$

C CAMPUTE VARIANCF AGQIJT LINE (VAL) OSTANDARD ERRQR AF LINEAR FIT (SELF)

C AND STANDAR? ERRAR OF MEAN VALUE (SEMV)

C IF VSL IS MUCH GREATER THAN VAL THFN SLOPING LINE IS BETTER

C IIT TO DATA THAN MEAN VALUE

$V A L=0$.

Do $300 I=1, \mathrm{~N}$

VAL $=V A L \&(Y(I)-Y I N T E H-S L O P E * X(1)) * 2$

300 CONTINUE

SELF ISURT (VAL/N)

$S E M V=S Q R T(S D Y Z / N)$

TETIME $=X(N)=X(1)$

HSLMEU०?

IF (SDY?.GT..009) RSLMESELF/SEMV

R V VLM $=0 \cdot n$

IF (VSL.GT•?•OO१) RVLMEVAL/VSL

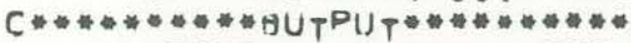

NFITE (10R, 3OO1) TEM,N,TETIME, YRAR, SEMV YINTER,

1 SLOPE, DRIFT,SELF, VSL, VAL, CQRK, RSLM, RVLM

3001 FARMAT $111 \times, 5.00,13,150 F 9.3,57,3, F 10.3,510.5,59.3$,

$1 F 7.3,257,2, F 7 \cdot 4 \cdot 2 F 8 \cdot 3)$

RETURN

F.ND 


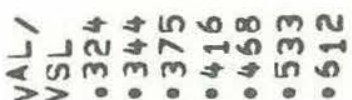

$\lambda$ in a num on

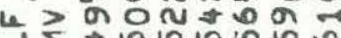
$\vec{\omega} \sum_{\text {w }}$ !n In $\ln$ !n ल ल

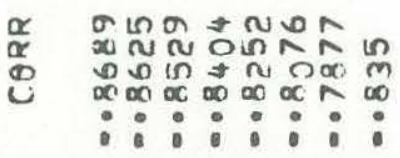

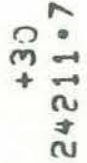

In $\rightarrow \div \div: m$ man mo: $>\Sigma: i n$ in min a

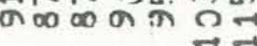

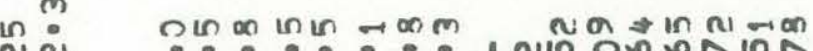

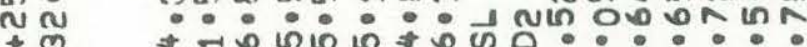
$+\frac{m}{\sigma}$

ก

ด ก N $\mathrm{N}$ N

I 4 两

c)

$\alpha \underline{\alpha}+\underline{N}$

$\pi x$

$\varangle \ll$

$\omega$

a

\& $5=5$

\&更 $\rightarrow \infty$

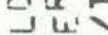

क w

$03 \omega 2$

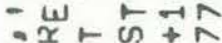

ヘ焉出

- F⿺ u or.

a $\alpha$ क $\frac{\sigma}{\alpha}$

wi $\frac{\omega}{2}$ w

niw

$\rightarrow 1-<$

$\because I>$

ㄷำ

药

$\sum_{\pi} \leftarrow \sum_{0}$

$\rightarrow \omega \Sigma$

$\alpha 5$

$\overleftarrow{\alpha} \Delta$

$\sum^{2}$

岂

$\stackrel{x}{a}$

$Z_{0} \pi$

$\stackrel{2}{a} \pi$

$\ll \Sigma$

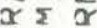

出

近是

द

C.

$x$ L 1

$\pm \vec{r}$

แั

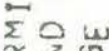

r. 2 ch

is $4<$

$\vdash \omega I$

20

$\frac{\pi}{10}$

光

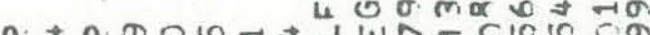

- : : : w

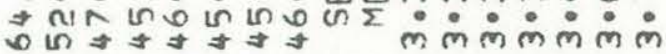

$\leftarrow \alpha \pi \sigma a n$ in

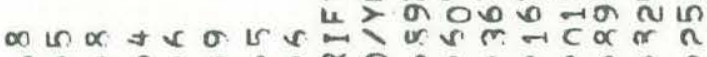

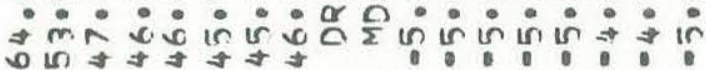

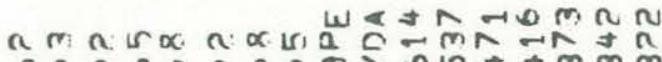

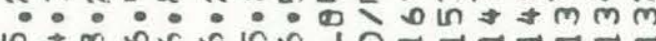
约 $::::::$ :

$\sim \alpha \Rightarrow \div<-\alpha=$

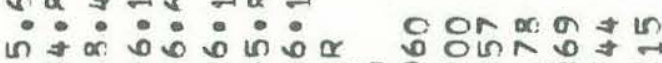

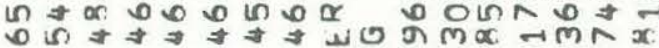

\section{与} Z

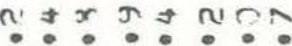

$\dot{0}$ in $\dot{x}$ in $\dot{0} \dot{0} \dot{0}$ in

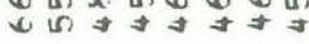

$>0 \hat{\sim} \hat{*}$

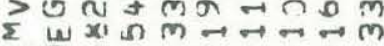

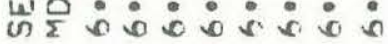

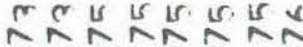

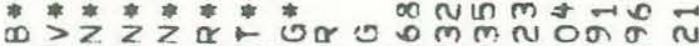

W

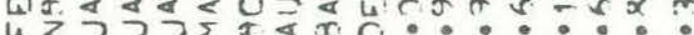

* * * * ${ }^{*} \sum \dot{\sigma} \dot{\sigma} \dot{\sigma} \dot{\sigma} \dot{\alpha} \dot{\sigma}$

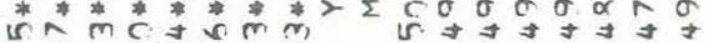

In nin ma

$\infty \rightarrow m \wedge m \neq \pi \infty$

m m $\rightarrow \div ?$ ?

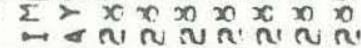

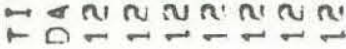

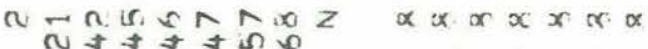

on un

尓

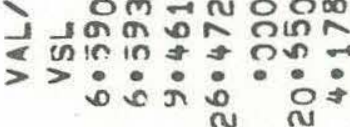

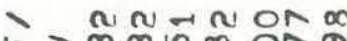
L. $>m m i n$ ON w $\sum_{\omega} \%$ ? तो $\rightarrow$

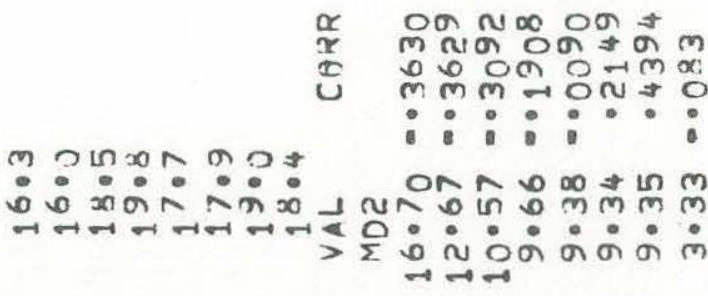

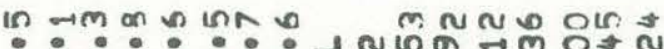
○ं

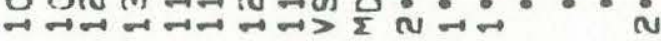

u.

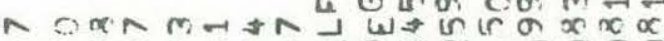
$\because \because \cdots+\cdots 0000$ is In $n \propto \omega$ On In e. $\Sigma: 0$

$-\alpha m \circ m \infty m i n$

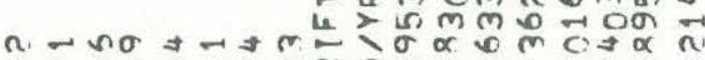
n. -ñ

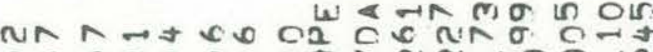

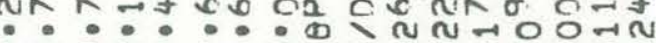

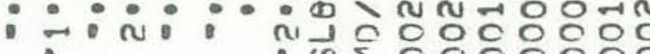
:

$\operatorname{nammaner}$

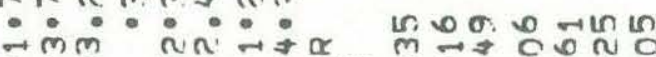

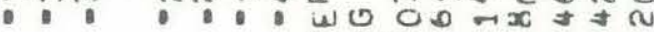
5 w. $0 \circ: \circ \circ$

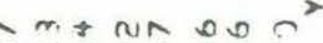
늄

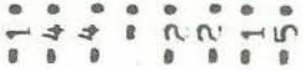

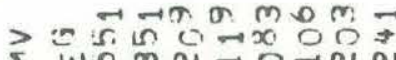
ए. Wल $\mathrm{N} \rightarrow 0 \mathrm{~N} N$

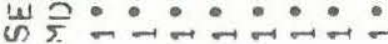

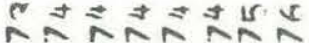
* 嵅

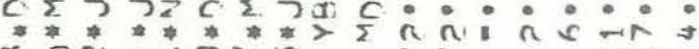

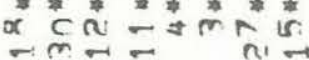

$x \rightarrow$ nan $\sim m 0$

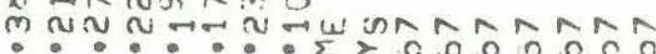

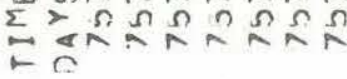

กำ

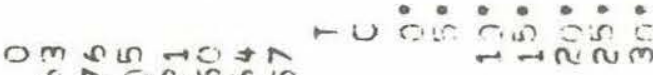

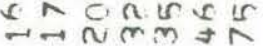

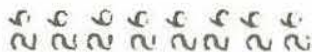

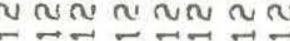




\begin{tabular}{|c|c|c|c|c|c|c|c|}
\hline TH & $B A$ & DATE & A & $B$ & C & PTS & RES \\
\hline 76 & 2 & $15 * F E B * 73$ & - $907276662 F=03$ & - $225276166 E=03$ & - $113410045 E=06$ & 7 & - 38 \\
\hline 76 & 21 & $27 * N \theta V * 73$ & $.908975703 E=03$ & -225058981E=03 & $.114031042 \mathrm{E}-16$ & 7 & .31 \\
\hline $\begin{array}{l}76 \\
76\end{array}$ & $\begin{array}{l}42 \\
45\end{array}$ & $\begin{array}{r}3 * J A N * 75 \\
20 * J A N * 75\end{array}$ & $\begin{array}{l}.908024765 \mathrm{E}=03 \\
.909638957 \mathrm{E}=03\end{array}$ & $\begin{array}{l}\cdot 225184518 E=03 \\
-224953966 E-03\end{array}$ & $\begin{array}{l}-113765542 E=06 \\
-114474836 E=06\end{array}$ & $\begin{array}{l}7 \\
7\end{array}$ & $\begin{array}{l}13 \\
017\end{array}$ \\
\hline 76 & 46 & $24 * J A N \$ 75$ & $.909740989 E=03$ & $.224942586 E-03$ & $.114489273 E=06$ & 7 & - 23 \\
\hline 76 & 47 & 6.MAR 75 & $.908756534 \mathrm{E}=03$ & - $225080322 E=03$ & $\cdot 114095987 E=06$ & 7 & - 24 \\
\hline 76 & 57 & $23 * \theta C T * 75$ & - $90827 \cap 114 E \cdot 03$ & - $225147885 E-03$ & - $113906734 E=06$ & 7 & - 09 \\
\hline 76 & 68 & $23 * A 1)(; * 76$ & . $909072729 E-03$ & - $225026889 E-03$ & -114297329E-06 & 7 & $\cdot 08$ \\
\hline 126 & 22 & $18 * D E C * 73$ & $.896564289 E-03$ & $.226727017 E=03$ & $.110085143 \mathrm{E}=06$ & 7 & .38 \\
\hline 126 & 34 & $30 * M A Y * 74$ & $.897339085 E-03$ & - $226609665 E=03$ & $\cdot 110487051 E=06$ & 7 & - 21 \\
\hline 126 & 36 & 12 JUN 74 & - $897704056 E=03$ & . $226546207 E=03$ & $110^{728311 E-06}$ & 7 & \\
\hline 126 & 37 & 11 * JUL 74 & $.896910969 E=03$ & - $226668113 E=03$ & - $110289750 E=06$ & 7 & \\
\hline 126 & 40 & $4 * N \theta V * 74$ & $.896478946 E .03$ & $.226728121 E=03$ & $.110142294 E=06$ & 7 & \\
\hline 126 & 41 & $3 * D E C * 74$ & $.895666766 E=03$ & - $226841587 E-03$ & $\cdot 109816519 E=06$ & 7 & 17 \\
\hline 126 & 49 & $27 * M A R * 75$ & $.89616 n^{833 E}=03$ & $\cdot 226770^{858 E}=03$ & - $110018335 E=06$ & 7 & $\cdot 23$ \\
\hline 126 & 59 & $15 * J A N * 76$ & $.895809412 \mathrm{E} .03$ & $.226809092 E=03$ & $.109991134 E=06$ & 7 & .10 \\
\hline
\end{tabular}


MANDATORY DISTRIBUTION LIST

FOR UNCLASSIFIED TECHNICAL REPORTS, REPRINTS, \& FINAL REPORTS

PUBLISHED BY OCEANOGRAPHIC CONTRACTORS

OF THE OCEAN SCIENCE AND TECHNOLOGY DIVISION

OF THE OFFICE OF NAVAL RESEARCH

(REVISED OCT. 1975)

1 Director of Defense Research and Engineering

Office of the Secretary of Defense Washington, DC 20301

ATTN: Office Assistant Director (Research)

Office of Naval Research

Arlington, VA 22217

3 ATTN: (Code 480)

1 ATTN: (Code 460)

1 ATTN: (Code 102-OS)

6 ATTN: (Code 102IP)

1 ATTN: (Code 200)

1 LCDR David Cacchione, (USN)

ONR Representative

Woods Hole Oceanographic Inst.

Woods Hole, MA 02543

1 Office of Naval Research

Branch office

495 Summer Street

Boston, MA 02210

Di rector

Naval Research Laboratory

Washington, DC 20375

6 ATTN: Library, Code 2620

1 National Oceanographic Data Center

National Oceanic \& Atmospheric Administration

Rockvil1e, MD 20852
12 Defense Documentation Center

Cameron Station

Alexandria, VA 22314

Commander

Naval Oceanographic

Office

Washington, DC 20390

1 ATTN: Code 1640

1 ATTN: Code 70 


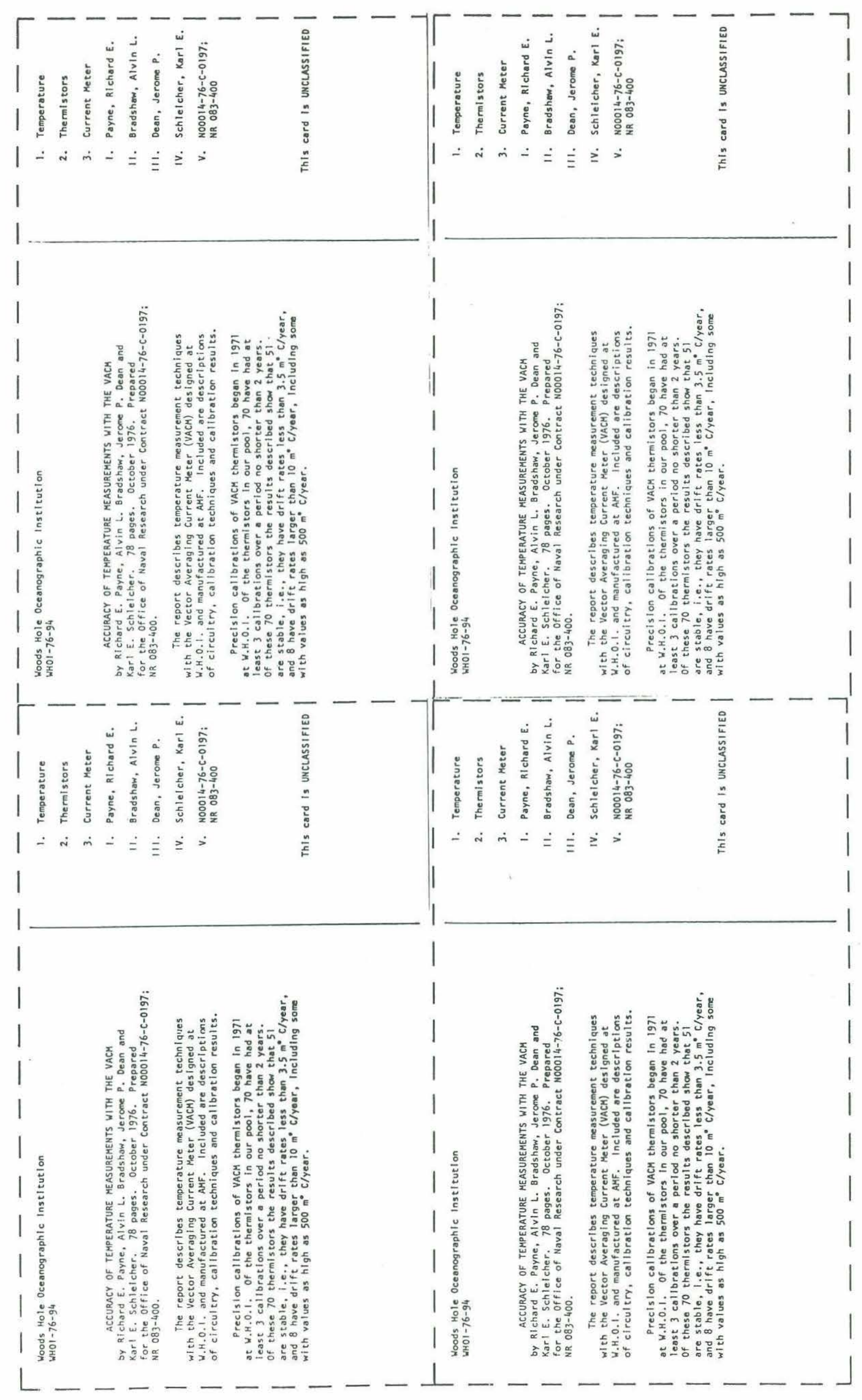




\begin{tabular}{|c|c|c|}
\hline \multicolumn{2}{|r|}{ REPORT DOCUMENTATION PAGE } & $\begin{array}{c}\text { READ INSTRUCTIONS } \\
\text { BEFORE COMPLETING FORM } \\
\end{array}$ \\
\hline$T$ & \begin{tabular}{l|l|l|} 
REPORT NUMAER & 2. GOVT ACCESSION NO. \\
WHOI $-76-94$ & &
\end{tabular} & 3 RTEIPIFNT'S CATALOG NUMBER \\
\hline \multirow[t]{2}{*}{4} & \multirow[t]{2}{*}{$\begin{array}{l}\text { TITLE (and Subulle) } \\
\text { ACCURACY OF TEMPERATURE MEASUREMENTS WITH THE } \\
\text { VACM }\end{array}$} & $\begin{array}{l}\text { 5. TYPE OF REPORT A PERIOD COVERED } \\
\text { Technical }\end{array}$ \\
\hline & & 6. PERFORMING ORG. REPORT NUMEER \\
\hline \multicolumn{2}{|r|}{$\begin{array}{l}\text { 7. AUTHOR(s) } \\
\text { Richard E. Payne, Alvin L. Bradshaw, } \\
\text { Jerome P. Dean, Karl E. Schleicher }\end{array}$} & $\begin{array}{l}\text { 8. CONTRACT OR GRANT NUMBER(a) } \\
\text { NO0014-76-C-0197: }\end{array}$ \\
\hline \multicolumn{2}{|r|}{$\begin{array}{l}\text { PERFORMING ORGANIZATION NAME AND ADDRESS } \\
\text { Woods Hole Oceanographic Institution } \\
\text { Woods Hole, MA } 02543\end{array}$} & $\begin{array}{l}\text { 10. PROGRAM ELEMENT. PROJECT, TASK } \\
\text { AREA \& WORK UNIT NUMEERS } \\
\text { NR } 083-400\end{array}$ \\
\hline \multirow{2}{*}{\multicolumn{2}{|c|}{$\begin{array}{l}11 \text { CONTROLLING OFFICE NAME AND ADDRESS } \\
\text { Office of Naval Research } \\
\text { Code } 480\end{array}$}} & $\begin{array}{l}\text { 12. REPORT OATE } \\
\text { OCtober } 1976\end{array}$ \\
\hline & & $\begin{array}{l}\text { 13. NUMBER OF PAGES } \\
78\end{array}$ \\
\hline \multirow{2}{*}{\multicolumn{2}{|c|}{ T4 MONITORING AGENCY NAME \& ADDRESS(It difforent from Controllind Office) }} & $\begin{array}{l}\text { 15. SECURITY CLASS. (ot thite roport) } \\
\text { Unclass ified }\end{array}$ \\
\hline & & $\begin{array}{l}\text { 15a. OECLASSIFICATION/DOWNGRADING } \\
\text { SCHEDULE }\end{array}$ \\
\hline \multicolumn{3}{|c|}{ 16. DISTRIBUTION STATEMENT (ol thia Roport) } \\
\hline \multicolumn{3}{|c|}{17 DISTRIBUTION STATEMENT (of the abotract ontered in Block 20,1 dilforent trom Report) } \\
\hline \multicolumn{3}{|c|}{18 SUPPLEMENTARY NOTES } \\
\hline \multicolumn{3}{|c|}{$\begin{array}{l}\text { 19 KEY WOROS (Continue on roverse aldo If necoeseary and identlly by block number) } \\
\text { 1. Temperature } \\
\text { 2. Thermistors } \\
\text { 3. Current Meter }\end{array}$} \\
\hline \multirow{2}{*}{\multicolumn{3}{|c|}{ 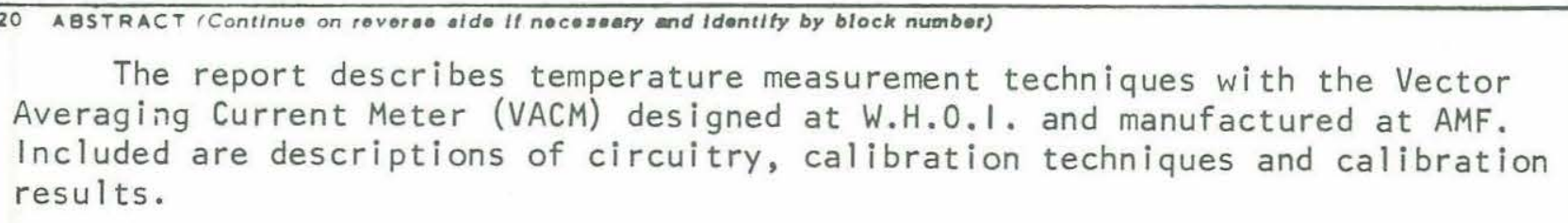 }} \\
\hline & & \\
\hline th & $\begin{array}{l}\text { Precision calibrations of VACM thermistors beg } \\
\text { he thermistors in our pool, } 70 \text { have had at least } 3\end{array}$ & $\begin{array}{l}\text { an in } 1971 \text { at W.H.0.I. of } \\
\text { calibrations over a period }\end{array}$ \\
\hline & $\begin{array}{l}\text { FORM } 1473 \text { EDITION OF I NOV BS IS OESOLETE } \\
\text { S/N } 0102.014 .6601\end{array}$ & UNCLASS I FIED \\
\hline
\end{tabular}


no shorter than 2 years. Of these 70 thermistors the results described show that 51 are stable, i.e., they have drift rates less than $3.5 \mathrm{~m}^{\circ} \mathrm{C} / y e a r$, and 8 have drift rates larger than $10 \mathrm{~m}^{\circ} \mathrm{C} /$ year, including some with values as high as $500 \mathrm{~m}^{\circ} \mathrm{C} /$ year. 